NISTIR 8216

\title{
Voices of First Responders - Identifying Public Safety Communication Problems Findings from User-Centered Interviews Phase 1, Volume 1
}

Yee-Yin Choong Shaneé Dawkins Susanne Furman Kristen K. Greene Sandra Spickard Prettyman

Mary F. Theofanos Authors are listed in alphabetical order 
NISTIR 8216

\title{
Voices of First Responders - Identifying Public Safety Communication Problems Findings from User-Centered Interviews Phase 1, Volume 1
}

\author{
Yee-Yin Choong \\ Shaneé Dawkins \\ Susanne Furman \\ Kristen K. Greene \\ Information Access Division \\ Information Technology Laboratory \\ Mary F. Theofanos \\ Office of Data and Informatics \\ Material Measurement Laboratory \\ Sandra Spickard Prettyman \\ Culture Catalyst, LLC
}

This publication is available free of charge from:

https://doi.org/10.6028/NIST.IR.8216

July 2018

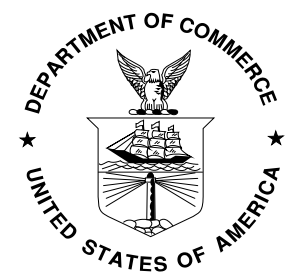

U.S. Department of Commerce Wilbur L. Ross, Jr., Secretary

National Institute of Standards and Technology Walter Copan, NIST Director and Undersecretary of Commerce for Standards and Technology 


\section{Voices of First Responders Series}

This report is a part of a series of publications amplifying the voices of first responders (VoFR) in four public safety disciplines: Communication Center \& 9-1-1 Services (COMMS); Emergency Medical Services (EMS); Fire Service (FF); and Law Enforcement (LE). The VoFR series reports on the experiences of first responders with communication technology, including their needs for, and problems with, communication technology.

Publications in this series are primarily intended for designers, developers, vendors, and researchers of public safety communication technology, as well as for public safety administrators and decision-makers.

Published as a part of the VoFR series include NIST reports, conference papers, presentations, posters, articles and blog posts, a book chapter, and a web tool for disseminating the research results and data collected from the interviews with and survey of first responders. The reports from which all published materials are derived are listed below and can be accessed from the PSCR User Interface/ User Experience Publications webpage at: https://www.nist.gov/ctl/pscr/user-interface-user-experience-publications. The PSCR Usability Results Tool, providing access to results of the large-scale survey and in-depth interviews with first responders across the U.S. about their communication technology use, can be accessed via https://publicsafety.nist.gov/. The datasets from this research project are available via https://doi.org/10.18434/mds2-2820.

\section{Voices of First Responders}

* How to Facilitate Adoption and Usage of Communication Technology: An Integrated Analysis of Qualitative and Quantitative Findings (NISTIR 8443) https://doi.org/10.6028/NIST.IR.8443

* COMMS (NIST SP 1286pt1)

* EMS (NIST SP 1286pt2) https://doi.org/10.6028/NIST.SP.1286pt2

* FF (NIST SP 1286pt3) https://doi.org/10.6028/NIST.SP.1286pt3

* LE (NIST SP 1286pt4) https://doi.org/10.6028/NIST.SP.1286pt4

Phase 1: Findings from User-Centered Interviews

* Volume 1 - Identifying Public Safety Communication Problems (NISTIR 8216) https://doi.org/10.6028/NIST.IR.8216

* Volume 2 - Examining Public Safety Communication Problems and Requested Functionality (NISTIR 8245) https://doi.org/10.6028/NIST.IR.8245

* Volume 3 - Examining Public Safety Communication from the Rural Perspective (NISTIR 8277) https://doi.org/10.6028/NIST.IR.8277

* Volume 4 - Examining Public Safety Communication from the Perspective of 9-1-1 Call Takers and Dispatchers (NISTIR 8295) https://doi.org/10.6028/NIST.IR.8295

* Volume 5 - Applying Human Factors and Ergonomics Knowledge to Improve the Usability of Public Safety Communications Technology (NISTIR 8340) https://doi.org/10.6028/NIST.IR.8340

Phase 2: Nationwide Survey

* Volume 1 - Methodology: Development, Dissemination, and Demographics (NISTIR 8288) https://doi.org/10.6028/NIST.IR.8288

* Volume 2 - Mobile Devices, Applications, and Futuristic Technology (NISTIR 8314) https://doi.org/10.6028/NIST.IR.8314

* Volume 3 - Day-to-Day Technology (NISTIR 8400) https://doi.org/10.6028/NIST.IR.8400

* Volume 4 - Statistical Analysis Results (NISTIR 8444) https://doi.org/10.6028/NIST.IR.8444 


\begin{abstract}
The public safety community is in the process of transitioning from the use of land mobile radios (LMR) to a technology ecosystem including a variety of broadband data sharing platforms. Successful deployment and adoption of new communication technology relies on efficient and effective user interfaces based on a clear understanding of first responder needs, requirements and contexts of use. This project employs a two-phased data collection approach for an in-depth look at the population of first responders, along with their work environment, their tasks, and their communication needs. This report documents the data collection of Phase 1 and the resulting data analysis. Phase 1, the qualitative component, focuses on interviews with approximately 200 first responders (law enforcement, fire fighters, emergency medical services, communications/dispatch) across the country. The results include user needs and requirements expressed by first responders. These needs and requirements have been organized into five categories of technology opportunities. Further analysis identified six user-centered design guidelines for technology development. Finally, the importance the role of trust plays in first responders' adoption and use of communication technology is presented.
\end{abstract}

\title{
Key words
}

First responders; Public safety communications research; Qualitative research; Usability; User-centered design; User needs and requirements.

\section{Audience}

The primary audience of this report is designers, developers, vendors, and researchers of public safety communications technology.

\section{Disclaimer}

Any mention of commercial products or reference to commercial organizations is for information only; it does not imply recommendation or endorsement by the National Institute of Standards and Technology, nor does it imply that the products mentioned are necessarily the best available for the purpose. 


\section{Executive Summary}

\section{Background}

The public safety community is in the process of transitioning from the use of land mobile radios (LMR) to a technology ecosystem including a variety of broadband data sharing platforms. While these new communication technologies offer potentially significant benefits for mission delivery, their design and implementation may not always reflect first responder needs, requirements, and contexts of use. Successful deployment and adoption of new communication technology relies on efficient and effective user interfaces based on a clear understanding of first responder needs, requirements and contexts of use.

The goal of the Usability and User Interface project is to understand the wide range of first responders, tasks and contexts of first responder work. It also examines their perceptions about their work, and the roles that communication and technology play. Part of this goal is to engage directly with first responders to understand current user experience and what they need to communicate efficiently and effectively and with user satisfaction. Engaging first responders in this work captures their voices so that they become audible to a broader community. Ultimately, the goal is to develop usability requirements for new and evolving public safety communication technologies that directly address first responder needs in the field.

\section{Methodology}

The project employs a two-phased data collection approach for an in-depth look at the population of first responders, along with their work environment, their tasks, and their communication needs. Phase 1, the qualitative component, focuses on interviews with approximately 200 first responders (law enforcement, fire fighters, emergency medical services, communications/dispatch) across the country. Phase 2 will utilize a quantitative instrument (large-scale national survey of first responders) to collect data to confirm and expand on the needs and problems related to communication and technology identified in the qualitative data. The phases complement each other providing a holistic view of first responders, their work, beliefs, and needs related to communication technology.

\section{Results}

This report documents the data collection of Phase 1 and the first iteration of data analysis ${ }^{1}$. It reports on how first responders' work influences:

- their communication and technology needs,

- their beliefs and perceptions about their current technology,

- what they would like technology to do, and

- why they do and do not use technology.

Over 3400 user needs and requirements expressed by first responders were collected. This report presents exemplars of the technology opportunities representing first responders' specific needs and requirements to solve the major problems they face in performing their work. Five cross-disciplinary opportunities emerged from the needs and requirements for the

${ }^{1}$ Subsequent iterations of data analysis will be reported in later volume(s). 
Public Safety Communications Research (PSCR) research and development (R\&D) community.

- Interoperability - The ability of a system or a product to exchange and make use of information with other systems or products without special effort on the part of the users - data integration and sharing from radios to radios, systems to systems, devices to devices, and departments to departments.

- Reliability and connectivity - $100 \%$ connectivity for radio, cellular, and wireless networks despite geography and topography_urban canyons, subways, basements, or other dead zones.

- Accountability and location - Development of technology that provides for accountability and location tracking of the crew, units, 911 callers, and building occupants.

- Maintenance, technical support and training - Minimization of the burden and costs of the associated maintenance, technical support and training of technology imposed on users and departments.

- Organizational policies and administration - Facilitation and promotion of technology adoption by first responders through policies, procedures, and administration to minimize barriers and hindrances to use while supporting first responders' primary tasks.

In addition to the opportunities, six user-centered design guidelines were identified from the data that first responders believe are requirements for developers when addressing opportunities.

- Improve current technology - improve functionality of what first responders currently have, make them more affordable, and more reliable, for example, better radios - coverage, durability, clarity; better microphones and cords. It is not necessarily new technology that first responders want, but the improvement of current technology that they believe is most important.

- Reduce unintended consequences - develop technology that does not interfere with first responders' attention to their primary tasks-which can cause distraction, loss of situational awareness, cognitive overload, and over-reliance on technology.

- Recognize 'one size does not fit all' - while there are similarities across the first responder disciplines and standardization is important for consistency, compatibility and quality, technology must accommodate the wide variety of public safety needsacross disciplines, personnel, departments, districts, contexts of use. All are different, requiring easy adaptability and configurability.

- Minimize 'technology for technology's sake' - develop technology with and for first responders driven by their user characteristics, needs, requirements, and contexts of use.

- Lower product/service costs - develop technology at price points that departments can afford, lowering costs for technology. For example, consider the 'One Laptop per Child' [28] approach where various entities collaborated to make and widely distribute rugged, low-cost, low-power, connected technology in areas that could not otherwise afford such devices. The goal was not only to design the tool, but to design it at a pricepoint that made it feasible and scalable for widespread distribution. 
- Require usable technology - know thy user and develop 'Fisher-Price' solutions - simple, easy to use, light, fast, and not disruptive. Technology should make it easy for the user to do the right thing, hard to do the wrong thing, and easy to recover when the wrong thing happens.

Finally, the role of trust was identified as a factor in successful public safety communications technology. In fact, trust emerged as a major theme even though we did not ask about trust. The relationship of trust to many of the problems identified by the first responder participants was prevalent in the data. First responders need to trust the related technology, people, and organizational policies, for new tools and technology to be adopted and accepted.

\section{Contributions}

The primary audience of this report is designers, developers, vendors, and researchers of public safety communications technology. This research effort documents first responders' beliefs, perceptions and needs of communication and technology, in their own words, and the recognition of trust as a significant factor in successful public safety communications technology adoption. Resources available in this report include a rigorous and systematic methodological approach, a repository of data, identified user needs and requirements, and principles for development. 


\section{Table of Contents}

ABSTRACT ………

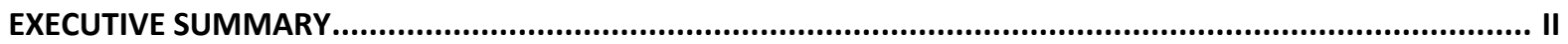

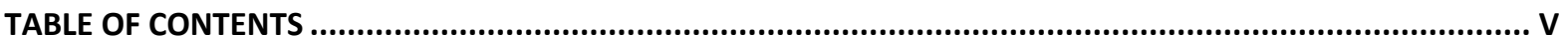

LIST OF TABLES

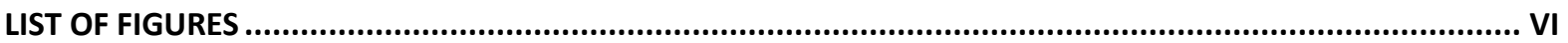

GLOSSARY

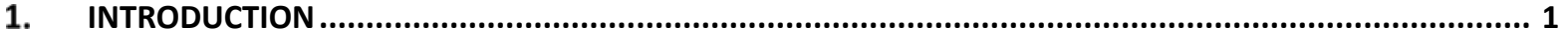

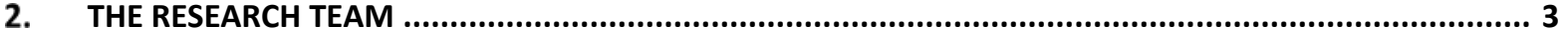

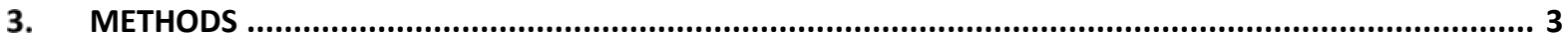

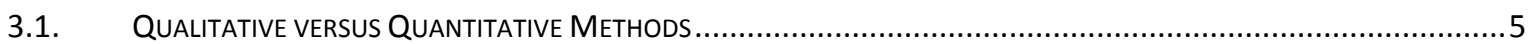

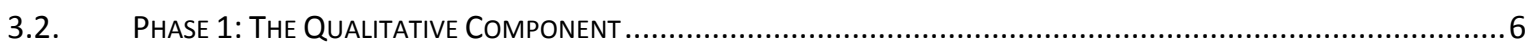

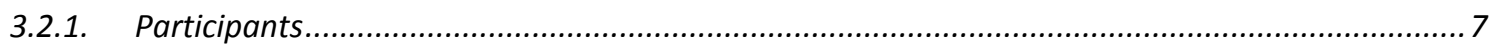

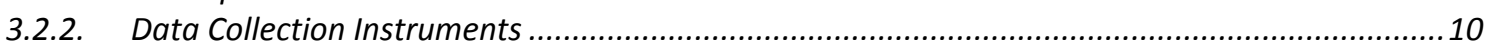

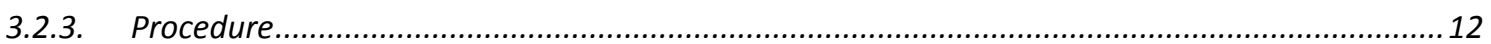

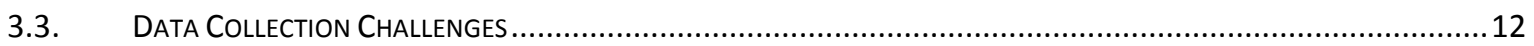

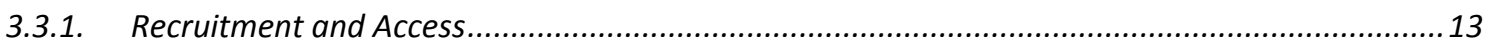

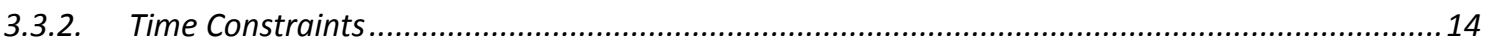

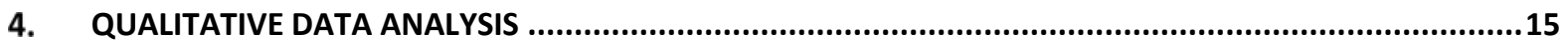

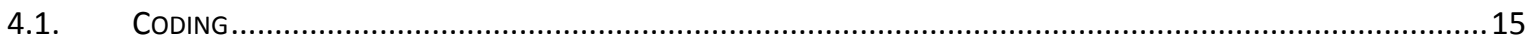

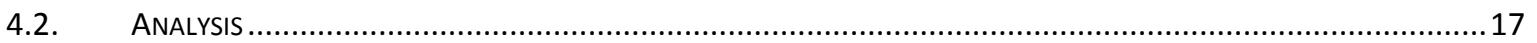

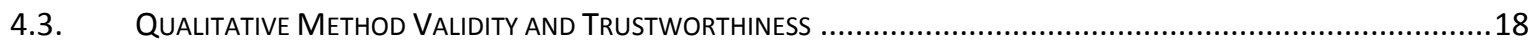

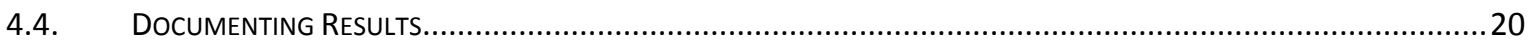

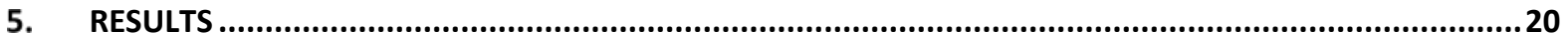

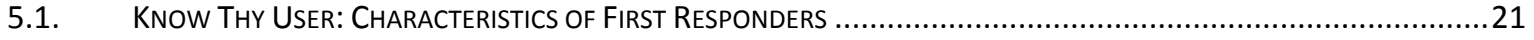

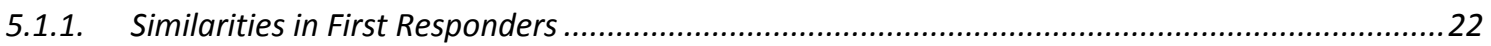

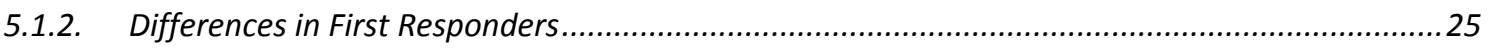

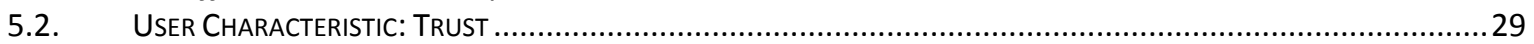

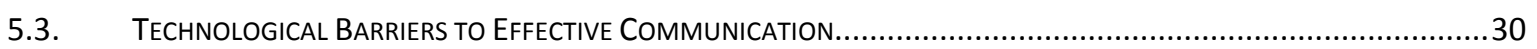

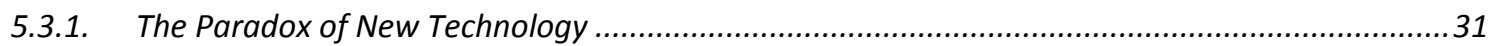

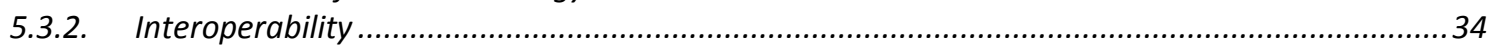

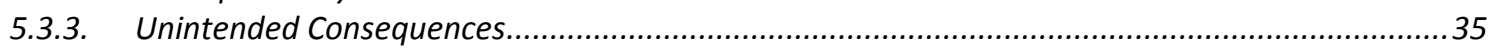

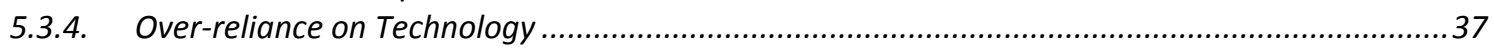

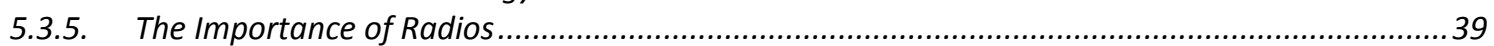

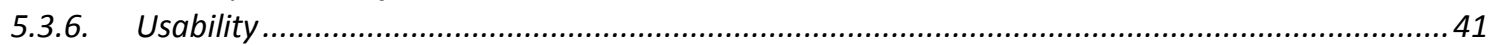

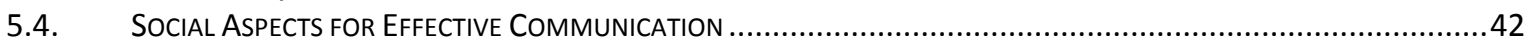

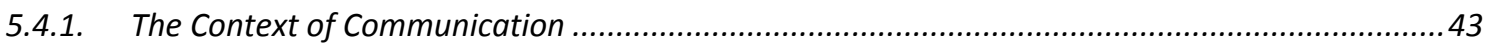

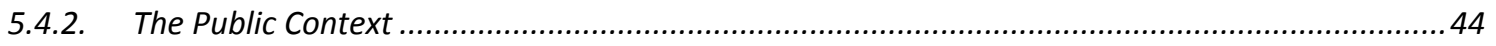

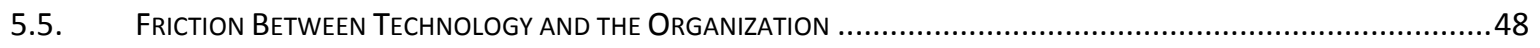

5.5.1. Conflict Between Technology and Limited Budgets ................................................................. 48

5.5.2. New Technology Requires New Organizational Policies ..........................................................50

5.5.3. New Technology Includes New Responsibilities................................................................52

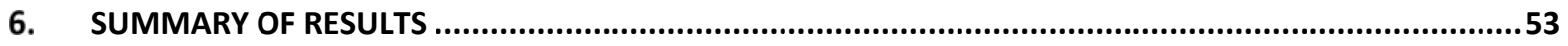

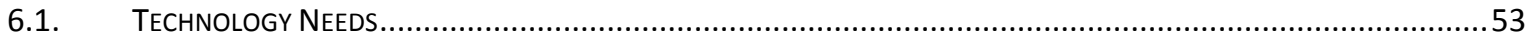




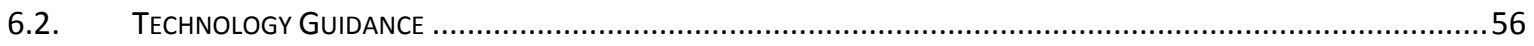

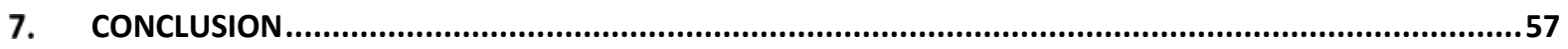

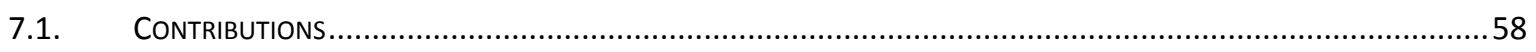

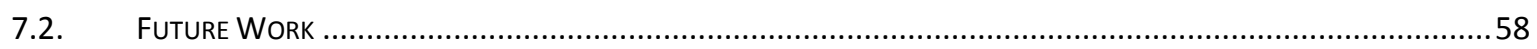

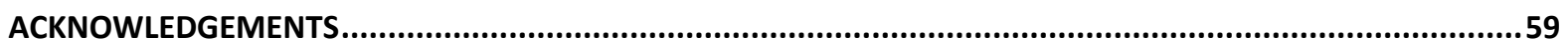

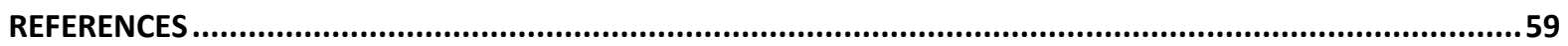

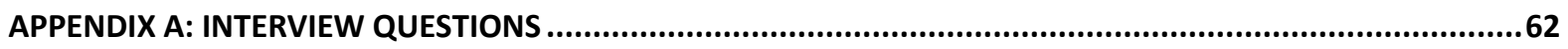

APPENDIX B: DEMOGRAPHIC QUESTIONNAIRE .......................................................................64

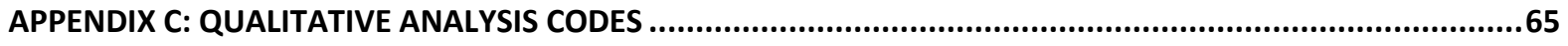

APPENDIX D: USER-IDENTIFIED TECHNOLOGY OPPORTUNITIES AND NEEDS .......................................68

\section{List of Tables}

Table 1. Experience with Technology......................................................................... 11

Table 2. Number of Participants Interviewed in FY'17 ................................................. 13

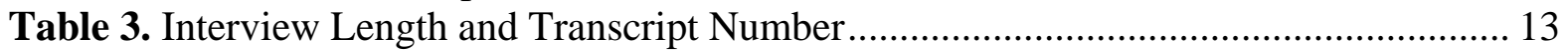

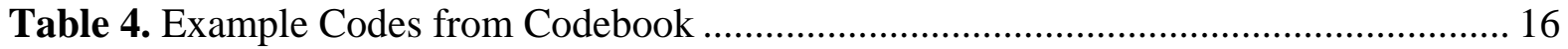

Table 5. Extraction Counts by Code and Discipline ....................................................... 17

Table 6. Quantitative Versus Qualitative Definitions .................................................... 18

Table 7. User Identified Needs, Problems and Requirements.......................................... 54

\section{List of Figures}

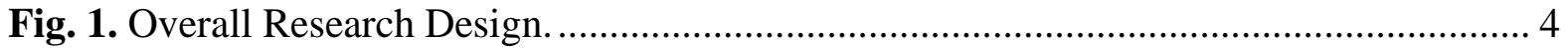

Fig. 2. Phase 1 of the Usability and User Interface Project............................................... 7

Fig. 3. Geographic Regions for Phase 1 Interviews. .................................................... 9

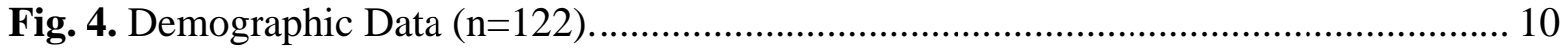




\section{Glossary}

$\begin{array}{lc}\text { CAD } & \text { Computer-aided Dispatch } \\ \text { COMMS } & \text { Communications } \\ \text { CT Scan } & \text { Computerized Tomography Scan } \\ \text { DOL } & \text { Department of Labor } \\ \text { EKG } & \text { Electrocardiograms } \\ \text { EMS } & \text { Emergency Medical Services } \\ \text { ER } & \text { Emergency Room } \\ \text { FB } & \text { Facebook }\end{array}$

FEMA Federal Emergency Management Agency

FF Firefighters

FN Field Notes

GPM Gallons per Minute

GPS Global Positioning System

HSPO Human Subject Protection Office

HUD Heads Up Display

IT Information Technology

LE Law Enforcement

LTE Long-Term Evolution

MCI Mass Casualty Incident

MDC Mobile data computer

MDT Mobile data terminal

OMB Office of Management and Budget

PCR Patient Contact Report

PIO Public Information Officer

POC Point of Contacts

PR Public Relation

PRA Paperwork Reduction Act

PS Public Safety

PSCR Public Safety Communications Research

RMS Record management system

R\&D Research and Development

SCBA Self-contained Breathing Apparatus

SDS Safety Data Sheet

SME Subject Matter Expert

SOP Standard Operating Procedure

T-Card Incident Command System Card: Resource Status Card (T-Card) (ICS 219s)

TAC Tactical Channel

TIC Thermal Imaging Camera 


\section{Introduction}

The United States Middle Class Tax Relief and Jobs Creation Act of 2012 created the First Responder Network Authority (FirstNet) to develop a high-speed backbone, Nationwide Public Safety Broadband Network (NPSBN), for public safety to take advantage of new technological innovations and enhance their communications and information sharing [1]. The establishment of the NPSBN with the ability to run Long-Term Evolution (LTE) solutions has provided a unique opportunity to advance public safety communications. However, if advanced public safety communications technology is to be successful, first responders ${ }^{2}$ must be able to achieve their goals and objectives with effectiveness, efficiency, and satisfaction in their specified contexts of use. Understanding a context of use includes understanding the users and their tasks, equipment (hardware, software and materials), and the physical and social environments in which they operate. In order for first responders to achieve their goals and objectives and support good decisions, it is critical that they receive the right information at the right time, delivered in the right way. Thus, understanding their contexts of use and what first responders believe about communication technology is imperative when developing new technology or improving current technology.

The Public Safety Communications Research (PSCR) community has identified human factors and user interfaces as important components for successful deployment and adoption of new communication technology. The challenge for communications technology developers and designers is truly understanding first responder needs, requirements, and their contexts of use. This is no easy task given the variability within the first responder population, however it is crucial to understand the different public safety user groups and their beliefs, perceptions, and experiences related to their roles and responsibilities and to communication. A clear understanding of how these different public safety user groups are similar and/or different, and what these similarities and/or differences mean in terms of their communication needs is necessary.

This Usability and User Interface project provides an in-depth look at the population of first responders, along with their work environment, their tasks, and their communication needs. The first phase, Phase 1 , of the project is a qualitative component, focusing on interviews with approximately 200 first responders. The second phase, Phase 2, will utilize the results of the qualitative interviews to inform a large-scale quantitative survey to be distributed nationally to first responders. The two phases of the project complement each other in order to provide a holistic view of first responders and their work, including their beliefs and needs related to communication technology.

Successful data collection relies on rigorous research methods and practices, which are detailed in the Methods section of this document. Three initial research questions informed the Phase 1 study:

1. How do public safety personnel describe the context of their work, including their roles and responsibilities as well as process and flow?

${ }^{2}$ For the purposes of this report, the use of first responders refers to personnel who are actively involved in day to day incident response and operations or in supporting roles. 
2. How do public safety personnel describe their communication and technology needs related to work?

3. What do public safety personnel believe is working or not working in their current operational environment related to communication and technology?

These questions served as guides for the development of data collection tools, analysis of the data, and the presentation of results. The goal is to ensure that the input from first responders is collected and incorporated as the PSCR community moves forward in developing technology to help first responders communicate more efficiently, effectively and with minimal frustration.

The goal of this project is to understand the behavioral, procedural, and technical pieces that first responders believe are necessary to facilitate communication and best address their technology needs. This information is meant to provide a repository of relevant data related to first responders and define the problem space with respect to communication technology to allow designers, developers, and researchers to focus on translating and incorporating the user experience into new and existing technology for first responders. The ultimate goal is to enable the public safety community to better achieve their primary goals of protecting lives and property.

There are approximately 4 million first responders in the public safety community in the United States (U.S.) [2][3], comprised of firefighters (FF), emergency medical services (EMS), law enforcement (LE), and communications (COMMS) personnel, including 911 call centers workers, to name a few. These various types of first responders have different roles and functions, respond to different types of situations, operate on many different levels, and have varied communication needs. The public safety community also differs organizationally, jurisdictionally, and geographically. The diverse makeup of the public safety community translates into different first responder contexts of use and communication needs.

The voices of first responders have often not been taken into consideration, especially when technology is developed for them and not with them. Firefighters repeatedly mentioned that the cord that connects the radio (a life safety device for firefighters) to the remote speaker microphone melts, rendering the radio useless and jeopardizing firefighters' safety.

Technology should not be developed in a vacuum. Before designing and developing technology first responder input must be collected — their voices should drive what technology is developed. Technology should be designed and developed with and for them. First responders believe they are there to serve and protect their communities, and that they are problem solvers. First responders see themselves as jacks of all trades who juggle many roles. This ability to be problem solvers, and to do many things for many people, often involves being able to create workarounds when things, like technology, do not work as planned.

Even with the many responsibilities they have, and the potential for danger that is always there, first responders love their jobs. When asked to describe their jobs, police officers used adjectives such as fun, interesting, dynamic, challenging, super rewarding, crazy and humbling. As a group they love going to work and many believe it is their dream job.

First responders hold a deep commitment to their work and to the communities they serve. The passion and dedication seen during the recent California forest fires in Santa Rosa and wine 
country are evidence of this commitment. First responders are dedicated to performing and completing their primary tasks, even to the point of exhaustion, and even when it comes at great personal risk. This dedication is evident in their words and how they describe their work experiences. Listening to them provides an understanding of what they do and how it may or may not be facilitated by the technology at hand.

The interviewed first responders believe that technology should help them accomplish their primary tasks, and if it does not, then they do not believe it is necessary and they do not want it. As a result, they become frustrated when technology has problems or limitations that interfere with their primary tasks. While they view communication as important, they do not believe it is their primary task - helping others is. In general, they also believe there is little need for communication if everyone knows what to do and is doing their job well. Many spoke about how during an incident they might not have to say a word to each other. They can look right in their colleague's eyes, and know what they need to do. While first responders see technology as useful, rarely do they see it as the most important factor in their mission.

This report provides information and resources about the contexts of first responders' work and how these contexts influence their communication and technology needs, as well as their beliefs and perceptions about their current technology, what they would like technology to do, and why they do and do not use technology. The report identifies approximately 3400 user needs and requirements expressed by first responders. Specific categories of technology opportunities are identified. Exemplars of the technology opportunities representing first responders' specific needs and requirements to solve the problems they face in performing their work are presented. A set of conceptual governing principles focusing on first responders as guidance and foundation for any technology development are described. Finally, trust has been identified as a factor in successful public safety communications technology adoption.

\section{The Research Team}

The research team for the Usability and User Interface project is multidisciplinary, with two computer scientists, three psychologists with specializations in human factors, and a sociologist who is a qualitative methodologist. Each team member brings unique disciplinary and methodological perspectives to the project. This diversity is particularly valuable when using a multiple methods approach. The multidisciplinary nature of the team also strengthens research quality "in terms of enabling sounder methodological design, increasing rigor, and encouraging richer conceptual analysis and interpretation” [4].

\section{Methods}

The research design for the project began by developing research questions (as stated in the Introduction section) that would guide the work during the project. This important formative stage of the research serves as a foundation and provides a focus for data collection and data analysis. 


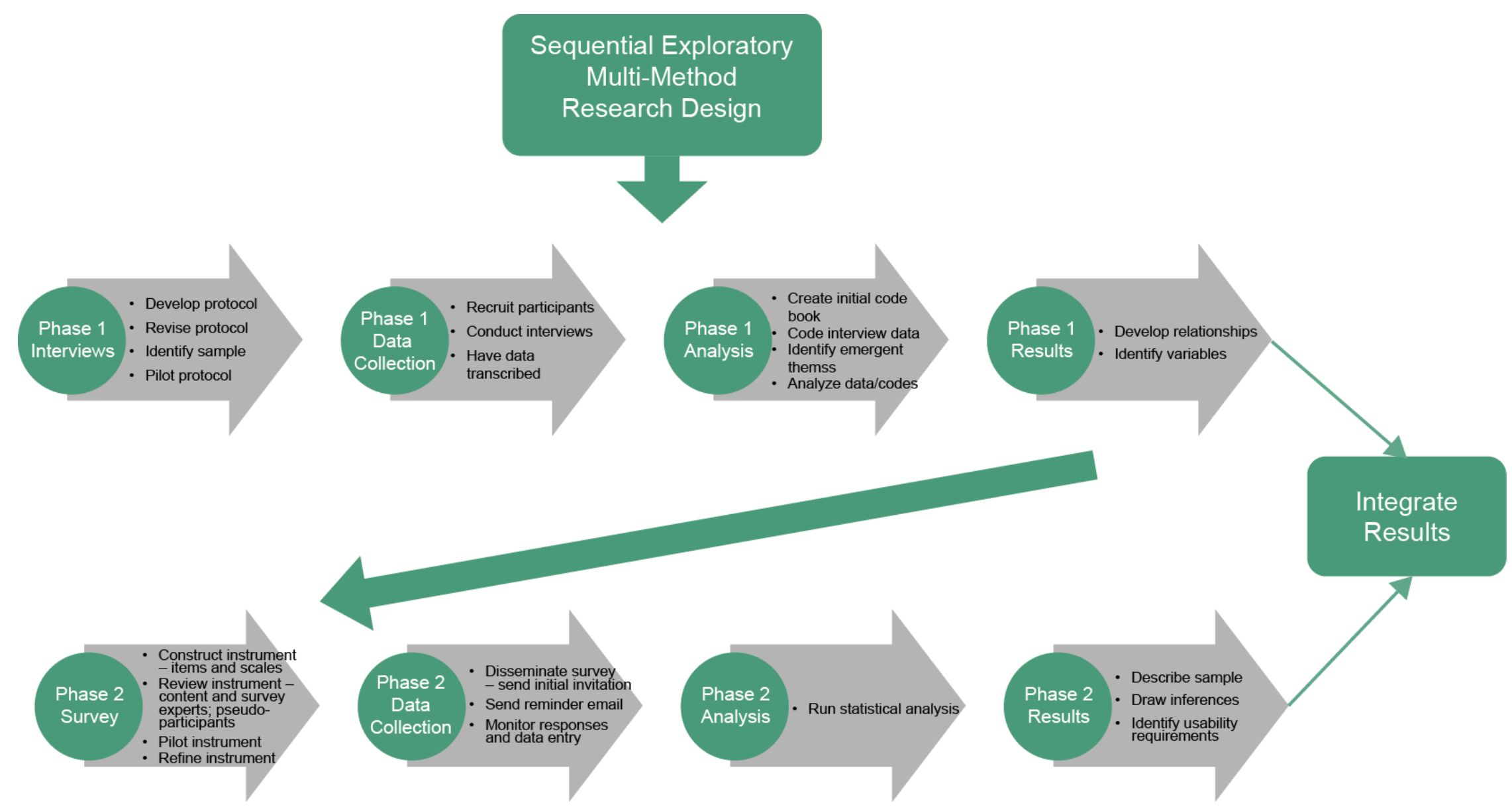

Fig. 1. Overall Research Design. 
The study can be described as a sequential, exploratory multi-method design. Data from both phases will be integrated for analysis to provide for a more holistic understanding of first responders and their communication. The overall research design for the project is depicted in Fig. 1 above.

\subsection{Qualitative versus Quantitative Methods}

Quantitative and qualitative research approaches rely on different paradigms to guide them. They utilize different methods of data collection and analysis, and they represent data differently - thus their purposes, their processes, and their products are different. There is often a misinformed image that quantitative research is "objective” while qualitative research is "subjective," which represents an oversimplification and misunderstanding of the strengths and weaknesses of each approach. Instead, each approach has different processes for ensuring rigor and for providing validity and reliability in the research.

Quantitative research is generally guided by a positivist paradigm that sees the world as comprised of facts that are observable and measurable. It assumes a fixed and measurable reality. In this paradigm, it is important to delimit phenomena into measurable and/or similar categories that can be applied to other situations or generalized to a larger population. It is explanatory in nature and relies on the quantification of data which allows for the generalization of results from a sample to an entire population of interest. Research questions in this approach are narrow and specific, and based on hypotheses that guide the research. Quantitative methods focus on collecting measurable, numeric data that works to place the diverse perspectives and experiences of people into a limited number of predetermined response categories. Data are analyzed through numerical comparisons and statistical inferences. Validity is the extent to which an instrument accurately measured what it is supposed to measure. Reliability in quantitative work demonstrates that similar results would be obtained if the research was repeated in the same context, utilizing the same methods, and with the same participants. There are a number of statistical tests and measures to assess validity and reliability in quantitative studies, which lends to their credibility as objective methods. On the other hand, most qualitative research aligns with an interpretivist paradigm that relies heavily on naturalistic methods in order to describe and understand the human condition-in all its complexity and with all its contradictions, from the participants' perspectives. It assumes a reality that is dynamic and negotiated. Qualitative research seeks to describe or explore a group or phenomenon in a comprehensive way. It is often exploratory or investigative and may or may not utilize hypotheses to guide it. Research questions are broad and focused on including voices and perspectives of participants. Data are collected by engaging directly with participants and analyzed by systematically identifying key ideas and concepts that occur across the data set, and then exploring where there are relationships amongst these. Although some erroneously view qualitative research as anecdotal, when a rigorous research design is in place, qualitative research can provide a deeper understanding about the group or phenomenon under study and may reveal information that is impossible to obtain through a survey or more mechanistic methods. With this type of research, it is not appropriate to generalize to the population at large, however readers are able to make decisions about a study's generalizability to their own situations based on how well the researchers 
describe process and outcomes of the research. Instead of validity, most qualitative researchers choose to discuss the "trustworthiness" of their work, focusing on methods of triangulation: tactics to insure honest responses from participants (such as informing them they can voluntarily withdraw or refuse to answer a question at any time); iterative questioning (to insure consistent data from participants); frequent debriefing sessions amongst researchers (to explore gaps in the process and/or product and insure exploration of varied and alternative ideas); and experienced investigators who are knowledgeable about the content and the population. Reliability in qualitative research is often referred to as dependability, which is provided by insuring transparency in the research process and providing detail about all research processes. This creates a model of the research that others can utilize as a template to conduct a similar study.

Just as the purpose and processes are different for quantitative and qualitative research studies, the products or results are different as well. Quantitative results are presented generally as statistical reports with correlations, comparisons of means, and calculations of statistical significance. Qualitative results include descriptions of contexts and participants, along with extensive quotes from the data. These quotes are meant to serve as exemplars of key concepts, ideas, and themes identified in the analysis rather than as just singular examples of data.

\section{2. $\quad$ Phase 1: The Qualitative Component}

Qualitative research is iterative in nature and focuses on the importance of participants' voices and perspectives throughout the research process. The research process consistently returns to the research questions to inform future elements of the process such as data collection and data analysis. Data collection and data analysis were conducted in tandem and occurred iteratively, each informing future iterations. As will be discussed in more detail in the section on Sampling Strategy, this project is cross-sectional including input from participants from all public safety disciplines, from a variety of ranks and levels, and from a variety of geographical areas to name just a few. It is also constructivist in that the focus is on how first responders construct and conceptualize their worlds - based on their individual understandings as well as based on shared meanings and social constructions. A case study approach was used, which Yin [5] argues is appropriate when exploring "how" questions where contextual conditions are relevant to the phenomenon under study, and where the behavior of those involved in the study is only observed. For this project, the phenomenon of study is experiences of first responder communication and technology, which cannot be understood outside of the first responder context. The research process for Phase 1 is depicted in Fig. 2 below. 


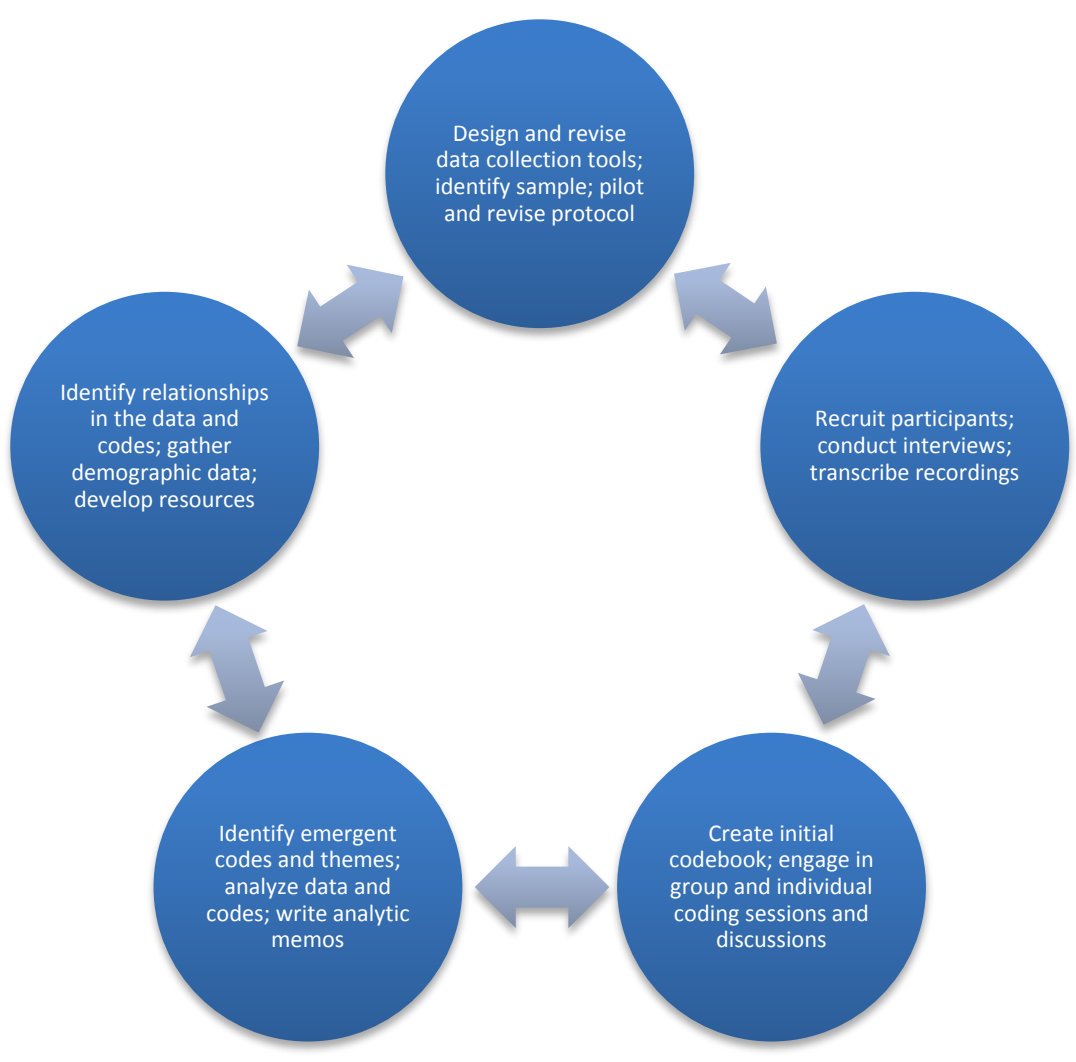

Fig. 2. Phase 1 of the Usability and User Interface Project.

A phased approach to data collection was used with approximately $66 \%$ (total of 133) of the interviews conducted in fiscal year (FY) 2017 and the remaining interviews to be conducted in FY 2018. The initial focus was on gathering data in urban and suburban areas from FF, EMS, and LE. In FY 2018, data collection is expanding to include rural areas as well as interviewing tribal and COMMS personnel. An in-depth explanation of the sampling strategy is presented later in this section.

\subsubsection{Participants}

As described in the introduction, there are approximately 4 million workers in the public safety community in the U.S., comprised of FF, EMS, LE and 911 call center workers, to name just a few of the major categories. They differ organizationally, jurisdictionally, and geographically [6], and have a variety of needs related to communication and technology. Thus this project demands a well-thought out and rigorous sampling strategy in order to produce results that are generalizable.

Since demographic factors such as age, years of service, and gender may play a role in participants' views related to public safety communication, purposive sampling ${ }^{3}$ was applied

\footnotetext{
${ }^{3}$ Purposive sampling is a non-probability sampling technique where characteristics of a population and the objective of the study are used to choose members of population to participate in the study.
} 
in Phase 1. The sampling involved seeking participants who represented the full range of first responder experiences. Phase 1 was also a convenience sample in that participants were often those who were available during our data collection times and trips.

\subsubsection{Sampling Strategy}

To provide a representative sample of first responders in the U.S., multiple variables were considered to develop the sampling strategy. These variables are detailed below.

\section{Role and Jurisdictional Diversity}

There are a wide range of different types of first responders. They have different roles and responsibilities, as well as different communication and technology needs. The sampling strategy includes interviewing FF, EMS, LE, PS (public safety personnel who are cross-trained in all three first responder disciplines - FF, EMS, and LE), and COMMS. Having input from each of these different types of first responders allows exploration of the similarities and differences among them, as well as the connections in their work.

The perspectives of first responders from a variety of positions within each of the public safety disciplines were also included since each level has differing needs related to communication and technology. Participants were currently in the field or had previous experience in the field, many having worked their way up the ranks into their current positions. Their responses represented not only their current positions and perceptions, but also those from when they were in the field as patrol officers, firefighters, or other first responders.

Another important demographic variable is jurisdictional diversity. The jurisdictional relationships among various agencies including federal, state, county and local may impact first responder requirements. These inter-agency relationships will be considered in future iterations.

\section{Geographic, Size, and Economic Diversity}

Due to the varied public safety issues faced in different parts of the country, geographic and cultural diversity were primary considerations. Areas for interviews were chosen that provide reasonable coverage of the depth and breadth of geographic and cultural diversity in the U.S. Also taken into consideration was coverage of the varied types of incidents that first responders face. These areas as shown in Fig. 3, align well with the 10 regions defined by the Federal Emergency Management Agency (FEMA) [7].

Across the U.S., urban (U), suburban (S), rural $(\mathrm{R})^{4}$, and tribal (T) districts are sampled to ensure that cities and districts of different sizes and different economic realities are represented (marked with the nearest airport codes in Fig. 3). These communities have different needs and experiences related to public safety and communication. This approach provides insight into the many different experiences of public safety communication across the U.S., ensuring coverage of both typical and unique experiences. The goal was to conduct five interviews each

\footnotetext{
${ }^{4} \mathrm{U}$ - Territory inside an urbanized area or a principal city with a population of 500000 or more. Urban areas represent densely developed territory that have a densely settled core with densely settled surrounding areas.

S - Territory outside a principal city and inside its own urbanized area with a population of at least 50000 . Suburban areas represent those in close proximity to densely developed urban areas.

$\mathrm{R}$ - Census-defined rural territory that is at least 5 miles or more from an urbanized area, as well as rural territory that is at least 2.5 miles from an urban cluster (territory with a population between 2500 and 50000 ).
} 
with police officers, firefighters, and EMS personnel in urban areas; three interviews with each discipline in suburban areas; and two interviews with each discipline in rural areas.

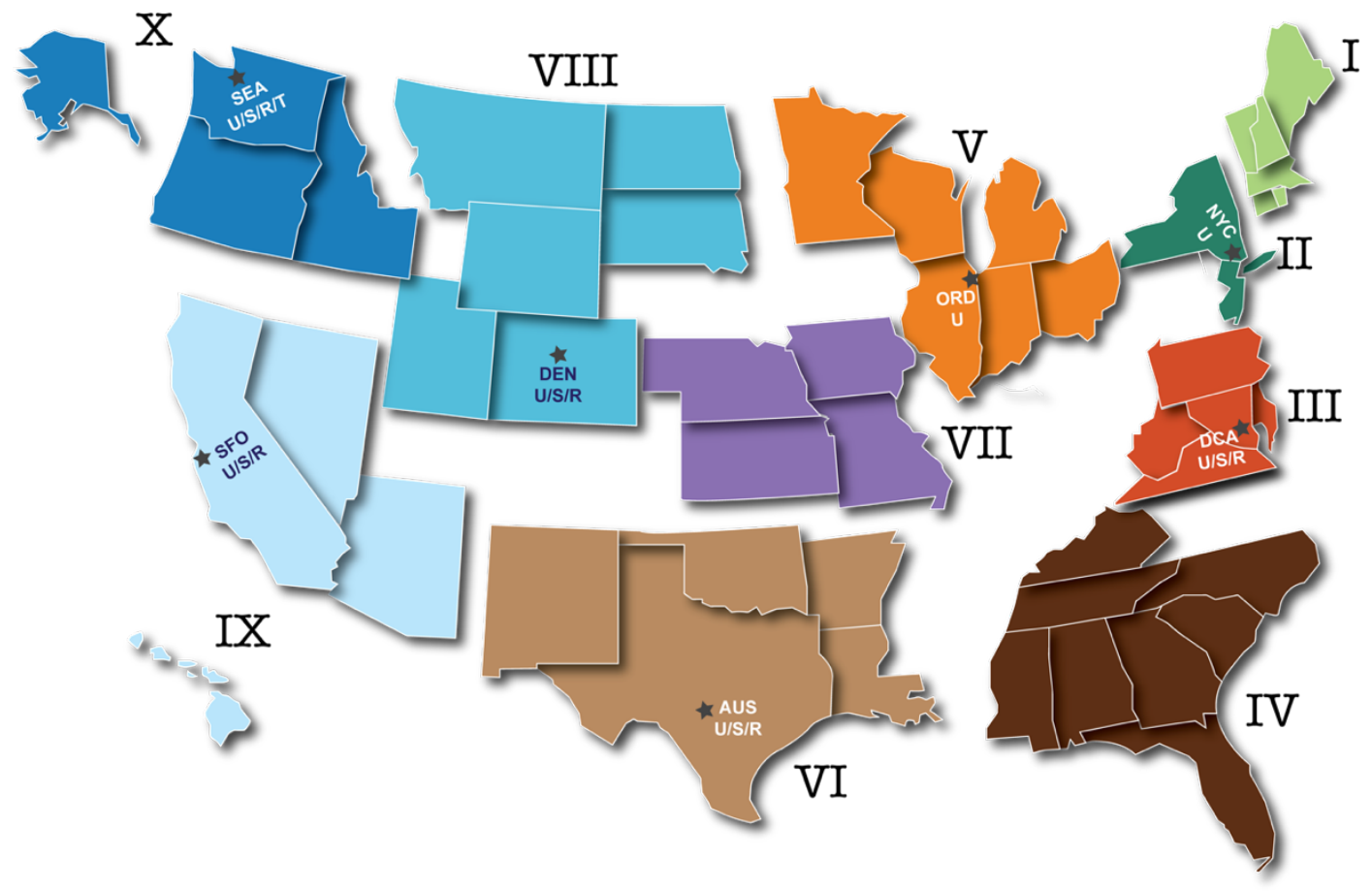

Fig. 3. Geographic Regions for Phase 1 Interviews.

Another variable related to size and economic diversity is the volunteer versus career status of first responders, this relates almost exclusively to firefighters. Of the approximately one million firefighters in the U.S. [3] about $70 \%$ are volunteer. Of these, $95 \%$ serve in areas with fewer than 25000 people, thus generally in more rural areas.

\subsubsection{Participant demographics}

This section presents the descriptive statistics characterizing the interview participants. Demographic statistics of the sample are presented below in Fig. 4. These demographic statistics were collected using a demographic questionnaire (see Sec. 3.2.2) at the start of each interview. 

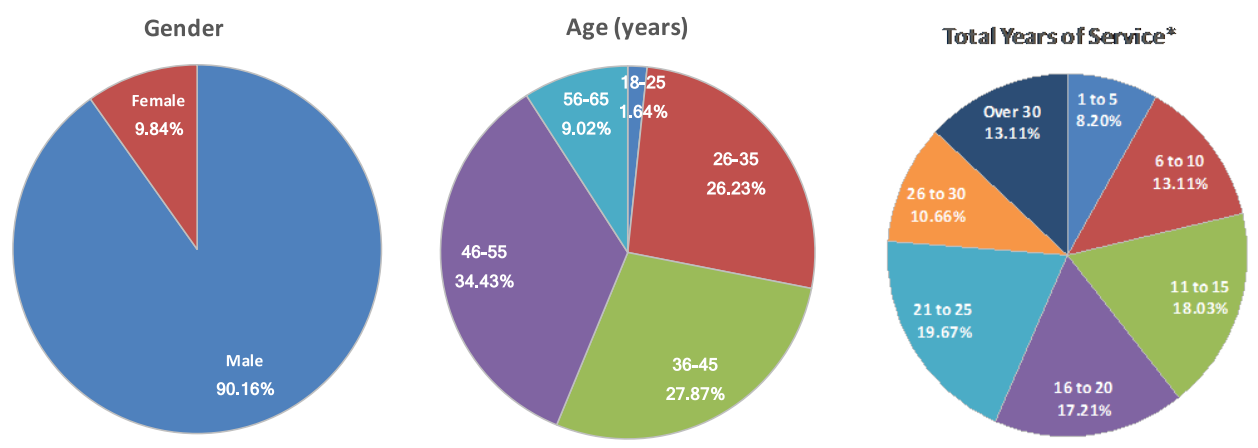

Fig. 4. Demographic Data $\left(n=122^{5}\right)$.

* Total Years of Service: Average=18.89, Range= $(1,40), \mathrm{SD}=9.38$

\begin{abstract}
While there were very few women in the interview sample, $9.84 \%$, this is representative of the first responder community in general. Women make up approximately $13 \%$ of LE [8] and less than $5 \%$ of FF [9]. Most of the women interviewed were in LE, representing the higher percentage of women found in that discipline rather than in FF. First responders from a range of age groups were also interviewed, providing opportunities to explore if and how age might affect their perceptions and experiences. Finally, participants were interviewed with a wide range of years of service, from those with less than a year in the field to those with over 30 years of service. Generally, those with more years of service held different ranks and were often in positions of authority, having moved up during their career. This provided valuable insights into the ways in which rank and position might impact first responders' perspectives related to communication and technology.
\end{abstract}

The demographic questionnaire included two questions about participants' experience with technology. The first questions addressed knowledge of technology while the second question focused on user characteristics of technology adoption. The results are listed below in Table 1.

\title{
3.2.2. Data Collection Instruments
}

A semi-structured interview protocol was developed for use during Phase 1. Based on the research questions, input from subject matter experts (SMEs), the literature, and background knowledge of the first responder community, a separate protocol was developed for each of the three first responder disciplines: FF, EMS, and LE. The protocols included a short demographic form, a variety of questions related to work tasks, relationships, and communication and technology tools, and several scenarios specific to each discipline.

\footnotetext{
${ }^{5}$ Note that the demographics in Fig. 4 are from $n=122$ first responders, as some participants did not complete all questions on the demographic questionnaire.
} 
Table 1. Experience with Technology.

\begin{tabular}{|c|c|}
\hline $\begin{array}{l}\text { Q1. Experience with different kinds of technology: (including } \\
\text { desktop or laptop computers, tablets, smartphones, and the } \\
\text { Internet). }\end{array}$ & Percentage $^{*}$ \\
\hline $\begin{array}{l}\square \text { I have limited experience using technology and I don’t know } \\
\text { much about how technology works. }\end{array}$ & $0.00 \%$ \\
\hline $\begin{array}{l}\square \text { I have some knowledge about how technology works, but } \\
\text { often need to ask for help to perform more advanced activities } \\
\text { - such as to configure the privacy settings on my cell phone. }\end{array}$ & $7.38 \%$ \\
\hline $\begin{array}{l}\square \text { I can do most things that I want to do with technology and } \\
\text { only need help occasionally. }\end{array}$ & $74.59 \%$ \\
\hline $\begin{array}{l}\square \text { I can do all things that I want to do with technology without } \\
\text { help from others. }\end{array}$ & $19.67 \%$ \\
\hline Q2. In general, when do you adopt new technologies? & Percentage $^{*}$ \\
\hline$\square$ I try the latest technologies as soon as they come out. & $21.31 \%$ \\
\hline$\square$ I follow technology trends. & $41.80 \%$ \\
\hline$\square$ I let others work out the kinks first. & $39.34 \%$ \\
\hline$\square$ I wait until my old technology dies. & $5.74 \%$ \\
\hline$\square$ I only adopt new technologies when it's required. & $3.28 \%$ \\
\hline
\end{tabular}

An iterative approach to refining the data collection instruments ensured that language, questions, and concepts were appropriate and would elicit valuable responses that would allow the research questions for the project to be answered and addressed. To determine face and construct validity and to assess language appropriateness for the population, pilot interviews with two or three first responders in each discipline were conducted. Several SMEs also reviewed the instruments to assess content validity and to ensure all relevant and related concepts were addressed by the instrument. An alignment matrix was created to ensure each of the research questions was adequately addressed and the goals for this phase of the project were achieved by the protocols. This ongoing review and refinement of the protocol is consistent with the iterative nature of qualitative research.

Based on results from the pilot interviews, a short demographic questionnaire was finalized focusing on gender, age and years of service since these three variables might influence participants' perceptions of and experiences with technology. Two additional questions related to participants' ease and comfort with technology were also included. The demographic questionnaire was short to allow maximum time for the interviews. Since usability focuses on users, their tasks, and the context of use [10], interview questions fell into two main categories: context of work; and perceptions of and experiences with communication and technology. Questions about context of work included descriptions of: their overall job, tasks, and daily routine; relationships with other people (their direct colleagues, other first responders, dispatch, the community, and the media, for example); and what work is like-both in and out of the station or specific work environment. The pilot interviews demonstrated that discipline- 
specific instruments were redundant and a generalized instrument worked well across all disciplines. The scenario questions were also found to be unnecessary.

The protocol and all relevant documents were approved by the National Institute of Standards and Technology (NIST) Human Subjects Protection Office (HSPO) and the Office of Management and Budget (OMB) Paperwork Reduction Act (PRA). The finalized interview questions are listed in Appendix A and the demographic questionnaire is in Appendix B.

\subsubsection{Procedure}

Phase 1 is based on the collection of in-depth, one-on-one, semi-structured interviews. Most interviews took place in the workplace, a police station or fire station, for example, in either a group gathering area or in a private office or conference room. Each participant was provided with a copy of the Information Sheet about the study, and was informed verbally that:

- their participation was voluntary,

- they could stop at any time without penalty,

- they could decline to answer any question(s),

- all data would be de-identified,

- the interview would take approximately $45 \mathrm{~min}$, and

- the study had been approved by the HSPO.

Participants were asked for permission to audio record the session. Only one participant declined, in that case the research observers took notes about the interview and participant responses. Participants sometimes were called away for incident responses.

Fiscal Year 2017 (FY'17) data collection ran from June through September, with 133 participants interviewed in a total of 105 sessions (some interviews included multiple participants). The breakdown of interviews is shown below in Table 2 below. There was a total of 5627 minutes in the recordings and a total of 1807 pages in the transcripts (in Table 3).

\subsection{Data Collection Challenges}

Given time and resource constraints and the importance of performing in-depth interviews to hear first-hand from first responders, it is not possible to reach a large percentage of the 4 million first responder population. At the end of FY'17, the sampling strategy resulted in overrepresentation and under-representation in certain areas such as disciplines, geography, size, and economic diversity. For example, career fire perspectives are somewhat over-represented in the current dataset due to the initial focus on urban centers, where career firefighters are the norm. This will be addressed in FY'18 where the focus will be more on rural areas where volunteer firefighters or combination departments are more common. These considerations do not in any way diminish the significance and contribution of the findings in this phase of the project. FY'18 data collection is intended to address the over and under-representation of the individual segments within the first responder population. In the public safety field, there is no such thing as perfect representation, because every place and station are unique in some way. Interviewing a wide variety of first responders, with a wide range of positions, responsibilities, years of experience, and other variables as described in the Participant Demographics section was intentionally pursued to address potential coverage and representation issues. 
Table 2. Number of Participants Interviewed in FY'17

(a) By discipline

\begin{tabular}{lcccccc}
\hline & FF & EMS & LE & COMMS $^{\text {a }}$ & PS & Total \\
\hline Urban & 35 & 11 & 26 & 1 & & 73 \\
\hline Suburban & 25 & 6 & 12 & 1 & 2 & 46 \\
\hline Rural & 5 & 3 & 5 & 1 & & 14 \\
\hline Total & 65 & 20 & 43 & 3 & 2 & 133 \\
\hline
\end{tabular}

(b) By sites visited (using airport codes to represent general locations)

\begin{tabular}{lcccccc}
\hline & FF & EMS & LE & COMMS $^{\text {a }}$ & PS & Total \\
\hline AUS & 9 & 4 & 7 & & & 20 \\
\hline DCA & 8 & 3 & 8 & & & 19 \\
\hline DEN & 11 & 8 & 10 & 2 & & 31 \\
NYC & 10 & & 2 & & & 12 \\
\hline ORD & 5 & 5 & 4 & & & 14 \\
\hline SEA & 15 & & 7 & & 22 \\
\hline SFO & 7 & & 5 & 1 & 15 \\
\hline
\end{tabular}

${ }^{\mathrm{a}}$ Although they were not planned for Year 1, there were 3 COMMS interviews due to convenience sampling, since they were present at the interview locations and expressed great interest in participating.

Table 3. Interview Length and Transcript Number

\begin{tabular}{lclrrrr}
\hline & Count $^{*}$ & Total Length & Average & Max & Min & SD \\
\hline Interview Recordings & 105 & 5627 (min) & 53.59 & 121 & 13 & 18.58 \\
\hline Transcripts & 105 & 1807 (pages) & 17.21 & 42 & 5 & 5.90 \\
\hline * There were only 105 interview recordings/transcripts - some interviews included multiple participants.
\end{tabular}

\subsubsection{Recruitment and Access}

Collecting data from first responders responsible for day to day incident response and operations posed several challenges that were not unique to our research team. A major challenge was simply gaining access to the first responders. The political nature of the public safety landscape was not originally anticipated. Permission was often needed from multiple authority levels, or from specific public safety officials, to schedule interviews and start the data collection process for a given location. This effect referred to as the 'gatekeeper effect' [11] was reflected more in larger organizations than smaller ones. At larger organizations, often permissions needed to start or go much higher in the chain of command to obtain the necessary approvals to conduct interviews. The requirement to receive the requisite permission to interview first responders took more time than originally anticipated and delayed data 
collection in some cases. It was often much more difficult to obtain the requisite approvals to interview law enforcement than firefighters. Given that it was easier to get permission to interview firefighters, more fire interviews than law enforcement interviews were conducted.

Logistically, it was also easier to interview several people at one fire station; they were already "at the station" and much more available. In contrast, although there are obviously many police stations, patrol officers are out on the road, so they are not typically at the station. In some notable cases, officers had to come in on their off time for the interviews. With EMS, the numbers are even lower since many areas cross-train fire and EMS. Interestingly, when interviewing cross-trained first responders, they often represented the fire perspective, even when recruited specifically for the EMS perspective.

Time of year affected the recruitment efforts and schedule as well, with summer travel schedules hampering obtaining the necessary approvals. Whereas there are always first responders on call, the upper levels of management-from whom we needed permission to interview-were sometimes unavailable.

Those in positions of authority were protective of their first responders and their time, and often controlled access to them, and rightfully so. Their time is extremely valuable, and we fully recognized that fact, knowing that their assignments and life-saving duties obviously take priority over interviews. Unfortunately, such controlled access may have been about more than simply protecting their time and may have also been since many first responders currently feel beleaguered (for example, law enforcement). Understandably, this sensitivity to externally conducted interviews may have led to concern and hesitation to participate.

Another challenge was the difficulty in identifying points of contact (POCs) with appropriate jurisdictional authority and connections to the population identified in the sampling plan. POCs were identified through professional public safety organizations and public safety conferences and meetings. Despite helpful POCs with best intentions, sometimes it was just not possible to make the appropriate connections within the tight interview schedule. In a few instances as a last resort, stations were contacted without pre-existing POCs.

The perceived relationship between the project and FirstNet may also have influenced participation and approvals. It was necessary to clarify the NIST usability team's third-party neutral research role of understanding user needs, tasks, and contexts of use. A formal recruiting letter listing our role and project goals was used to mitigate concerns.

\subsubsection{Time Constraints}

The qualitative interview process gathers extremely rich data, but is undeniably timeconsuming. In addition, qualitative data analysis is a highly iterative process. Given the vast quantity of interview data (see the Procedure sub-section), this report (Phase 1, Volume 1) documents the data analysis completed in FY'17. Therefore, the current document does not necessarily portray the full breadth and depth of the dataset. Rather than wait to fully complete the iterative process of qualitative data analysis, it was deemed more beneficial for the PSCR Research and Development (R\&D) community to publish preliminary results. For example, there are existing grantees and developers who can benefit from this document now. Furthermore, a debt of gratitude is owed to the many first responders, schedulers, and POCs 
who graciously gave their time to help the data collection effort; their voices deserve to be heard and be heard sooner rather than later.

\section{Qualitative Data Analysis}

This section describes the qualitative data analysis process and procedures used to analyze the interview data. The data consist of interview transcripts, demographics, field notes, and analytic memos. The interviews and field notes provide an in-depth and yet overarching look at first responders and their work in their own words. All interview recordings were transcribed by an external transcription service. The transcripts form the major dataset for analysis. In addition, research team members wrote field notes related to interviews they conducted, which served as additional data for analysis. Data analysis for Phase 1 involves both individual and research team coding and analysis sessions.

\subsection{Coding}

In contrast to coding in the computer science and software engineering domains, qualitative coding is a process of labeling sections or chunks of narrative data capturing the essence and/or salient features to group, compare, and/or manipulate similar chunks. In essence coding is a process for reducing and/or reconfiguring data in an organized and meaningful way.

Coding is the beginning of the analysis process. The coding process began with an a priori code list (Appendix C-a A Priori Code list). The a priori codes are a set of labels based on the research questions, relevant literature, and an understanding of the communication and technology space in the first responder community.

Each research team member used the a priori codes and coded (labeled) the same sub-set of five randomly chosen transcripts to ensure that the codes were being used by the team in similar ways and to identify needs for additional codes. The goal of this step was to recognize where there was convergence and divergence among the researchers' coding and to use these points of intersection/difference to explore the data more fully. The code book was revised and the codes were operationalized based on ongoing discussions, ensuring that the multiple points of view were captured. Operationalizing each code consisted of providing the definition of the code, when to use it, when not to use it, and examples for each code. Examples from the codebook illustrate the level of detail associated with each code (Table 4). For the full codebook (see Appendix C-b).

The second step of coding is data extraction. Data extraction refers to pulling all the data associated with a code from each transcript into a separate document. This process of breaking apart the data, is a technique to study the data in different ways, providing access to the "whole" and to the "parts" to determine if and where relationships exist or what themes might be developing across codes. Table 5 provides a view of the data by those codes particularly relevant to this report sorted by first responder disciplines. Table 5 presents the number of coded extractions from all of the transcripts for all of the FY' 17 cities: Austin, Washington, D.C., Denver, New York City, Chicago, Seattle and San Francisco. 
Table 4. Example Codes from Codebook

\begin{tabular}{|c|c|}
\hline Codes and Sub-codes & Code Operationalization \\
\hline Context of Work & Tasks related to what is done as part of the job \\
\hline Stress/Overload & $\begin{array}{l}\text { Physical, cognitive, or emotional expressions of anxiety, tension, or feeling } \\
\text { overwhelmed }\end{array}$ \\
\hline Risk/Safety & Situation involving exposure to danger; harm or loss \\
\hline Relationships & $\begin{array}{l}\text { The sense of community developed among individuals or groups of people, a } \\
\text { connection, association, or involvement, including relationships present } \\
\text { within a discipline, between disciplines, or with the public }\end{array}$ \\
\hline Frustration & An expression of annoyance, because of inability to change or achieve something \\
\hline $\begin{array}{l}\text { Information } \\
\text { Control }\end{array}$ & $\begin{array}{l}\text { Data, evidence, or intelligence related to an incident or to work environment/situation } \\
\text { Entity who has the ability/responsibility to act or pass on information }\end{array}$ \\
\hline Operational environment & $\begin{array}{l}\text { This can refer to the station, the department, the leadership, the city/state; anything } \\
\text { that's larger than just the user (we) }\end{array}$ \\
\hline Problems & Identification of issues identified by participants related to doing their jobs \\
\hline Technology & Issues with technology \\
\hline People & Issues with people \\
\hline Information & $\begin{array}{l}\text { Issues with information (in getting, receiving, or producing information; situations } \\
\text { where there was too little or too much information) }\end{array}$ \\
\hline Policies/Procedures & $\begin{array}{l}\text { Issues with formal or informal rules and operating processes and procedures for how } \\
\text { things should be, have been, or are being done }\end{array}$ \\
\hline Rules/Politics & $\begin{array}{l}\text { Formal or informal guidelines that directly or indirectly govern the work, expectations, } \\
\text { and/or environments of first responders }\end{array}$ \\
\hline Priority/Influence & Related to priorities of the administration (e.g., station, local government) \\
\hline Technology & Devices utilized by first responders to do their jobs or as part of their daily tasks \\
\hline Reliance on technology & $\begin{array}{l}\text { Situations when responders don't know what to do without the technology or when } \\
\text { it's not available (either when it breaks or is not appropriate to use) }\end{array}$ \\
\hline User characteristics & $\begin{array}{l}\text { Participant related demographics, or identification of demographic pieces related to } \\
\text { other work colleagues }\end{array}$ \\
\hline Knowledge/experience/skills & Discipline relevant understandings and abilities related to their work \\
\hline Wish List & $\begin{array}{l}\text { Things (funding, information, processes, technology, devices, or equipment) that would } \\
\text { facilitate first responders' job. }\end{array}$ \\
\hline
\end{tabular}


Table 5. Extraction Counts by Code and Discipline

\begin{tabular}{lrrrrr}
\hline \multicolumn{1}{c}{ CODE } & FF & EMS & \multicolumn{1}{c}{ LE } & PS & Total \\
\hline Context of Work & 510 & 252 & 532 & 9 & 1303 \\
\hline Context of Work - Stress/Overload & 85 & 27 & 95 & 8 & 215 \\
\hline Context of Work - Risk/Safety & 106 & 36 & 109 & 14 & 265 \\
\hline Context of Work - Relationships & 212 & 93 & 279 & 5 & 589 \\
\hline Frustration & 155 & 53 & 198 & 6 & 412 \\
\hline Information & 143 & 70 & 93 & 2 & 308 \\
\hline Information - Control & 71 & 30 & 92 & 2 & 195 \\
\hline Operational Environment & 439 & 282 & 368 & 13 & 1102 \\
\hline Problems & 63 & 36 & 32 & 3 & 134 \\
\hline Problems - Technology & 611 & 211 & 631 & 33 & 1486 \\
\hline Problems - People & 142 & 32 & 95 & 2 & 271 \\
\hline Problems - Information & 136 & 46 & 105 & 2 & 289 \\
\hline Problems - Policies/Procedures & 116 & 49 & 112 & 2 & 279 \\
\hline Reliance on Technology & 37 & 21 & 29 & 1 & 88 \\
\hline Rules \& Politics & 2 & 2 & 1 & 0 & 5 \\
\hline Rules \& Politics - Priority/Influence & 40 & 8 & 28 & 7 & 83 \\
\hline User Characteristics & 52 & 26 & 93 & 2 & 173 \\
\hline User Characteristics - & 153 & 88 & 161 & 5 & 407 \\
$\quad$ Knowledge/Experience/Skills & & & & & \\
\hline Wish List - Needs & 388 & 121 & 356 & 18 & 883 \\
\hline & $\mathbf{3 4 6 0}$ & $\mathbf{1 4 8 3}$ & $\mathbf{3 4 0 9}$ & $\mathbf{1 3 4}$ & $\mathbf{8 4 8 6}$ \\
\hline
\end{tabular}

\subsection{Analysis}

Qualitative analysis is the process of exploring the relationships of the data and the codes to identify themes. Analysis includes thematic, negative case, values, and descriptive exploration of the data and the codes [12]. Analytic memoing is used to document the relationships of the data and the codes. The iterative process of going back and forth between data and codes, between the full data set and extracted files facilitates the identification of themes, trends, outliers and provides an overall impression and understanding of the data.

Themes emerged during our analysis discussions. Early in the analysis discussions, several concepts including problems and trust emerged as cutting across the data in many ways. While the interview protocol did address communication problems, it was surprising how often the concept of trust was introduced by participants, even though the interview protocol did not ask about it, nor did the team identify trust as a code. Upon further examination, trust seemed connected to several items in the codebook including technology, budgets, and people. As the coding was refined, each of these three codes became sub-codes under the broader umbrella of Problems. Re-examining the data set, it became clear that each of the problem sub-codes was related to trust. The team also discovered, that trust was one of the most consistent themes cutting across the data, irrespective of geography, city type, rank, age, years of service, or other variables.

Analytic memoing continued to document ideas both about the data and from the data. Memoing revolved around trust and problems, but also about relationships of first 
responders - to technology, to their environment, and to each other to name just a few. The analytic memos continued to guide the group discussions and thoughts about the implications of the findings. For example: What is the relationship between technology and trust?

As with all parts of the qualitative research process, analysis is an ongoing process and iterations continue to delve into the data and explore ideas. There are many other interesting and important relationships to explore in this dataset. However, this report focuses on the themes of problems and trust due to the prevalence and cross-cutting nature of these themes in the data, as well as the implications of these themes on acceptance and adoption of new technology.

\subsection{Qualitative Method Validity and Trustworthiness}

Qualitative methods require different approaches of providing validity than quantitative methods. Even similar terminology has different meanings. The definitions presented in Table 6 illustrate how qualitative and quantitative methodologies use the same terminology in different ways.

Table 6. Quantitative Versus Qualitative Definitions

\begin{tabular}{lll}
\hline \multicolumn{1}{c}{ Term } & \multicolumn{1}{c}{ Quantitative Definition } & \multicolumn{1}{c}{ Qualitative Definition } \\
\hline Significance & $\begin{array}{l}\text { The number that expresses the } \\
\text { probability that the result of an } \\
\text { experiment could have occurred } \\
\text { by chance. }\end{array}$ & $\begin{array}{l}\text { Identification of trends or ideas in the data } \\
\text { that are not obvious, but which point } \\
\text { toward a new, emerging, and/or interesting } \\
\text { understanding of the data }\end{array}$ \\
\hline Reliability & $\begin{array}{l}\text { The overall consistency of a } \\
\text { measure }\end{array}$ & $\begin{array}{l}\text { The dependability of the process and } \\
\text { product of the research, which can be } \\
\text { provided through an inquiry audit or other } \\
\text { means of demonstrating consistency }\end{array}$ \\
\hline Validity & $\begin{array}{l}\text { The method of power analysis } \\
\text { used to detect a relationship }\end{array}$ & $\begin{array}{l}\text { The trustworthiness provided by } \\
\text { transparency in study design and process, } \\
\text { including the delineation of analytic } \\
\text { processes that are systematic and rigorous }\end{array}$ \\
\hline Sample size (n) & $\begin{array}{l}\text { The number of participants or cases needed } \\
\text { necessary to reach a certain } \\
\text { to reach saturation in the data }\end{array}$ \\
\hline
\end{tabular}

Qualitative methods rely on trustworthiness as a measure of validity. Trustworthiness consists of four different components: credibility; transferability; dependability; and confirmability [13].

Credibility refers to a belief that the findings are congruent with reality (specifically with the reality of the participants). This is accomplished through a variety of measures, including the use of:

- Well-established research methods (such as interviews and observation field notes), 
- Triangulation (across time, person, location, and organization),

- Practices to encourage accurate responses from participants (such as informing them they can voluntarily withdraw or decline to answer a question at any time, and data are collected without identifiers),

- Iterative questioning (to insure consistent data from participants),

- Frequent debriefing sessions among researchers (to explore gaps in the process and/or product and insure exploration of varied and alternative ideas),

- Experienced investigators who are knowledgeable about the content and the population,

- Member checking (the use of participants and subject-matter experts to review research interpretations),

- Detailed description of the phenomena under study and the use of participants' own words. As Geertz [14] said, "A good interpretation of anything...takes us into the heart of that of which it is the interpretation. The goal is to provide readers with a "thick description" or "densely textured" account of the phenomenon or group under study. In fields such as sociology and human-centered design, a thick description of a human behavior is one that explains not just the behavior, but its context as well, such that the behavior becomes meaningful to an outsider.

Transferability is about the extent to which findings from this study could be applied to other situations. In quantitative methods generalizability is built into the research design and occurs at the time the research is conducted. In qualitative methods, it is incumbent on the researchers to use rich, thick description of the research process, including a focus on the participants, to provide readers with a good understanding of participants and experiences delineated in the research. The detailed description of the methodological process promotes the transferability of research findings to the readers.

Dependability, or reliability in quantitative terms, refers to the likelihood that if the work were repeated in the same context with the same methods, and same participants, similar results would be obtained. In qualitative research, dependability is provided by ensuring transparency in the research process and providing detail about all research processes. This creates a model of the research that others can utilize as a "prototype" to conduct a similar study. In this report, specific detailed descriptions of the research design, data collection methods, tools, timelines, and analysis processes are provided.

Confirmability is about ensuring that the findings presented are based on the knowledge, beliefs, and experiences of the participants and not on what the researchers believe or prefer. Confirmability is about providing objectivity — in the data collection and in the data analysis. One key to this is recognizing researcher biases and pre-dispositions. The research team reflected about how the team's backgrounds and disciplinary training might influence their thinking about the project. For example, the sociologist/qualitative methodologist on the research team grew up in a family of police officers and fire fighters, and several members of her family continue the family tradition today. Her experiences and background knowledge were monitored so as not to bias the results. The team documented self-reflections in analytic memos as a technique to monitor biases and pre-dispositions. Another important component is the provision of detailed methodological descriptions of the decisions about the data collection and analysis to provide transparency in the process and in the product (the interpretations). 
This type of data audit trail provides a step-by-step guide to what was done, when it was done, how it was done, and why it was done. A 'theoretical audit trail' (the analytic process and how different tools were used to interpret the data) was also constructed. Together, the data and theoretical audit trails provide a strong foundation for confirmability of the research.

\subsection{Documenting Results}

While the overall project has two phases, this report focuses on Phase 1 - the qualitative component, and on data collected in FY' 17 as listed in Table 2 focusing on the codes within Problems. This report documents Phase 1, volume 1 of the data analysis. Additional reports are planned that will address the qualitative analysis results of the complete (FY'17 and FY'18) Phase 1 dataset.

\section{Results}

This section reports on the findings from the data analysis. The section includes the themes of problems, trust, and the relationship with technology, people, and budgets given the prevalence of these themes in the data/transcripts and the importance of these themes to acceptance and adoption of technology.

According to ISO [15] usability is defined as "the extent to which a product can be used by specified users to achieve specified goals with effectiveness, efficiency and satisfaction in a specified context of use”. The standard definition identifies who, what, where and how to measure. The first tenet of usability is to know thy user. This includes user characteristics as well as demographics. The second according to the definition requires a thorough understanding of the user's goals and tasks (the what). A final factor that highly influences the outcome is the context of use (the where).

The results are presented according to the ISO definition of usability with a focus on users, and tasks. The best way to present the findings is by using the words of the first responders who participated. The conventions for referencing data include:

All direct participant responses are verbatim in blue text and come directly from participant transcripts. The participant responses are followed by a notation that is comprised of three parts: discipline (FF; EMS; LE; COMMS; PS); city type (Urban=U; Suburban=S; Rural=R; Tribal=T); and interview number. Thus (FF-R-009) refers to an FF interview, from a rural location, who is fire interviewee number 009. This convention provides assurances to the reader of the data's provenance and that the data can quickly and easily be located within the larger dataset when necessary.

Field notes are qualitative notes taken by the researcher during or after interacting with participants Field notes (FN) were used to capture important data beyond verbatim speech (gestures, for example) and when audio recording was not permitted. Comments from participants drawn from FN are enclosed in Guillemets $(<<>>)$. The notation following these comments starts with FN number, followed by the team member number who wrote the notes, followed by discipline, and finally by the city type, U/S/R. Thus (FN1-4-LE-U) refers to FN 
number 1 , written by team member 4 , an LE interview, from an urban location. Field notes represent near verbatim speech from participants.

The direct participant responses used to illustrate the findings in the following sections are exemplars from the coded transcriptions. Each was chosen as an excellent example representing the set of extracted quotes to describe the concept. For the majority of the presented findings an exemplar from each discipline (designated in the notation for each quote) is presented demonstrating the cross-cutting nature of the finding.

\subsection{Know Thy User: Characteristics of First Responders}

Many studies have demonstrated that usability problems are influenced by product properties such as functional complexity [16][17][18]. However, user dissatisfaction of technology is increasingly caused by usability problems that are not technical in nature but problems where the most important issue is that users are dissatisfied with the quality of the interaction [16][19][20]. This type of usability problem is the outcome of the interaction between user characteristics and design properties. The following two examples illustrate the differences between usability problems. Consider a washing machine where when a user pushed the start button the machine does not start versus the washing machine where the user cannot determine what to do to start the machine. Both are usability problems from the user's perspectives. However, the first is a technical or functional problem while the second is an interaction problem. Consider a link on a website that when clicked does not load or returns an error. This error again is technical or functional in nature. But the usability problem associated with inability of users to find the correct link on a website is an interaction problem.

User dissatisfaction is often a mismatch between product properties, user characteristics, context, and user expectation. Deeper understanding of the interaction between user characteristics, product properties, and context by the design and development team can identify and mitigate interaction usability problems [16].

Thus designing products that satisfy target users requires a holistic understanding of user characteristics. According to Mayhew [21] these characteristics include:

- Psychological characteristics (e.g., attitude, motivation, personality)

- Knowledge and experience (e.g., skill and task experience)

- Job and task characteristics (e.g., frequency or use, task structure)

- Physical characteristics (e.g., demographics, color blindness).

Hackos and Reddish [22] in their seminal textbook recommend considering user characteristics beyond their tasks and identify a long list of questions including the following:

- How do the users think about their relationship to their work? Are they trained professionals, career, volunteer? Are they simply putting in eight hours, working at home, on their own time?

- Do they want to invest a lot of time learning a new product or will it be a minor part of what they do?

- What motivates them to do the job? The money, the social interaction of the workplace? 
- How well do the users read? Do they prefer to learn by asking other people? Are they college graduates with experience using complex texts - are they willing to read text to understand and use a new product?

- What languages are the users most comfortable using? Do they have a special professional vocabulary?

- Do the users enjoy taking risks and finding new ways of doing the same work or do they prefer tried and true solutions?

As demonstrated by these questions, when developing technology it is not possible to separate users from the things they think and do [22]. Applied properly, the user centered design approach requires a deep understanding of user characteristics. The holistic view of the user assists in minimizing both technical/functional usability problems such as placement of buttons for example and the usability problems users face when interacting with technology. The detailed understanding of user characteristics helps to minimizes user dissatisfaction with technology and encourages factors such as adoption and acceptance of new technology.

As described in Sec. 3.2.1.1., the sampling strategy was designed to include a wide variety of first responders with an array of different job responsibilities, at different levels of the hierarchy. In addition to the variability across individual job responsibilities and public safety disciplines-FF, EMS, LE-several other important and informative sources of variability were incorporated in the interviews. For example, variability in geography, variability in types of areas (urban, suburban, rural, and tribal), variability in budgets and size of department, and variability in levels of authority.

The discussion of user characteristics is divided into two sub-sections. The first section reports on similarities and the second on differences.

\subsubsection{Similarities in First Responders}

Given the diversity and variability of the user population in this report, it is more telling when consistencies in participant responses so clearly cut across all these disciplines-FF, LE, and EMS. Two similarities stood out: first responders' dedication to their profession and the variable nature of their work.

\section{Dedication to the Profession}

Perhaps key among the similarities was the clear passion and commitment these first responders have for their jobs and for helping people. Repeatedly, adjectives like 'best,' 'exciting,' and 'interesting' were used when first responders were asked to describe their jobs. Across the board, first responders love their work and are passionate about what they do.

For one, it's the best job in the world. We get to have fun all day long. One of the biggest things about it is we actually do get to help people on a daily and sometimes even an hourly basis. Of course, everybody, you see a big red truck going down the street and kids will wave and we wave back at them. I mean, it's hugely a public service job. (FF-U-006) 
Best job in the world. Never the same. It's always something new. It's exciting. You get to work with your friends. You get to help the community out. (EMS$\mathrm{R}-002)$

I think it's everything. It's challenging, exciting. It's scary at times. I like being out and about. I like not having the same thing to do day by day. So that's the thing with being a police officer. You never know really what to expect the day that you go to work. It can be a slow day with really nothing going on, or it can be a busy day where it's just out of control. That's what I like about it. Yeah. It's so exciting, I would say that. (LE-U-025)

In addition to fundamentally enjoying the work they do; first responders also care about the people and the communities they serve. One of the ways in which first responders demonstrate this care is that they take pride in their jobs, and in their responsibilities to their communities and fellow first responders. They are committed to public service, as evidenced by the quotes below.

Pretty much, we're going to go help anybody that needs help, whether it's medical, fire, anything like that. If they need something, just call the fire department, we'll come and help them. I'd say that we're at their disposal for them. So if it was really coming down to, "What do we do?" just be anything for the citizens we work for, pretty much. (FF-R-009)

So that's what my job is, is to try to make people's lives better while protecting them and protecting my guys in the process. (FF-S-040)

I help others. I mentor other police officers. I mentor other people. ... I arrest people who break the law. I enforce traffic violations. I help officers learn their job, learn exactly what it is they're supposed to do. I am like a teacher. I proofread reports. I make sure their arrests have probable cause to go with the arrest. I make sure the case report and the arrest report all tell the same story. So we're also like storytellers. (LE-U-026)

First responders routinely go above and beyond the call of duty, for example, by arriving to work early to help the off-going shift or prepare for their days (or nights), mentoring others, doing extra projects for their stations, volunteering for additional assignments, and regularly conducting and participating in extra training. Many of the places visited had their own training facilities, and regularly conducted hands-on training drills for their first responders. They often came in on their own time to help train "newbies" or review a training themselves (FF10-4FF/EMS-U).

So I come in in the morning probably around 5:30 in the morning. My shift doesn't start until 7:00, but I've got a lot of stuff to do beforehand. And basically, I pull up the schedule for the day to see what personnel are working. (FF-S-041)

Typically, I report to my duty assignment, whatever station that may be by at least 6:00 AM. Our report time is at 7:00. So that gives me an hour ahead of time to just kind of help with a last minute call or whatever needs to be done. Makes smooth transition. (EMS-S-015) 
We're multi-faceted. We're teachers, doctors, nurses, medics, moms, dads, coaches, counselors is[sic] a big one, mental health specialists, which is what we get a lot of in [city redacted]. We're jack of all trades. We do everything. Report takers, problem solvers, crime fighters. I mean, we do everything in [city redacted]. (LE-U-013)

User characteristics of the first responder population interviewed clearly include passion, pride, commitment, and dedication to their jobs. These characteristics suggest that first responders are willing to devote attention to technology even when the technology is interfering with their primary task or job. Instead, the technology should rise to the occasion.

\section{Flexibility}

When asked to describe their work, first responders discuss the importance of being flexible and willing to go into unknown and dangerous situations daily. They see themselves as problem solvers who must continually adapt to rapidly changing and highly stressful incidents.

You can get a call with absolutely no information. You can get very basic 911 hang up and then at that point, you would know absolutely nothing and you walk into potentially anything. You can walk into a murder scene, you can walk into a burglary, you can walk into someone needing medical assistance. I mean, you can walk into absolutely nothing. So our officers are very good about being flexible for these things... Officers are good about being reactionary and flexible. (LE-U-005)

You got to be able to adapt to the minute's notice, not even a minute, a moment's notice, from what your reaction is to what somebody else's reaction is. (LE-U025)

We often come upon situations that are very unusual and require a fair amount of thought to figure out how to best approach them. So that's the thing that I kind of enjoy about my job. Not only do I get to help people but it's often very challenging to try to figure out how to mitigate whatever the problem is with minimal risk to ourselves and to help the folks that we're there to help. So it's a very interesting career. (FF-S-040)

First responders know that each day and each call will be different and require different kinds of thinking and action. For many first responders, this was the "excitement" about the job, what they loved about it. Additional user characteristics of first responders include flexibility, adaptability and the ability to solve problems in stressful situations.

Given the uncertainty of many situations and the necessity to make complex decisions quickly, first responders need as much information as technology can provide. But this information must be easy to understand and use so as not to overtax an already stressful situation by increasing the cognitive load. First responders certainly do not need the added complexity and challenges often associated with technology. First responders' flexibility and adaptability should be saved for the emergency situation and not to interface with the technology. Limited cognitive abilities in stressful situations must be focused on the actual problem as opposed to the technology. 


\subsubsection{Differences in First Responders}

Despite the many similar user characteristics and similarities in how they described their work, there were differences among and within the various disciplines of FF, LE, and EMS. These differences imply that there is no easy "one size fits all” technology and data solution.

So that's the challenge [for developers]. Whatever you come out with, it's not going to be one size fits all. (EMS-U-001).

Key differences were in their communication needs, perception of generational differences, and the perceived value of their profession.

\section{Communication}

In sharp contrast to the overwhelming consistency in participant responses regarding first responders' commitment to their jobs and to helping others, very distinct differences were observed in their communication and information needs and practices, depending in large part on their discipline, their position, and especially their role in the chain of command. Participant responses clearly show that not all first responders need access to all types of communication tools, nor to the same communication tools-everyone does not need everything. There are some important similarities across disciplines; for instance, FF, EMS, and LE all need to know the location and nature of incidents, and traffic patterns while in route to a location. However, it is critical that technology developers and data providers know that even within a single discipline, technology and information needs differ based on both individual first responder roles, and the scale and nature of the incident to which they are responding.

In the public safety realm, communication is a hierarchical act in that people at different levels need different tools to communicate and have different reasons for communicating and potentially different types of information to communicate. For example, for FF it was much more efficient at a fire scene for one person to control the communication.

We're very strong in the practice of the chain of command. So when my lieutenant is sitting right seat of the engine and we are going in an incident, unless there is something desperately wrong or I need to communicate with something that he's asked me to keep communicating to him with or about, I'm not talking on the radio. He's the lieutenant and that kind of helps filter it a little bit, right? Not every guy is going to be out there going, "Oh, I see this, I see this." I'm going to come straight to [my lieutenant] and I'd say, "Hey, did you catch that?" And filter it that way. It's probably the most-- I believe it's the most appropriate way to try to manage that radio traffic and get the most critical information out there in an appropriate manner. (FF-S-035) (Suburban Firefighter EMT)

Not everybody needs to talk [at a fire scene]...it’s [about] controlling the communication... There's certain information that I could tell them to reinforce, and then there's certain information that I kind of hold back so that it doesn't stop the flow of the incident... I help the communication and flow of the incident 
and sometimes I have to control what is disseminated to them. (FF-S-041) (Suburban Battalion Chief)

If I went on a call right now, I would be dealing with two battalion chiefs, three engines, two truck companies, a rescue squad, so I have a lot of people...so we organize that by either just talking to the officer in charge of those engines or breaking them up into groups and talking to just one person. (FF-U-014) (Urban Assistant Fire Chief)

In FF, information and communication needs differ drastically between incident commanders (IC) and the firefighters under their command. The ICs need a much more holistic view of the incident to monitor and direct all teams involved, whereas the individual firefighters are often completing very specific tasks and communicating only with their immediate crew. Likewise, information and communication needs for a single-family home structure fire differ from a high-rise fire or a large-scale hazmat incident.

For EMS, information and communication needs of an EMS squad supervisor responsible for directing multiple crews are different from those needs of an individual paramedic and his/her partner. Coordinating and providing patient care for a mass casualty incident (MCI) is different than dealing with a single cardiac arrest patient.

In LE, information and communication needs for a single patrol officer during a routine traffic stop are very different than those of an incident commander in charge of coordinating police response to an ongoing active shooter incident. The needs of shorter duration incidents versus more extended ones, such as public protests and demonstrations require different information and communication.

During incidents, another communication need is accountability and location tracking. Those who monitor and direct personnel expressed the need to have the capabilities for accountability and location tracking of the crew, units, and building occupants.

There's a lot of rescue stuff for downed firefighters. It would be great to have location devices on firefighters' hats so that I can see, "I have two in the basement right now and there's supposed to be only two. Good. I have three on the second floor, and there's supposed to be five. Where are your other two people? Hey, there's a mayday in the basement." And, "Okay. It looks like I have this engine in the basement, and they must be calling the mayday." It'd be great to have a-- and again, that's that screen. It'd be good to have just a regular house layout. (FF-S-041) (Suburban Battalion Chief)

So I think that my number one thing would be that, either through the use of our radios or some device, that we can get accurate physical accountability on the fire ground. So it's not just the X, Y coordinate. I want the X, Y, Z coordinate. (FF-U-014) (Urban Assistant Fire Chief)

You can actually pull up locations, you can pull up overheads of locations, you can touch screen. So like if I respond and someone's barricaded inside their house, I can pull up the location on [service name redacted]. I can touch screen and go, "Officer Jones is there, Officer Smith is over there." You can actually 
map out your tactical situation so you can have awareness.... Everybody on the call, you can track people by their GPS locator on the radio so you know where officers are at, at these critical incidents. If you have, whether it's a barricade or a bad car accident or something, it gives the commander the ability to know what's going on at the entire thing. Right now we actually end up using paper and pencil to do that. (LE-U-029) (Urban Assistant Patrol Chief)

I can tell you that for large-scale events, from the command side of things, I would like to see or have some type of a booklet saying, "Okay, you know what? These ambulances are coming from this direction and these ambulances are coming from this direction. Where can I place them so that they don't running[sic] into each other or direct them in a way...?" (EMS-U-010) (Urban District EMS Chief)

Communication needs vary dramatically according to the chain of command, the type and size of the incident, and responsibility for accountability and location tracking.

\section{Generation Gap}

Another difference that emerged from participant responses was with respect to age and the perception of a "generation gap" similar to what is seen in the culture at large [23] Many participants with extended years of service spoke of how younger folks were "better" with technology, and how older members were often resistant to working with technology and adapting to new tools. While many saw the younger generation as more technologically "savvy," they also saw this savviness creating other communication issues, like the expectation of instant communication, and the loss of important skills, for example map reading skills and interpersonal skills.

I think we're starting to see the trend for immediate gratification, or immediate need of information to make decisions. And having that immediate access to that information is a good thing, but as soon as we don't have access to that information instantly, there's that "Oh no" type feeling in these people that haven't grown up with maps and need to relearn how to look at a map and read a map to get them to a location. Just pre-plans. And understanding that it can't always be instantaneous on a device, you need to have a back-up plan. (FF-S015)

I mean there's a lot of folks that just don't use it [the new system for car to car communications]. A lot of the old-timers, so to speak, that are not technologically savvy, they are not interested in even attempting to figure it out. (LE-S-033)

These new guys coming on now, they can run circles. The two generations would be perfect together. You can have the younger generation show the older generation how to work the system, the computer and everything else, if you can have the older generation come in and actually lend them some of their social skills. It would be a perfect mix. (EMS-U-009) 
In addition to hierarchical communication needs, communication is also impacted by age as illustrated in the above quotes. First responders with many years of service have skills sets that include more social and interpersonal communication skills. They tend to rely less on technology using stronger experiential skills. In contrast the younger generation tends to be more technology savvy and embraces new technology more quickly.

\section{Perceived Value of the Profession}

Differences also emerged with respect to the perceived value of the three disciplines. Everybody loves firefighters: "So when they see us, from childhood, they have a positive idea of what firefighters are."(FF-U-012) In contrast, several LE and EMS participants spoke about how they felt that they were not always valued and respected as first responders, and the lack of support they felt.

I think law enforcement, because of the lack of community support, because of the lack of political-- because of the lack of support as it relates to our administrators and our politicians and elected officials because they are more consumed with the pressure from the public, it is making our job very difficult because the average patrol officer does not feel like the administration has their back. (LE-S-033)

We have the same courage. We have the same that a firefighter has, that a police officer has. And sometimes, like I said, we're not recognized at that level, and it's difficult to accept...Sometimes we don't get the credit that we deserve. (EMS-U-010)

Some of the LE participants noted how this lack of respect translated into fewer young people wanting to go into the profession. As a consequence, several departments felt the need to lower hiring standards to attempt to maintain adequate staffing levels.

I know that we have definitely lowered our standards for hiring in the last few years. I've seen it, it's pathetic, to me personally, to see that we lower our standards. We should never lower our standards. If anything, as we become more of a professional society in our group, we should have higher standards in my opinion. We've lowered our standards just because we can't make the quota to get bodies in to actually do the job. (LE-U-005)

I don't think people are quite as keen about being police officers as they were....We're losing as many people as we hire. And I think it's — talking to other agencies, they're saying the same thing. It's just not as many people want to be a police officer as they used to. (LE-U-029)

Given there is direct correlation with advanced education to solving complex tasks and problems, lowering hiring standards suggests different user interaction paradigms and training approaches. As described in Sec. 5.1, cognitive load is a definite factor in user interaction and dissatisfaction with technology. 
There were also differences in the relationships that first responders developed with their colleagues. For example, FF often described the relationship with their colleagues as a "family," not surprising since they always work in a team and they cook, eat, train, exercise, and live together in a firehouse. In contrast, it is more difficult to develop those relationships in LE, where police officers spend little time at the station, and are generally patrolling alone (whether in a car, on a bike, or on foot). The work, according to one participant, is: "Lonely, it's a lonely job” (LE-U-013).

\subsection{User Characteristic: Trust}

This project is about communication, and ultimately, communication is a human endeavor, it is about human connection, even when that connection is made through technology. Although technology can enable and enhance communication, it can never replace the power of the human relationship. As organizational consultant, Simon Sinek notes: "A team is not a group of people who work together, a team is a group of people that trust each other." [24] Effective communication requires trust, which is built when positive connections are made repeatedly over time. It is the build-up of positive human interactions over time that leads to trust, cooperation, understanding, and acceptance.

In general, trust has three components:

- Honesty - you do what you promise to do,

- Competence - you do what you promise effectively and efficiently,

- Benevolence - you do the right thing.

Honesty, competence, and benevolence are the foundations of trust, and when someone has reliably demonstrated them, a trust relationship is built. This trust relationship is developed over time when we continue to experience these three components, and through repeated exposure to positive experiences and outcomes. Reinforcement of the positive experiences over time continues to build the trust relationship.

It is important to note the fragility of trust. While trust is not built in a day, a single event can erode or even destroy trust. When first responders do trust (in each other and in the technology), they are able to focus on their primary task with minimal communication. Firefighters remarked on how trust and human connection influence communication.

The best fire grounds are run when you hardly hear anything. There's a lot of implicit communication on the fire ground, and the good crews have it and the bad crews don't. So in my crew, we have implicit communication. We've worked together for a long time. We have a game plan for every event we're going to come to. (FF-U-003)

I know that the people I'm riding with tomorrow, if we have to cut a car, we might not have to say a word to each other. I can look at my technician or my officer right in the eyes, and I know what I need to do. (FF-S-039)

As the quotes elucidate, when there is trust, you know that everyone is where they are supposed to be and doing what they are supposed to be doing. Thus, there is often no need for communication. 
During the data analysis, the relationship of trust to many of the problems identified by the first responder participants emerged. The relationship of trust to three highly salient factors emerged: technology, people, and budgets \& organizational polices. The three factors do not exist in a vacuum, but are interconnected. Trust is implicated in each of these-first responders do not always trust the technology, they do not always trust people outside of their work community, and they do not always trust the contexts that govern their work.

What first responders do trust is each other. Repeatedly, we heard how they have established deep bonds with their colleagues, that facilitates communication and simplifies their work and the execution of their primary task. First responders are members of a team who trust each other.

The experiences of the participants related to technology, people, and their environment lead to an overarching lack of trust that often results in frustration for first responders. The development of this trust takes time and relies on first responders knowing that their input and experiences matter. Fundamentally, this trust has an impact on the acceptance and adoption of new technology and the ability of first responders to do their work. The following sections identify these trust relationships from the data and the ways in which trust does or does not facilitate communication and the adoption of new technology.

\subsection{Technological Barriers to Effective Communication}

Many participants spoke about the importance of technology that was "tried and true", that they "trusted," rather than new technology that they did not know. Often, participants did not see the need for the new technology. They did not trust it yet, “... the unfortunate thing is that even as things become easier or become stronger or better for us, that first impression of technology as a whole is challenging and complicated and unreliable." (FF-S-032) Trust is built over time and requires good experiences. Unfortunately, many participants' experiences with new technology have predisposed them not to trust technology. For many first responders, new technology is not predictable, a key component of trust.

In my opinion, technology should make life easier, not harder. Right? And if the radio doesn't do anything other than just add more weight to your beltwith these new radios, I'm not accessing any new channels that I didn't have privilege for. (LE-U-003)

So there's technology that isn't good, or that we don't understand the use for it. It doesn't make our job easier. The goal is safety, but it doesn't really seem to make it safer. (EMS-S-014)

I mean, the big thing is everything we use, I mean, we don't have time to mess with it, or tweak it, or play with it. It has to work the first time, every time, or people will just to stop using it. They will just refuse to use it and go back to the old way of talking on the radio. (EMS-U-003)

User's first impressions of a new technology heavily influences trust of that technology, adoption, and continued use. 


\subsubsection{The Paradox of New Technology}

Reliability is recognized as a primary concern of first responders. While all users of technology have at some point experienced glitches and problems, the concern of technology reliability is exacerbated in emergency situations. Participants consistently emphasized wanting their current technology to work. New technology is not always perceived as the right answer to the problems they face. Instead, they overwhelmingly spoke about how the improvement of current technology is what they want and what they believe will be most helpful. When answering the interview question "if technology could do whatever you wanted it to, what would you want?" - first responders' answers reflected the most pressing problems on their mind - most of the time the pressing need was to make the current technology work rather than desiring new technology. Many participants described this tension.

Instead of introducing all this extra new stuff let's, one, make sure what we have actually works better. And then, two, let's not rely on it so much. (FF-U-042)

And I don't know what the answer is, but I mean, there's hundreds of millions of dollars of grants that have been thrown towards it and we get better but I don't know if-- I don't know what the answer is to that streamless[sic] communication. Practice. But I mean, there's always technology that's going to give you problems. (FF-U-021)

Give us good, basic technology. (LE-U-013)

I'd like to see great cell phones and great MDTs but really this [the radio] is it. (LE-U-031)

Participants' concerns with new technology were observed throughout the data. The idea of technology being "a theory and a concept" that was developed outside of the intended context of use is one that resonates throughout participant responses.

The idea of emergency alerting on radios is absolute crap. It's a theory and a concept that was created in an air-conditioned room on a whiteboard, but when you're scared to death, you're going to do what you do $99.9 \%$ of the time, and that is you're going to hit the side button. (FF-R-008)

But all in all, the adoption of technology and the level of technology that we have is pretty outdated, it seems. Yeah. And I think that that-- as prevalent as the kind of hesitation to change is throughout the department, I would say it's also, maybe ironically, there's also a very common feeling that our technology is old and outdated and doesn't work. So it's kind of an-- it's kind of a catch 22, right? We don't want to use new technology, it's not reliable, but at the same time, our technology is horrible and it's outdated and we want something better. (FF-S-032)

Several firefighters in a major urban area spoke about biophysical sensors and how $<<$ everybody's on that bandwagon>>, but they were greatly concerned also about all the issues that could arise, the unintended consequences, and possible litigation.

$<<$ What happens if a firefighter blood pressure gets high, you do pull him off? Then you need an ambulance. Do you leave him on and if there's a mistake or 
something happens to him are you responsible? Really it goes on and on. All this stuff sounds good until you think about the consequences. >> (FF10-4FF/EMS-U)

These examples underscore the point that even if "better" technology exists, it is not necessarily useful for first responders and their work. First responders want their input and experiences fully understood and considered in the development of new technology. As one police officer stated:

That's the biggest thing with a lot of the stuff is you make it, but you never test it out on the real person who's going to use it. And then will it get lost in translation, and then it becomes useless. You may have thought it was a great idea. And it might be a great idea, but there's a few tweaks that don't make it useful at all. (LE-U-036)

Just because technology exists, does not mean it makes sense considering first responder work and responsibilities - in other words, just because we can does not mean we should. While many first responders do not want "technology for technology's sake," they do want new technology when it makes sense for their work. Participants want their current technology to work as well as the technology that is available today to the public. In an EMS interview, a Paramedic noted how the global positioning system (GPS) in their vehicles was not nearly as good at the Waze $^{\odot}$ app. First responders expressed tremendous frustration when they knew there was better technology, for example, one battalion fire chief described a tablet they currently use:

So the tablet is the biggest complaint. It's clunky. It's slow. I mean, if I can pull up my iPhone and get a map of the scene quicker than I can on there, then what's the point? I don't know why it's so slow. It doesn't do things that you just think it would do. (FF-U-044)

Cell phones and their applications were certainly the clearest and most mentioned example of generally available technology. Some departments provided cell phones for all first responders. Often first responders (across all three disciplines) were using their personal cell phones for communication and for access to data and information. Participants also noted many problems associated with the use of their personal cell phones, specifically the legal implications and the fact that phones could be subpoenaed due to information on them. In spite of this, most first responders felt that the benefits outweighed the potential problems and chose to use their personal cell phones for work, although they said they would much prefer to have an up-todate department cell phone.

While first responders questioned the appropriateness of new technology for their work, many also questioned why departments were slow to implement current technology that could improve their work environment — especially related to cell phone technology. In some ways, they were asking: If we can get all this stuff in our personal lives why can't we get it professionally? The following quotes are indicative of a sentiment heard across participant responses.

She [my daughter] goes to a computer and she types in Find My Phone and it pings the GPS signal off of her phone, and she goes, and she finds it underneath 
the couch or it's on the bus at school or what have you...if everybody in the globe has the technology to find their phone, why can't they find me based on my radio? (FF-U-002)

Our current system is, like I said, it's kind of a very like slimmed down version of Google Maps. More like MapQuest, like 1990 style where it doesn’t give you a whole lot of info other than the streets. When I was on patrol, I usuallyif I was going somewhere new or if I was having to go across town, I would just pull up Google Maps. I wouldn’t really look at the work computer because Google Maps knows traffic. (LE-U-003)

I mean, if the regular person running an errand, and then an Uber has to find an address quickly and can do it accurately, then you'd think that it'd be quite important for the ambulances to be able to do that. You can be detailed to an area you're not familiar with...So if the average person would do it, it seems crazy that the ambulances don't have it yet, but they don't. (EMS-U-011)

It's hard to explain to folks why I can get this cellphone that does all this stuff for a few hundred dollars, but it costs thousands of dollars for a radio that does not near as much as the cellphone does with current technology. (FF-S-040)

Participants opined that affordability of new technology for public safety and budgets are the main reasons for a lack of access to the technology, for example, department cell phones and the applications. In addition to the upfront cost of the phone, ongoing costs include data plans, IT support, maintenance, and replacement.

Many participants feel overwhelmed by evolving technology. They see changes with technology as happening too quickly and find it difficult to keep up financially or technologically. This may be due to a first responder culture that is, as one participant put it, "hesitant to change” (LE-U-013), something echoed in most of the interviews.

It seems like everyday something new is rolling out, and then the next day it's old news. (FF-U-006)

I think some technology can cause some problems. Technology advances can be an issue, maybe as not catching as fast as we want. Or maybe we're using a system that's one down from what's already happening because I'm sure you know as well as I do, technology is always moving, and a jurisdiction has to operate under here because they've already spent a lot of money on particular ends, and it may not communicate with that technology because it's outdated. (EMS-S-014)

Those things are out there but they're not really utilized very well by us currently. And some of that has to do with the fact that it's change and it's different. And the speed at which technology changes is a lot faster than the speed at which the personnel on the fire department change, is maybe the most politically correct way to say that. (FF-S-032) 
For a profession that I got into that I thought was supposed to be the most adapting profession of the world, we're the least adapting profession of the world. We hate change. We absolutely hate change. (PS-S-002)

First responders' resistance to change combined with the rapid pace of technological advances and limited budgets contributes to first responders believing that they are always "behind." There is an aspect of stability in being behind the curve or being late adopters of technology. As with all information technology (IT) shops, it is a balancing act. While first responders want new and effective features, they require stability and reliability.

\subsubsection{Interoperability}

Since interoperability is recognized as a current problem in the public safety communication community, it was not surprising that it emerged as a problem in participant responses. However, the pervasiveness of interoperability in participant responses was surprising -it was mentioned by all participants, in one way or another. For example, systems (e.g., radios) that do not talk to each other; forms that do not auto-fill even though information was entered on one platform; devices that cannot communicate with each other; or organizations that cannot connect with each other even though they use similar devices. These are just some of the interoperability issues first responders mentioned.

It's very easy to have 12 different devices that all do one thing. For the most part, if we can get three devices that are somewhat compatible with it or there's a lot of ability to sort of do multiple things, then we're always going to try to do that. But there's still a lot of diversity out there in terms of technological platforms.... I think that I would like to see a-- well, in time interoperability.... For example, we have Apple phones, we have the Microsoft tablets, we have whatever it may be. And some of those don't mesh well, as far as trying to transfer information, or whatever. That's one of the technology things that we are continually struggling with, is compatibility. I personally try not to get unitaskers. (FF-S-035)

We've got one design for body cams, we've got one design for in-car cams, we've got one design for CAD, and then we've got all these other small things. And they're all from different vendors, because of whatever reason. The city was trying to beg, borrow, steal these things from different vendors and they didn't want to pay full price, so none of them integrate well together, which is a huge issue for us. (LE-U-005)

[speaking about how forms do not auto-fill]...it's frustrating and especially when they're trying to get us to finish our reports and get back to the service from the hospital as quickly as possible. It's like they want us to get all this done real quick, but they don't want to provide us the tools or can have them configured so that we can do it quickly. (EMS-U-017)

The lack of interoperability forces first responders to spend more time on secondary tasks such as paperwork than on "helping people" which they see as their primary task. The lack of interoperability also complicates the communication process resulting in longer response times. 
Is this compatible with that so we're not wasting hundreds of millions of dollars on all of that sort of stuff?" And for me, personally, that's really the name of the game and how are we most efficient with what we have now and will it integrate with some of the stuff in the future, and how do we go from there, so? (LE-S033)

First responders use many different tools and technologies to accomplish their tasks, and they do not trust that affordable options that will work with the current tools and technology they have will be available.

\subsubsection{Unintended Consequences}

While researchers, developers, and vendors often focus only on the functionality of new technology, first responders are concerned about the unintended consequences. Technology today can provide first responders with information at their fingertips and new ways of seeing and dealing with emergencies, however there are often unintended consequences of technology including distraction, loss of situational awareness, and cognitive overload. First responders' work environments can change quickly: from the fire station to the truck to a fire scene, from a patrol car to a street corner for example. When speaking about the fast-paced and changing nature of their work, many first responders discussed the need to perceive and interpret the environment around them (situational awareness) as critical to decision making. Many first responders, especially police officers, expressed concern that technology may interfere with the use of innate human senses to interpret their environment. When you pay attention to the technology, you are not always paying attention to what is going on around you, which could potentially cause safety issues for the first responders.

It's a huge officer-safety issue having an officer doing a report, or whatever, on the phone, looking down at the phone and stationary in one particular spot for too long. That's a concern. (LE-U-014)

You're distracted no matter what. You're not paying attention to your surroundings. ... With all the different functions, it makes actually seeing what's going on in the neighborhood harder. And somebody's looking at this box to tell them what's going on as opposed to actually looking at the surroundings and figuring out what's going on. (LE-U-024)

On bikes, to be honest with you, kind of a downside of technology in iPads and stuff, and I think it's the same in a car, is now my eyes are here and I'm not paying attention to what's going around me. So I know that if we had those devices what I would tell my officers is, "We need one person just watching while somebody else is doing something." So that's why I would go back to my desk to pull that information. I wouldn't want to do that out in the field. (LE-U031)

I think the technology is good when you've got the time to use it. Meaning it's safe to do it. As far as, well I got eight people in the corner, but I'm on my [app redacted] looking. I mean, first and foremost, your safety first and using your head. If you got time, and I don't want to say distance, but a safe area where 
you could access this computer and not worry about somebody taking a shot at you. I think that's my biggest fear. That's me personally is. I know what areas are bad in town. I know where those hotspots are. (LE-U-025)

Sometimes we put too much emphasis on what the technology says versus we know what's going on and human intelligence. Human intelligence is probably a little bit more than the computer. (LE-U-026)

For LE personnel, use of technology can be a major source of distraction pulling focus from their primary task of awareness. Similarly, for EMS participants, the required use of technology for record keeping results in less of a focus on their primary task - taking care of the patient.

$<<$ Operation command wants this information in real time, but our responsibility is on people... There is an expectation of technology versus the reality of the field. It can only do so much and really more focus needs to be on patient and not on technology. >> (FF10-4-FF/EMS-U)

In a mobile recording unit back way back when we started documenting patient care, people thought that, there were certain individuals at a higher level who thought that, "Hey, if we give them a drop-down list of things that they can select, all they have to do is select, select, select, select, and that'll tell us-- it will be easier for us to grab data so that we can do some Q on it." So they don't have to write a report anymore, and I didn't agree with that. I think that we always have to paint the picture is what we call it. What you saw. What you found. Give me some facts. What you did. What you didn't see. And so I think technology may get in the way of-- that we take that human aspect out of it and you're just tapping drop-down lists or typing yes or no... (EMS-U-010)

Distraction is only one of the unintended consequences about which participants expressed concern. Many spoke about information overload and the tension between the deployment of technology and new sources of information and safety concerns.

It's hard to manipulate a phone in stressful situations, and you don't want to be looking at your cell phone when there's a guy with a gun. (LE-U-013)

I think there's a lot of pros but my standpoint, I just don't want people to get overloaded with information. Sometimes you can. So I would love to come up with a way for communications to be able to prioritize on safety issues first. Because now they've got computers, they've got cell phones, they've got so much technology stuffed into the cars. And so I don't want that important officer safety to get lost in the snowstorm of information coming towards them. (LE-U-029)

But so they keep trying to do these things, and I think they're trying to do it with safety in mind, but they're not really keeping what really your day-to-day job is in mind. So the safety hinders you from doing your job. (EMS-R-007)

Another unintended consequence of technology is the disruption of relationships. Most first responders see the development of relationships as imperative to their work. They see 
technology as often interfering with relationship building. There is a preference for face-toface communication, among each other as well as with the public. Technology needs to be able to facilitate this communication, not hamper it.

But the newer, they live on their phones. And I get mad at the newer officers because they do that. They're on their phone. And I'm like, "You know we're on a traffic stop. We don't know who that guy is. We don't know," and they're on their phone. And I tell them, "Please get off your phone until we finish this traffic stop." But it's the younger generation. They live on their phones. (LE-U013)

They don't go into the fire house and socialize like kids from years ago. You know why? Because they don't have to. They go in, they check out their rig, and then they stare at their phone for 24 hours. They don't interact, they don't do anything, yeah. So our last class, there's a no-phone rule in this building. They don't bring their cell phones in. We had forced communications, we had forced where they had to learn about each other, and do this and do that. And I tell you what, I get compliments on this class that just graduated....And when I told the-- like I told this class, I said, "You're very independent of each other. You are all head-down all the time. You're not engaging. You're not interacting." And I said, "What concerns me about that is that you are rendering patient care to people soon. You're going to be out in the field. How are you supposed to figure what's going on with them if you can't communicate with them? You must communicate with them. (EMS-U-009)

Given first responders' concerns about unintended consequences, their views of the overall value/benefit of technology may clash with those of researchers, developers, and vendors.

\subsubsection{Over-reliance on Technology}

Another view expressed by participants in the data is the belief that there was a growing reliance on technology. Many participants expressed concerns that this reliance might interfere with their core mission. First responders believe that they should be able to perform their primary tasks independent of whether technology is working and available.

Many were hesitant to depend on technology that they viewed as not always trustworthy: signals can be dropped, cell towers can go down, equipment can break. Many continued to carry pagers, or “cockroaches” (EMS-U-001) because they were always there and never diedthey could rely on them. The concern of reliance on technology triggers contingency planning - first responders wanted to ensure there would always be a back-up for what they needed to accomplish.

The participants stressed the importance of always having contingency plans in place. More seasoned first responders recognized the importance of not relying too heavily on technology.

I think if you-- if you start doing too much with technology and relying on it too much when it goes down, you won't know how to-- or a person wouldn't know how to respond if you relied too heavily on technology. I think it's good 
for us to move forward with it, but I don't think we should put too much weight into it because then, like I said, if it goes down-- like when a computer goes down at work, and you're scrambling to find a notepad so you can write down addresses and things of that nature. (LE-S-038)

Contingency. And that's why I have T-Cards to not only do radio communication stuff, but resources, engines when they move around, and we lose our card system, or we lose connectivity to the mother ship. How do we track our resources, and how do we maintain that situational awareness? So it's things like that that-- I think technology is good, but you can't drop what we've learned over the years that have worked. ... I'm not sure that they [young people] understand when we have an event and what happens to those cell phones. So again, this is that learning curve and, "Oh, that's old technology." Pagers. I still carry a pager because it's not attached to any cellular network, and it's not impacted by civilians. So having that mode to be able to communicate or at least get information out that's not impacted by the event is huge. All of my engines, all of my command staff and leadership all still have pagers just for that reason. And then I get the newer kids saying, "Oh, that's old technology. That's ancient. Why do we still carry a pager?" Well, they haven't experienced an earthquake or a big event where everything comes down. (FF-S-015)

First responders who participated are constantly concerned with what if technology fails, what do you fall back on? Having a contingency plan in place with other methods of communication or ways to do their job was important. For example, if the mapping software goes down, first responders need a backup-perhaps a paper map, "going old school” as many of them put it.

So, at that point, it's sometimes best-instead of holding on to technology like you do, it's just better just to go back to the old school, and say, "Okay, what do I have?” And just start writing it down... (FF-R-008)

Before you used to have a wooden board with a piece of paper on it and you could quickly jot down notes...You don't want to limit your patient care by doing this [entering information on a tablet] so much that they [patients] just sit there. This [a paper notepad] requires no password and it will always boot up... That thing [a paper notepad] requires nothing more than the ink that comes out of your pen. This thing [the tablet] doesn't always work, right? (FF-S-035)

... So I think it's good to have. I think it's a great tool. I think it's a tool we all should use. But I don't think it's something we should all rely heavily on in case it does go down, which has happened before, so. (LE-S-038)

We do have cell phones on the ambulances. They don't have data. They're just flip phones. So we can do phone calls. That's another backup and a way for us to communicate with them if the radio system is down or we're having problems. (EMS-U-001)

Participants feel it is imperative that all first responders, including those who are younger and technologically savvy, know how to use the "old school" tools. Technology should augment, not replace, user skills such as using the "old school" tools. 
Those respondents with significant experience were concerned that the younger generation may not know how to approach a situation when technology is not available. They also expressed concerns about the younger generation not knowing how to interact face-to-face with someone because they are so used to interacting with technology and not with people.

And especially as our department-- some of the older generations, a lot of them are retiring and we're becoming a younger department again. So a lot of these guys, they're good with computers. The old guys, I've heard them complain about computers and stuff. The young guys are obviously much more comfortable but on top of that, they haven't ever had to learn how to do it without it, so now that even makes it worse because now they're really dependent on that technology. (FF-U-004)

People just getting new on the job don't have that ability to talk to people... they think there's going to be an app that's going to save their life, where they can send an emoji or a meme that's going to get them through a situation. There's not. Sometimes you just got to figure out how to talk to people... they'll bring me something, 'Hey, what about this one?' 'Did you ask them that?' 'Well, no.' 'Go ask them.' 'I don't know how.' ...people hide behind technology. (LE-R017)

Many participants saw a "generation gap" related to technology, with negatives related to both older and younger first responders. "Older generations" were resistant to change, and younger generation were too dependent on the technology. Many saw the dependence as especially problematic since technology was often unreliable.

\subsubsection{The Importance of Radios}

Almost all participants, irrespective of discipline, emphasized how they trust their radio and noted how it was their 'lifeline' and the 'most important piece of equipment.' As one urban police officer noted: "I'd say the most important tool that we have is the radio" (LE-U-004). While first responders recognize the importance of the radio, they are often frustrated by the problems they continue to experience. Many of these problems are known:

- Coverage problems due to urban canyons, subways or basements, or dead zones in rural and other areas,

- Cord problems,

- Channel problems.

First responders have developed workarounds for many of these known problems. However, many still expressed frustration, as described below by a suburban firefighter:

And then if you're in that high rise or wherever you are, and you find you don't have coverage, somebody basically has to walk back out to find coverage, use a cellphone, or pick up a landline phone to communicate what they need, if they need help or whatever. So that's the most challenging circumstance, is when you got those two-person crews, everybody goes into the incident, and then they find themselves out of coverage. So that's, from a fire rescue perspective, the trouble scenario. Law enforcement deals with that on almost every call, essentially. Law enforcement doesn't have the luxury of traveling in multi- 
person units... So that's where the coverage is really important. To have robust coverage available, to try to minimize the number of times that those single resources find themselves out of communications. (FF-S-040)

We heard repeatedly that the cord that connects the radio to the remote speaker microphone melts, rendering the radio useless and jeopardizing firefighters' safety. According to one incident commander two of his firefighters were killed in the line of duty because they could not communicate with him due to the microphone cords melting.

Numerous attempts to contact them. We never heard back from him, and I believe it was because of his microphone cord failing.... And I think it's almost criminal that they are giving any firefighter in this country a microphone cord that, at 160 degrees, begins to degrade. (FF-U-014)

National Fire Protection Association (NFPA) has established a committee to develop a new standard for hand-held radios, remote speaker mics and future voice communication devices expected to operate on the public-safety broadband network to address failures of such devices in high-heat, fireground environments. According to Bob Athanas, chair of the NFPA 1802 committee and a Fire Department New York (FDNY) firefighter, "the committee is reviewing portable radios reliability after recent structural firefighter fatalities were blamed partly on failings of radios and accessories. ... The standard is focused on the interior, structural firefighter facing hazardous environments." [25]

The number of channels can be another problem with radios. Depending on their roles and responsibilities, most first responders noted that they only use one or two channels on their radios - and that they almost never had the need to use the others. In fact, they often reflected on how most people did not even know how to access the other channels.

We buy a system, and we buy a radio that's going to hold a million channels in it. When am I going to use a million channels? And so I'm paying for capacity that I'm not probably going to use in a life of that piece of equipment. (FF-R008)

... with these new radios, I'm not accessing any new channels that I didn't have privilege for. They're mainly for if for whatever reason you're doing law enforcement stuff out of state or whatever, then I guess you can add some new channels with that. But majority of the officers are never going to do that. So it's like a newer radio with some new technology that, as far as I know of yet, the city has yet to-- they have GPS and then [this and that?], but the city's not paying for it, so we're not using it. So it's like bigger, badder[sic] new radios that we're not really using to the full capacity. (LE-U-003)

So we have radios that you're able to scroll to and get to those places, but because we don't do it very often, it's not real easy. It's kind of clunky. (FF-U014)

A distinction must be made between the number of channels used by most first responders on an everyday basis and the number of channels used in multi-jurisdictional or multi-disciplinary incidents and events. In these cases, having access to multiple channels is beneficial and 
necessary. Many Incident Commanders remarked that they do indeed use a wide range of radio channels for complex incidents or large-scale events (e.g., parades, festivals, sporting events). Some first responders need the full range of channels and access that radio technology has to offer, while others do not perceive that they will have a use for the larger range. This highlights that "one size doesn't fit all” and perhaps vendors and developers need to recognize that a single department might need access to different levels of communication technology at different price points.

First responders often feel that their departments are 'held hostage' to radio technology in some ways by vendors who make technology beyond what most of them need and can afford. As a result, there is a lack of trust and a fair amount of frustration-with the technology and the companies who provide it. While participants know that the radio is their lifeline, what they would like is affordable technology they can trust at all times, no matter where they are.

\subsubsection{Usability}

Many first responders stressed the need for usable technology. First responders expressed usability needs in terms of easy to learn, easy to use, and saving time. Several participants referred to usability as the 'Fisher-Price model.'

But for firemen, it needs to be built by Fisher-Price. It's got to be bacteria resistant. It's got to be waterproof. You've got to be able to throw it in the dishwasher. It's got to go through high temps, got to go through low temp. It can't have thin wires. It's got to have big buttons because I'm wearing gloves. It's got to be built for a three-year old. Because this is how we use it. We use it in the water. We use it in the cold. We use it in the heat. We use it with calls.... (FF-R-019)

But when you're in a dynamic environment, you need relatively simple what I call "Fisher-Price technology." Big shapes, big buttons, colors, things like that so that I don't have to scroll down menus and things like that. I need it very simple because I don't have the time or the mental capability or the bandwidth to be looking at a lot of different things. When you're under stress, you want something that will do simple things quickly. (FF-S-035)

I think there's room for it as long as it's durable and it's user-friendly. That's huge. Because when we need the technology, we need it to be simple. We don't need it to be complex because we don't have the time to work through complexities in anything technology because our decisions are instant, and some things that we need to do need to be made. The decisions need to be made now and not in 10 minutes. We're not sitting in an office and trying to sort through different programs and analysis. We need to make a decision now. And so technology is great, but if it's complex, it kind of is counterproductive, so. (FF-U-025)

In the police world, if you want somebody to use something, it has to be simple. The more complicated it is, it's very seldom getting used. (LE-R-001) 
No. It's over-complicated. I call it "dumbifying." They should "dumbify" a lot of-- just make it simple. Cops are smart, but we're smart in a different way.... Simple, simple, simple. We want simple, easy to use, simple. (LE-U-013)

The pervasive term used by participants is simple. First responders require technology solutions that are simple to use, simple to learn, and simple to integrate into their environments.

\subsection{Social Aspects for Effective Communication}

Public safety is all about people. Participant responses show that first responders care deeply about people and work hard to build relationships with those around them. Participants realize that building relationships and establishing trust is critical to their work.

First and foremost, first responders trust their colleagues. One first responder articulated this trust relationship.

But for the most part, we are family. So not just because we're together 24 hours a day at a given time. But due to the job we have and the level of danger and risk associated with it, you kind of get to a point where there's a level of, "I've got to know you have my back," and vice versa. (FF-U-034)

The trust among colleagues is a requirement to perform their jobs effectively and efficiently. In addition, trust has an impact on communication. When the trust relationship is present, communication can often be implicit, but when that trust has not been established or has eroded, then more explicit communication is necessary, as evidenced in the quote below from a suburban fire fighter.

It definitely requires a mutual trust. And I think that a lot of times people do it [talk on the radio] because they've seen that they can't necessarily have that trust all the time. And a lot of times people would rather rely on the expectation that you can't trust the units because it's probably safer that way, right? So you can't blame them for that. For saying, "Hey, if I don't tell them to do this it might not get done." Versus, "If I tell them to do it there's a little more radio traffic but I know it's getting done." So they have to weigh that in their heads. And that's a benefit that we have here because right now if we were in a fire, our chief of this department can run that with us. And if he's command, he knows that he doesn't need to tell us what to do. But the ... County Battalion Chief might not know us and might not know that he can trust us. We've never proven otherwise but maybe if a different rescue squad has, or a different engine company has. And then because he might not-- he might have experienced that lack of trust, he might just rely on that. (FF-S-039)

Fire fighter (FF-S-039) recognizes that trust is sensitive to associations. A negative experience with a group or member not only disrupts that trust relationship but also tends to erode trust with other associated groups or members who are similar. Thus trust erodes when one of the components-honesty, competence, benevolence-is violated A final attribute of trust is the asymmetric relationship between building trust and destroying trust. A single event can erode or even destroy the trust relationship but building trust requires slow, steady, and consistent interaction, which requires time. 
First responders interact with many people during their duties in addition to their colleagues. Many of the problems first responders' experience in dealing with others results in a lack of trust. Participants often articulated their calculation of the trust they did or did not have in others, based on previous interactions. They also talked about the credibility they had in different groups of people based on what they saw as their motives. Sometimes they discussed the trust others, like the community, had in them and the ways in which they worked to develop this. The following sections explore the different groups that first responders in our sample interacted with and the levels of trust they did or did not have.

\subsubsection{The Context of Communication}

The development of interpersonal relationships relies on communication. In turn, communication helps build trust. First responders generally believe that one of their primary responsibilities is to build relationships with others (for example, with the community and with their colleagues). They recognize that opening lines of communication are crucial.

I mean, it's funny if you look at personality and look at how people behave, when you analyze people communicating or working together, they tend to work together if they can talk to them... But as soon as you make it so they can just casually talk to each other, then the relationships grow. And it's not even an intentional thing but it just-- because that foundation is there, they talk, and then they work together more. And I think that's important. That's a subconscious thing that actually happens when you look at interpersonal dynamics. (FF-R-019)

The power of communication with others is undeniable. Unfortunately, communication today has become more and more impersonal. The increased use of cell phones, texting, email, and social media are often seen as inhibiting the personal interactions between people that are the foundation of deep, meaningful relationships. Simon Sinek in his video on Millennials in the Workplace [26] describes the human need for social interactions and social skill sets necessary to create deep meaningful relationships. "Trust doesn't form at an event, in a day, even bad times don't form trust immediately. It's the slow steady consistency. We have to create mechanisms where we allow for those little innocuous interactions to happen.” To establish trust, there need to be opportunities for consistent interaction among people.

The participants recognize how technology can disrupt relationships among their colleagues and the communities they serve. In fact, many emphasize the value of face to face communication and interactions as the underpinnings of the foundations of trust.

Most communication, preferably, is done face-to-face. You have less chance for a misinterpretation of the message. You can maintain eye contact, interpret body language and posture, and things like that. So face-to-face is always the preferred means of communication, even on the fire drill ground. We try to do face-to-face communication as much as we can..... So first and foremost, faceto-face communication is priority. (FF-S-033) 
The value of talking directly with each other and with those they serve was a consistent message. However, most participants also noted how many recruits today no longer have the social skills necessary to engage in this way.

But you just look at kids today and society, and everybody's so wrapped up in their phone and their texting and the computer, that there's a lot less interpersonal communication that I don't think is a good thing. (FF-U-34)

I mean that's another issue is texting. You can't talk to anybody anymore. That's our biggest problem right now and that's why we're in the issue nationwide because nobody knows how to talk to anybody anymore. ... They don't know how to communicate. (LE-U-010)

One sergeant from an urban law enforcement department summed it up.

Talking to people is so powerful. That's the number one tool. We cannot forget that. That's kind of what the most difficult part about this whole thing is. We're all human beings. I'm a human being. My victim's a human being. The offender's a human being. We're all human beings. That kind of gets lost in the day-to-day grind. When you start just going by the numbers, and start looking at stats, and this and that, it gets lost. And my partner and I never lost that, and we were able to come up with phenomenal results based on building trust relationships within the community. ... The police can't be everywhere at all times, but the community is everywhere at all times. Can't forget that. And if they're willing participants, if they trust you-- and that comes with work. See, trust doesn't come from a community-police event. It's just an event. When the event's over, the trust is over or that engagement is over. It comes with building relationships over extended periods of time. (LE-U-023)

Ignoring the influences of technology on communication runs the risk of destroying long term first responder relationships, preventing the establishment of new relationships, and further eroding trust. Continuing to foster opportunities for face-to-face communications and personal interactions remains a need and priority for first responders, especially with the public.

\subsubsection{The Public Context}

First responders are easily identifiable by their uniforms, badges, apparatus, and vehicles to the general public. Also, activities and services performed by first responders are visible to the public. This constant visibility influences both the first responders' and the public's behaviors and perceptions. The public visibility often prompts rapid adoption of new technology by first responders.

The relationship between the community and first responders is changing in part due to technology as described in the previous sections, such as the impersonal nature of technology preventing strong connections with the community. Other changes are related to new policies and procedures impacting knowledge and understanding of the community they serve. For 
example, in most areas it is no longer a requirement for first responders to live in the community they serve.

I think our biggest thing is because we hire outside [city redacted], like, hypothetically, recruit from, I'll get that recruit from [location redacted]. Has never been to [city redacted], never been on the bus, never been on a [public transit redacted]... And all of a sudden now, he's a cop in [city redacted]. (LEU- 010)

Right now, a third of my staff lives out of the county because they can't afford to live here. They commute to work here. So I don't like that, but I don't have a lot of choice. My people live as far away as [city redacted]. That's 150 miles. (EMS-R-008)

The impact of hiring from the outside is about more than just the commute. Those from outside the community do not know the city in the same way as people who live there or who grew up there. Unfortunately, this alone will have an impact on their ability to build relationships and develop trust. When a first responder grows up in and/or lives in the area, he/she understands the population, the people and the place, that those from outside may not. Often, community bonds and relationships pre-exist, or at least they have a greater likelihood of being developed, in part because they have had hundreds if not thousands of "little innocuous interactions" [26] with members of the community which allow them to establish meaningful trust relationships.

\section{Building Public Trust through Interaction}

Most first responder organizations recognize the need and long-term benefit of community interaction and actively pursue opportunities to engage. As the participants relayed, first responders participate in many community activities from education programs, to installing smoke detectors, to "Coffee with a Cop." These activities take them out of the department setting and into the community, where they engage directly with community members and develop relationships with them.

I think it's our interaction with the community. Very rarely do we say no to a request that the community makes for some kind of public appearance. If they have an event at the school, we're going to be there. If there's an event at the park, they're going to call us and ask if we can attend, and we're always there. So we're very visible in the community. We're not just sitting, waiting for a call to happen. They do have a lot of calls too, but we're also very visible, which is, I think, one of the reasons why we have so much support. It's because they know that we're there for them even if it's not an emergency. (FF-S-037)

First responders across all domains sampled recognized the importance of visibility in their communities. This visibility resulted in community support for their work. Many first responders intentionally spend much of their day out in the community preferring this visibility to the department setting.

Yeah. We try to-you do the ownership. By having it [same patrol area] every day you know everybody on the street. "Oh that's [name redacted]. That's so- 
and-so." But the biggest thing is you get a hold of the business owners and you check in with the business owners. The foot beat officer, if he does it right, would know everybody on the street. (LE-U-010)

We would literally go to a coffee shop in the morning, get our coffee and review all case reports in the morning, decide .... The second thing was we always wanted to know the people, and it was an opportunity to meet people. It was an opportunity to meet the neighbor. Or while we're standing in the backyard looking at where the bike was taken from, the next-door neighbor decides to look over the fence and say, "Hey, I noticed that--" and that was so powerful, and you can't get that sitting in an office. (LE-U-023)

$<<$ we actively get out here every day, we want the community to see us, and know us, and like us, they're our biggest supporters.>> (FN6-4-FF-U)

The participants recognize that through direct engagement with the community they are able to build trust. The development of trust with the community is important for first responders whose work often depends upon knowing the people and places they interact with in their work.

\section{Public Misconceptions of First Responders}

Despite active attempts at community engagement, visibility and interaction are not always enough to combat the technology that also contributes to public perceptions about first responders and their work. As described by fire fighters in the interviews when they are out in the community, sometimes they are perceived by the public as "not working."

And that's-- everything we do is crew-based. So we get asked sometimes if we're shopping or something, why does it take four of you guys to shop? And it's not that it takes four of us to shop. It's that we all have to be together in case we get a call because we're not off-duty while we're doing that. (FF-U-010)

Many first responders reported they are sensitive to looking down at their tablets or cell phones while out in the community, for fear they will be accused of watching a video or "playing" instead of working. These misperceptions about first responder work often lead to a lack of trust on the part of community. The constant public visibility contributes to community's scrutiny of first responders' activities.

Technology today, including social media, allows for quick communication with a large number of people. This ability to communicate rapidly, often in real time, has tremendous implications for first responders and their work. As one participant put it: "there's goods and bads with everything" (EMS-U-001). A field note from one of the sites shows how the use of social media by the community can be a positive for first responders.

While we were talking, a woman came in with a little boy, about 5 or 6 years old. She asked if she could take a photo of him with the firefighters because that's what he wanted to be when he grew up. They willingly obliged and went outside to take photos. They let him come up in the cab of the truck, with his mom taking photos all along. She asked if she could post them and they said of 
course. He was so excited, smiling and laughing in the lap of the fire fighter, what great PR. One of the fire fighters told me $<<$ We love this, this is what we love about our job. Kids love us, and stuff like this shows us out in the community interacting in positive ways. >> (FN6-4-FF-U)

Social media today has the capability of reaching a wide audience very quickly. While the above example demonstrates how the public can use social media to promote the image of first responders in the community, it is often just the opposite according to many of our participants. From the same field note as above, one fire fighter noted how things are often very different for LE.

$<<$ Yeah, this is the difference between us and the cops, people love us and we get all this positive press. But when's the last time you saw something on FB about a cop like this? We're usually the heroes and they're, well they're just not. Social media for them is usually a nightmare.>> (FN6-4-FF-U)

Technology allows for easy audio and video recording that can be streamed live or posted directly after an interaction. Social media can be used by the public to promote a positive image of first responders, it can also be used to unfairly portray a negative image of first responders, particularly for LE. Social media has resulted in many first responders shifting how they perform their duties in negative ways. Having to consider what the public will post about them is an additional stressor for first responders today, causing many to change how they interact with people and accomplish their tasks.

But this is what deters a brand-new officer is when people start putting up phones and going well, "You're harassing me." "I'm not harassing you. I don't know who you are. And this is the area that I cover. It's the area that I patrol." But that normally doesn't make the news. What makes the news is that officer harassed this person of color and said-- and he's irate and it's all on film. So what happens, we get the tendency of officers go, "I'll just go wait for that person to call 911 and just go handle the call," right? "Because I can't get in trouble that way. But I can get in trouble, accused of racism or something like that, for just making contact with somebody." And they get afraid. (LE-U-010)

More and more today, there is often an assumption on the part of the public that they have a right to know everything in real time, and many first responders believe that technology is being used against them. There are positives and negatives to this easy, instant access to information and the ability to communicate.

And there's goods and bads with everything. It's just like this. I mean, everybody's a reporter now, right. Everybody has a video camera. Everybody has a camera. When it's going to go to instead of calling 911, everybody decides to start recording this guy getting beat here or something. Because you can go on a call downtown and they want their 15 minutes of fame, right. But, on the other hand, for PIO, I can Facebook live, I can do this, I can do everything, I can create a whole movie from this thing. So, it's great but it's dangerous. (EMS$\mathrm{U}-01)$ 
As illustrated in the quote, many first responders noted how this instant access complicates their work.

\subsection{Friction Between Technology and the Organization}

Many things have an impact on the adoption and use of technology in the first responder community. Adequate budgets are required to purchase, maintain, troubleshoot, upgrade, integrate, and replace technology. Policies must be written and reviewed regarding the appropriate use of technology. Mostly, it is administrators who set budgets and construct policies related to the purchase, implementation, and use of technology, often without input from those first responders who will be using the technology in the field. Although, the interview protocol did not contain any questions about policies, regulations, administration, or budgets, these topics emerged as significant issues in participant responses. It is extremely telling that these topics were clearly and frequently articulated by the participants. Consistent with findings of the previous sub-sections, conflicting priorities leads to a lack of trust. From the first responder's perspective saving lives and property should be the highest priority, which results in frustration on the part of first responders.

\subsubsection{Conflict Between Technology and Limited Budgets}

Participants often cited budget issues, including shrinking budgets, as the reason that they did not have adequate technology. For example, while it was common for those in higher positions of authority to have department-issued cell phones, most other first responders did not, and departmental budget limitations were given as the reason. As noted by an Assistant Chief of Patrol "At this point, I would love to buy officers smart phones, but I don't have the funding for it. So right now the only communication device that the department supplies is the radio." (LE-U-029) Although some departments may have been able to afford the initial investment to buy cell phones for their first responders, they could not afford the ongoing data plans and replacement costs associated with cell phones. Given the lack of budgets necessary to supply all first responders with department-issued phones, many first responders used their personal cell phones to supplement their work technology. Participant responses on this topic mirror what was noted in a recent Washington Post article [27], that "Many police officers, firefighters and paramedics carry their own cell phones to do the things their department-issued equipment can’t."

Most participants recognized the benefits of having access to a cell phone today, and as a result many were willing to use their own phones to accomplish work-based tasks when a department issued one was not provided or available.

I'd say that public safety is probably on the back end of technology, because we didn't have these-I had my personal cell phone way before the department gave me one, probably years. But in terms of being able to phone a friend when I run across something that's difficult, Google is my best friend when it comes to making emergency calls. "[name redacted], I don't remember hydrogen sulfide's chemical properties." And so I can just Google hydrogen sulfide, and it'll give me the SDS, which is the way that everybody has to-- any hazmat, any hazardous material, it's a government regulation that you have to have, basically, 
a sheet on it that tells about the chemical properties, how it's going to harm people. And so I can look it up now on my cell phone. (FF-U-001)

In this quote, the Battalion Chief used his personal cell phone for years prior to a department issued one, recognizing the advantages illustrated above. Later in the interview he also noted that today only "officers" received department cell phones in his jurisdiction-a concern that was expressed quite often in the interviews. Many first responders acknowledged the ways in which cell phones are one of the biggest and best changes in technology they have seen. Capabilities including maps and traffic programs, online access to forms and manuals, and email/texting were often cited as necessary tools for first responders today. While most participants believe the benefits outweighed the risks, they understand that the use of cell phones on the job can cause potential safety issues for first responders.

The use of personal cell phones for work purposes often posed concerns with issues of privacy and liability. One urban police officer articulated this idea.

If it's a personal device, I can see issues in basically just what the officer's outlook on it is. This is my device. I don't want to take a picture of a crime scene with my cell phone. I don't want that saved on my phone. If I'm now taking pictures of a crime scene, can my whole phone be subpoenaed? Are they going to see all of my text messages? This is none of their business. This is my personal cell phone. (LE-U-004)

First responders and their commanding officers worried about losing their personal cell phones to a subpoena - potentially opening their entire phone up for examination, including personal data on it. Given society's dependency on personal cell phones, the thought of surrendering a personal cell phone was disturbing - prompting questions like: would they need to purchase a new phone, would a department phone be provided to them in the interim, how would they access their contacts and other data? First responders did not trust that departments could protect them in these instances.

For many, it was also an issue of 'fairness' - they believed that if they were going to use personal devices, the department should pay toward their data plan. Using their personal cell phones aided them in their work, however many were frustrated that there was no departmental reimbursement. Most were concerned that departments would never reimburse them for the use of personal devices due to limited budgets.

Budgets and technology adoption and integration were tightly coupled issues. Because of government procurement policies, many first responders believed that access to new technology was limited.

They're trying to make it better. They keep improving, and that's fine. But we're also governed by lowest bidder and other restrictions that prevent you from just getting what you want. You may have to get-- well, this vendor has this, this and this. They're an approved vendor. And that's what you get. (FF-U-012)

Well, I think in general, law enforcement's always been way behind the curve in terms of technology because we're government. We're lowest-bidder type of 
government, so the stuff we have is the cheapest. It's usually decades old. (LEU-003)

\subsubsection{New Technology Requires New Organizational Policies}

Unfortunately, many reported that their departments are continually short-staffed. In addition, participants were regularly being asked to do more with less, including adhering to a host of rigorous policies and administrative requirements for reporting and documentation. New technology, such as body cameras, often places an additional burden on first responders, especially when it does not properly integrate or communicate with their existing devices. This LE quote illustrates both the staffing problem and the technological issue.

...one of the big issues that I brought up last week with these guys is, this is going to be compounded 5 to 10 fold once we go to body cams. The community hasn't quite realized that we're already short on bodies, and now you're throwing a piece of equipment that's not been field-tested and their city's not buying the appropriate equipment to allow that piece of technology to communicate effectively with our other toys. So we have to be the middleman as far as documentation and metadata as far as making sure case numbers are inside, auditing all that information that goes in. So that's going to be a tremendous amount of time for us not being on the street as well. (LE-U-005, emphasis added).

Time pressure is ever-present in public safety: emergencies are inherently time-sensitive. Another time-consuming task is incident reporting that may detract from time spent responding. An EMS quote clearly describes the pressure of quickly reporting and returning to service.

It's frustrating and especially when they're trying to get us to finish our reports and get back to the service from the hospital as quickly as possible. It's like they want us to get all this done real quick, but they don't want to provide us the tools or can have them configured so that we can do it quickly. (EMS-U-017)

Understaffing and incident reporting are intertwined: reduced staffing levels place pressure on first responders to finish their reporting quickly to return to a ready status. Technology cannot solve the understaffing problem, but it can help ease some of the burden of reporting for first responders through integration and interoperability of devices and data, and by eliminating the need to enter the same data multiple times in multiple systems.

As described in sections 5.3.1 and 5.5.1 first responders recognize that smartphone could address many of their current needs. Many described their current situation and the need to carry two cell phones.

If I'm with my family, I don't want to have to carry my pager and my phone. I want to have one device that can somehow split that. If I need to be able to do work on it, I can do work. If it's also my personal device, then it can do my personal stuff, keep those roles separate. But again, it's one piece that goes with me. (LE-U-006) 
This one is personal, this one's department. So I tend to forward my department to my personal. Probably not the smartest in the world, legally wise. But to me, it's just easier... I don't like carrying two phones. (FF-U-021)

Pie in the sky, I would like it to somehow work with my existing technology. I won't have to carry two phones. So if it can somehow handle that transition of, this is either my personal phone that does both or my city-issued phone that I can - whether it's a double SIM or something - I can still do-- because I mean, these phones are huge now, which is great. But I don't want two of them. So something like that would be-- it's the only thing that I just hope that we get there. I know we will someday. (LE-U-006)

Many organizations including Federal Agencies have adopted new policies that allow for bring your own device (BYOD). These policies include solutions for separating the data thus addressing the multiple phone dilemma of employees.

First responders were also concerned that budget and policy decisions do not always support their mission of caring for and protecting the public. In some cases, there was an apparent tension between first responders and administration.

I think law enforcement, because of the lack of community support, because of the lack of political-- because of the lack of support as it relates to our administrators and our politicians and elected officials because they are more consumed with the pressure from the public, it is making our job very difficult because the average patrol officer does not feel like the administration has their back, .... Officers are not patrolling the way that they used to patrol and as a result. (LE-S-033)

In other cases, participants referenced political decisions that had direct, and negative, impacts on their work. For instance, one firefighter described effects arising from the decision to unify communications centers.

It's a unit with all the SCBA bottles and a mobile cascade. He called that firehouse and asked, "Is [Unit X] available?" And said, "Yeah, [it's] in the firehouse." "Okay, we need them to respond on a water rescue at the river." And the guy who picked up was like, "You need the air unit on a water rescue?" "Yeah, we need the helicopter." They don't even know-a lot of dispatchers don't even know, truly know where the firehouses are, what apparatus. It's a huge training issue we have because it's an outside agency and that was the big political thing to do and a lot of places like to go to that and want their unified communication. But it's not good for these organizations because these people don't actually know what they're-- they don't actually know what these things are. (FF-U-042, emphasis added)

First responders often saw these decisions as hindering their work rather than supporting it. In the above quote, there was a disconnect between dispatch and those in the field. Since the decision had been made to go with an "outside agency," dispatchers were no longer required to know the district and often had no sense of who, what, and where they were dispatching. 
The idea that "appropriate policies" could play a role in helping strike a balance between the administration's needs and first responders' needs also came up in participant responses.

[referring to body cameras] You just have to make certain that at administration level, departments put in good policy so administrators can't go on a "fishing expedition" to try and find an officer saying something inappropriate or doing something inappropriate. So the officers see it as a big brother program and the admin sees it as a liability-clearing ordeal, when both of those can equally coexist if the appropriate policy is set in place, an adequate policy set in place protecting the officer himself. (LE-S-033)

Like the participant quoted above, many first responders said their reticence to adopt and use new technology was linked to their assumption that the department was 'watching them.' The idea of 'big brother' was often linked to GPS or location-based technology, and some first responders spoke about how they could even be tracked by their cell phone or other device.

\subsubsection{New Technology Includes New Responsibilities}

Many department level participants believed they could not keep up with new technology available for first responders. Even if a new technology works reliably and solves a pressing public safety need, departments may still be unable-or unwilling - to adopt new technology even if the budget for the technology is available. Participants reported a wide variety of issues beyond affordability that must also be addressed to meaningfully integrate new technology into public safety work contexts. Technology does not, and cannot, exist in a vacuum. New technology requires adequate consideration for the ripple effects. Examples of ripple effects reported include:

- Integration with current technology platforms,

- Deploying new technology,

- Sufficient training of staff on the new technology,

- Allocation of additional resources (funding and/or time) toward training,

- Updating and disseminating Standard Operating Procedures (SOPs),

- Availability of technical support,

- Securing servers for sensitive data storage and handling,

- Development of plans for repair and replacement costs.

Technology is being developed (and purchased) more quickly than the policies, laws, administrative procedures, and budgets required to fully support them, especially for the public safety community.

You learn how to use something, you get used to using it, that's obsolete, next generation, or that company just went out of business. I just got an email today saying that our scheduling program, which is very complex, and I schedule 65 employees, they're discontinuing it. (EMS-R-008)

Technology advances can be an issue, maybe as not catching as fast as we want. Or maybe we're using a system that's one down from what's already happening because I'm sure you know as well as I do, technology is always moving, and a 
jurisdiction has to operate under here because they've already spent a lot of money on a particular ends, and it may not communicate with that technology because it's outdated. (EMS-S-014)

The constantly evolving nature of current technology means that first responder population is always playing catch-up with the technology. The rapid pace of technological change impacts technology acquisitions for first responders. As one participant succinctly observed, "It's just time and money...” (LE-U-012).

\section{Summary of Results}

As evidenced in the results section, participants are excited about technology and see opportunities for technology advances in their work environments, but they want the technology to "solve the right problems" - those problems identified by first responders that directly impact their work. First responders' input should be at the forefront when considering design, development, and adoption. The participants in the study believe that new technology should directly benefit first responders with respect to their primary tasks while improving the user experience.

They won't do it. I mean, I can't make any of my employees do anything. Okay. They're here 24 hours a day. I've done their job. It's not easy. If you throw all kinds of harder stuff to make their job harder on top of it, it's not going to work. I mean, I can put all of the sanctions and rules and everything I want on it, but I have to motivate people to want to use this technology and show them the advantage of using it. We get paid faster. We can post statistics that show us what we're really doing, how it's useful. But if it's not to them, what's in it for them? (EMS-R-008)

The participant noted that EMS personnel are often "forced into using this technology" with the associated huge costs. He expressed concern that even if new technology is adopted at the administrative level, it is impossible to convince employees to use it. Successful technology deployment and adoption requires a focus on users, tasks and context of use and incorporate the usability goals of:

- Effectiveness - how the technology will be useful in first responders' primary task of protecting lives and property while preserving or enhancing situational awareness,

- Efficiency - how the technology will be easy to use and save time,

- Satisfaction - how the technology will promote the first responders' comfort and confidence in use.

- As in the other sections, the participant quotes are representative of the data set at large across domains.

\subsection{Technology Needs}

Most of the interview questions (Appendix A) focused on understanding first responders' characteristics, their tasks and contexts of use. As discussed in the Results section those questions also elicited a set of problems. However, one interview question asked first 
responders to think outside the box and describe their technology wish list: "pie in the sky here-if technology could do whatever you wanted it to, what would you want?”

Universally, participants want cheaper, faster, and better technology. Beyond those universal needs, first responders identified many items. Usability research has shown that users often express their needs in terms of specific technology and solutions familiar to them. In order to provide the best solutions to users' needs, usability research focuses on solving the underlying problems expressed in the specific technology and solutions mentioned by participants. First responders often identified pressing needs and requirements in response to the "wish list" question.

Table 7. User Identified Needs, Problems and Requirements

\begin{tabular}{|c|c|c|c|c|c|c|}
\hline CODE & & FF & EMS & LE & PS & Sub-total \\
\hline \multirow{4}{*}{ Problems } & Urban & 20 & 5 & 13 & 0 & \\
\hline & Suburban & 28 & 8 & 11 & 3 & \\
\hline & Rural & 15 & 23 & 8 & 0 & \\
\hline & Sub-total & 63 & 36 & 32 & 3 & 134 \\
\hline \multirow[t]{4}{*}{ Problems - Technology } & Urban & 285 & 101 & 372 & 0 & \\
\hline & Suburban & 271 & 56 & 162 & 33 & \\
\hline & Rural & 55 & 54 & 97 & 0 & \\
\hline & Sub-total & 611 & 211 & 631 & 33 & 1486 \\
\hline \multirow[t]{4}{*}{ Problems - People } & Urban & 81 & 15 & 48 & 0 & \\
\hline & Suburban & 51 & 12 & 23 & 2 & \\
\hline & Rural & 10 & 5 & 24 & 0 & \\
\hline & Sub-total & 142 & 32 & 95 & 2 & 271 \\
\hline \multirow[t]{4}{*}{ Problems - Information } & Urban & 75 & 20 & 62 & 0 & \\
\hline & Suburban & 40 & 23 & 24 & 2 & \\
\hline & Rural & 21 & 3 & 19 & 0 & \\
\hline & Sub-total & 136 & 46 & 105 & 2 & 289 \\
\hline \multirow{4}{*}{$\begin{array}{l}\text { Problems - } \\
\text { Policies/Procedures }\end{array}$} & Urban & 56 & 14 & 53 & 0 & \\
\hline & Suburban & 47 & 13 & 37 & 2 & \\
\hline & Rural & 13 & 22 & 22 & 0 & \\
\hline & Sub-total & 116 & 49 & 112 & 2 & 279 \\
\hline \multirow[t]{4}{*}{ Reliance on Technology } & Urban & 18 & 17 & 18 & 0 & \\
\hline & Suburban & 18 & 2 & 9 & 1 & \\
\hline & Rural & 1 & 2 & 2 & 0 & \\
\hline & Sub-total & 37 & 21 & 29 & 1 & 88 \\
\hline \multirow[t]{4}{*}{ Wish List - Needs } & Urban & 201 & 70 & 236 & 0 & \\
\hline & Suburban & 145 & 34 & 81 & 18 & \\
\hline & Rural & 42 & 17 & 39 & 0 & \\
\hline & Sub-total & 388 & 121 & 356 & 18 & 883 \\
\hline Total & & 1493 & 516 & 1361 & 61 & 3430 \\
\hline
\end{tabular}

One of the most important codes to emerge across the dataset was problems first responders experience. After several iterations, this code was broken into several sub-codes. Additionally, problems surfaced in response to the wish list question when participants described technology they would like to have to solve issues they are experiencing with their current tools. The useridentified needs, problems, and requirements provide a blueprint for the PSCR R\&D community to develop solutions for solving the "right problems." Table 7 presents the 
breakdown of the 3374 user-identified needs, problems, and requirements from the extracted codes by first responder discipline and across urban, suburban and rural areas. The numbers represent the number of times first responders expressed the need or requirement.

Overwhelmingly the user-identified needs and requirements are related to technology, but problems with people, with information, with processes and procedures were also identified. The user-identified needs and requirements include improvements to current technology as well as the development of new technology. Some of the problems are very specific such as when firefighters talked about the microphone cords melting for fire fighters. Others were more abstract such as police officers talking about a self-driving car and fire fighters wanting an easy way to determine how many people are in the building. While some items were identified by multiple participants, one should not assume that this indicates a universal need by all first responders. As described in the results needs are highly dependent on the discipline, the users' primary tasks and the context of use.

Deeper examination across the user identified needs, problems and requirements, five crossdisciplinary opportunities emerged for the PSCR R\&D community.

- Interoperability - The ability of a system or a product to exchange and make use of information with other systems or products without special effort on the part of the users - data integration and sharing from radios to radios, systems to systems, devices to devices, and departments to departments.

- Reliability and connectivity - $100 \%$ connectivity for radio, cellular, and wireless networks in spite of geography and topography—urban canyons, subways, basements, or other dead zones.

- Accountability and location - Development of technology that provides for accountability and location tracking of the crew, units, 911 callers, and building occupants.

- Maintenance, technical support and training - Minimization of the burden and costs of the associated maintenance, technical support and training of technology imposed on users and departments.

- Organizational Policies and administration - Facilitation and promotion of technology adoption by first responders through policies, procedures, and administration to minimize barriers and hindrances to use while supporting first responders' primary tasks.

These opportunities are what first responders see as the most important for developers to address. Given the number of user-identified needs and requirements referenced in Table 7, it is not possible to document each in this report. However, the table in Appendix D elaborates on the five cross-disciplinary opportunities demonstrating the breadth and depth of the needs accompanied with first responder quotes.

The PSCR R\&D community may already be familiar with many of the underlying problems that first responders face. Since it is not possible to discuss every problem given the extensive nature of the list, five exemplars of current needs are presented below, which were chosen due to their cross-disciplinary nature and the frequency with which they occurred in the data. In addition, four futuristic needs are identified below, demonstrating the breadth of ideas that first responders had in response to the wish list question. 


\section{Current Needs}

- Better solutions for microphones and cords - e.g., microphones: clarity, feedback, noise reduction; cords: melting in high heat, need cordless solution

- Critical communication devices should be the most affordable - e.g., radios, cell phones can be less expensive and more ubiquitous

- Longer Battery life

- Improved Location tracking - e.g., provide exact locations (including z-axis) of responders, units, callers, and building occupants.

- Real-time information for situational awareness - e.g., provide visual information to augment audio communication from radios and cell phones

\section{Futuristic Needs}

- Heads Up Display (HUD) - e.g., provide environment and operational information

- Advanced medical equipment - e.g., facilitate faster diagnosis and to support patient care on the spot

- Self-driving cars - e.g., allow first responders to attend to more important information rather than focusing on driving

- Smart Buildings - e.g., provide smarter intelligence (e.g., occupant number and locations) or to put its own fire out

\subsection{Technology Guidance}

The number and severity of issues first responders experience with current technology permeated the interviews and resulting data. Although PSCR is forward-looking and interested in new technology, first responders feel strongly that the more immediate improvements to existing technology cannot and should not be ignored by the R\&D community. Indeed, proving to first responders that their input is heard by effecting meaningful improvements in their current technology would increase their trust and interest in future technology. To establish trust and encourage adoption, new technology must be developed with and for first responders.

The cross-disciplinary opportunities discussed in 6.1 provides developers with what first responders need in relationship to communication technology. Six user-centered design guidelines from the data that first responders believe are requirements for developers when addressing the opportunities were identified.

- Improve current technology - improve functionality of what first responders currently have, make them more affordable, and more reliable, for example, better radios - coverage, durability, clarity; better microphones and cords. It is not necessarily new technology that first responders want, but the improvement of current technology that they believe is most important.

- Reduce unintended consequences - develop technology that does not interfere with first responders' attention to their primary tasks. Technology interference can cause distraction, loss of situational awareness, cognitive overload, and over-reliance on technology. 
- Recognize 'one size does not fit all' - while there are similarities across the first responder disciplines and standardization is important for consistency, compatibility and quality, technology must accommodate the wide variety of public safety needsacross disciplines, personnel, departments, districts, contexts of use. All are different, requiring easy adaptability and configurability.

- Minimize “technology for technology's sake” - develop technology with and for first responders driven by their user characteristics, needs, requirements, and contexts of use.

- Lower product/service costs - develop technology at price points that departments can afford, lowering costs for technology. For example, consider the 'One Laptop per Child' [28] approach where various entities collaborated to make and widely distribute rugged, low-cost, low-power, connected technology in areas that could not otherwise afford such devices. The goal was not only to design the tool, but to design it at a pricepoint that made it feasible and scalable for widespread distribution.

- Require usable technology - know thy user and develop 'Fisher-Price' solutions simple, easy to use, light, fast, and not disruptive. Technology should make it easy for the user to do the right thing, hard to do the wrong thing, and easy to recover when the wrong thing happens.

These guidelines can promote first responders' trust with technology, people, and organizations. Participants were not opposed to technology, but they want technology that makes sense to them and makes their work easier to accomplish. They don't want technology to sever and replace the human connection they see as so important. Equally important is that the technology must work with first responders' other equipment and tools, and cost is always a consideration.

\section{Conclusion}

New technology is exciting, and the possibilities for it are endless. While new technology may sound good and make sense to researchers and developers, adoption requires buy-in from first responders. And the key to adoption is trust $-<<$ Trust is the tiebreaker. $>>$ (FF10-4-FF/EMS$\mathrm{U})$

First responders need to trust the related technology, people, and policies, for new tools and technology to be adopted and accepted. Technology is a double-edged sword and there are both positives and negatives to it, as one firefighter alluded to.

More than anything, it's like a tool. I mean, a knife can either be a weapon or it could be a cooking tool. It's just on how you use it. And with every new whatever, new fire truck, new gadget, new app, new everything, there's always that double edge of both negative and positive of whatever it is. (FF-R-019)

It is easy to focus only on the positives of emerging technology, without thinking about the unintended consequences and additional burdens it may place on first responders. Instead it is important to respect the input provided by first responders about their needs and requirements. The opportunities and user-centered design guidelines presented above provide the PSCR R\&D community a mechanism to do this. 


\subsection{Contributions}

This is the first time that the voices of first responders are documented using a rigorous and systematic methodology focusing on human behaviors, human factors and usability. The primary contribution of this empirical report is to present first responders' beliefs, perceptions and ideas about what they need with respect to communication and technology, in their own words. To our knowledge, this is the first research effort where trust has been identified as a significant factor in successful public safety communications technology adoption.

The dataset for this project is extremely rich because of the diverse and extensive first responder population who participated, representing a wide array of domains, jurisdictions, geographic areas, sizes, and communities. This can serve as a valuable resource for the PSCR R\&D community as it provides a repository of first responders' needs, problems they experience, and what they believe would be most beneficial in terms of communication technology. Another resource this project provides is a detailed description of the research design, including data collection and analysis processes and findings from in-depth interviews. Performing this type of rigorous, systematic qualitative research is resource intensive which can be prohibitive for many R\&D organizations. Having access to the findings and the methodology from this project allows developers to have direct connection to the voices of first responders as they work to design, develop, and improve communication technology.

While trust was identified as the "deal maker or breaker" for successful technology, first responders identified a variety of needs and requirements, detailed in Appendix D. These needs and requirements provide the opportunity for developers to build trust by solving the "right problems.” Tackling the right problems is not the only ingredient for success. Successful implementations will focus on first responder needs and requirements while also meeting higher level needs of interoperability; reliability and connectivity; maintenance, technical support and training; policies and administration, and adhering to the user-centered design guidelines of improving current technology; reducing unintended consequences; considering 'one size does not fit all'; minimizing “technology for technology's sake”; lowering product/service costs; requiring usable technology. Doing it 'right' is a tall order. Fortunately, this document and the Usability Handbook for Public Safety Communications [10] provide the PSCR R\&D community with a blueprint for developing technology for first responders that fosters trust while enabling them to complete their tasks effectively and efficiently.

\section{2. $\quad$ Future Work}

This report documents Phase 1, volume 1 of the qualitative data analysis of the data collected in FY' 17. This analysis focused on first responder characteristics and tasks associated with the problems expressed during the in-depth interviews. Additional analysis is underway examining the first responders' contexts of use across the FY'17 data. Initial analysis of the FY'18 data collections has also begun. An additional report is planned that will address the qualitative analysis results across the complete dataset. In conjunction with the qualitative analysis, a comprehensive analysis further characterizing the 3400 plus user identified needs, requirements and problems is underway. 
Finally, a large-scale quantitative survey is under development to be distributed nationally to first responders. The goal of this survey is to gain a broader perspective from the first responder community around the issues identified in the qualitative phase and to provide a degree of confidence in the analysis beyond the qualitative.

\section{Acknowledgements}

The authors gratefully acknowledge and thank the many first responders who graciously gave of their time to participate in these interviews, the many people who helped coordinate and schedule interviews, and the stations and other locations where we conducted interviews. The authors would also like to express their sincere gratitude to many subject matter experts for their valuable discussions enabling us to gain deeper understanding of users in the public safety communications space. The authors also thank Brian Stanton of NIST for his support and assistance in this project.

\section{References}

[1] Middle Class Tax Relief and Job Creation Act of 2012, Public Law 112-96, 126 Stat. 156, February 22, 2012. Accessed on February 13, 2018 from http://www.gpo.gov/fdsys/pkg/PLAW-112publ96/pdf/PLAW-112publ96.pdf

[2] Bureau of Labor Statistics (2017) May 2016 National Occupational Employment and Wage Estimates - United States, Last modified, March 31, 2017, Accessed on February 13, 2018 from https://www.bls.gov/oes/current/oes_nat.htm

[3] National Fire Protection Association (NFPA) (2017) U.S. fire department profile -2015, Issued April, 2017, Accessed on February 13, 2018 from https://www.nfpa.org/newsand-research/fire-statistics-and-reports/fire-statistics/the-fire-service/administration/usfire-department-profile

[4] Barry C, Britten N, Barber N, Bradley C, Stevenson F (1999) Using reflexivity to optimize teamwork in qualitative research, Qualitative Health Research, 9 (1): 26-4.

[5] Yin RK (2003) Case study research: Design and methods ( $3^{\text {rd }}$ ed.). Thousand Oaks, CA: Sage.

[6] The Visiting Committee on Advanced Technology (VCAT) of the National Institute of Standards and Technology (NIST) (2012) Desirable Properties of a Nationwide Public Safety Communication System - Report and Recommendations of the Visiting Committee on Advanced Technology of the National Institute of Standards and Technology, Published January 24, 2012.

[7] Federal Emergency Management Agency (FEMA), https://www.fema.gov/riskmapping-assessment-and-planning-risk-map

[8] United States Department of Justice (2013) Women in Law Enforcement, in COPS Community Policing Dispatch. Accessed on October 31, 2017 from https://cops.usdoj.gov/html/dispatch/07-2013/women_in_law_enforcement.asp

[9] National Fire Protection Association (NFPA) Firefighting occupations by women and race, Accessed on October 31, 2017 from http://www.nfpa.org/News-and-Research/Fire- 
statistics-and-reports/Fire-statistics/The-fire-service/Administration/Firefightingoccupations-by-women-and-race

[10] Theofanos M, Choong Y-Y, Dawkins S, Greene K, Stanton B, Winpigler R (2017) Usability Handbook for Public Safety Communications - Ensuring Successful Systems for First Responders. NIST Handbook 161.

[11] Shenton A, Hayter S (2004) Strategies for gaining access to organisations and informants in qualitative studies. Education for Information, 22: 223-231.

[12] Saldaña J (2013) The Coding Manual for Qualitative Researchers ( $2^{\text {nd }}$ ed.). Thousand Oaks, CA: Sage.

[13] Shenton A (2004) Strategies for insuring trustworthiness in qualitative research projects. Education for Information, 22: 63-75.

[14] Geertz, C. (1973). The Interpretation of Cultures: Selected Essays. New York, Basic Books.

[15] ISO 9241-210:2010. Ergonomics of human-system interaction -- Part 210: Humancentred design for interactive system.

[16] Kim, C., \& Christiaans, H. (2012). 'Soft' usability problems with consumer electronics: the interaction between user characteristics and usability. Journal of Design Research, 10(3), 223-238.

[17] Donoghue, S., \& de Klerk, H. M. (2006). Dissatisfied consumers' complaint behaviour concerning product failure of major electrical household appliances-a conceptual framework. Journal of Consumer Sciences, 34(1).

[18] Law, E. L. C., Roto, V., Hassenzahl, M., Vermeeren, A. P., \& Kort, J. (2009, April). Understanding, scoping and defining user experience: a survey approach. In Proceedings of the SIGCHI conference on human factors in computing systems (pp. 719-728). ACM.

[19] den Ouden, E., Yuan, L., Sonnemans, P. J., \& Brombacher, A. C. (2006). Quality and reliability problems from a consumer's perspective: An increasing problem overlooked by businesses? Quality and Reliability Engineering International, 22(7), 821-838.

[20] Thiruvenkadam, G., Brombacher, A. C., Lu, Y., \& den Ouden, E. (2008, July). Usability of consumer-related information sources for design improvement. In Professional Communication Conference, 2008. IPCC 2008. IEEE International (pp. 1-7). IEEE.

[21] Mayhew D. J. (1999). The usability engineering lifecycle: A practitioner's handbook for user interface design. (pp. 36). San Francisco, Calif: Morgan Kaufmann Publishers.

[22] Hackos, J. T., \& Redish, J. (1998). User and task analysis for interface design. (pp. 2324). New York: Wiley.

[23] Ramasubbu S (2015) From Gen X to Y and Z: Technology and the Generation Gap, HUFFPOST, Dated June 23, 2016, Accessed on October 31, 2017 from https://www.huffingtonpost.com/suren-ramasubbu/from-gen-x-to-y-and-ztec_b_7645410.html

[24] Sinek S (2012) A team is not a group of people who work together, a team is a group of people who trust each other, @simonsinek on Twitter, 6 Aug 2012, 12:18pm, Accessed on October 31, 2017 from https://twitter.com/simonsinek/status/232556392114974721

[25] Athanas, R. (2014) New NFPA radio standard to fix fireground failures, Dated February 12,2014. Accessed May 2017 from https://www.firerescue1.com/fireproducts/communications/articles/1670433-New-NFPA-radio-standard-to-fixfireground-failures/ 
[26] Sinek S (2016) Millennials in the Workplace, Interview with Tom Bilyeu on Inside Quest, December 2016, Accessed on October 31, 2017 from https://www.youtube.com/watch?v=vudaAYx2IcE

[27] The Washington Post (2017) FirstNet, broadband network to enable police and fire responders to talk to each other, ready to launch, Dated August 2, 2017. Accessed October 13, 2017 from https://www.washingtonpost.com/news/truecrime/wp/2017/08/02/firstnet-broadband-network-to-enable-police-and-fire-respondersto-talk-to-each-other-ready-to-launch

[28] One Laptop Per Child Project, http://one.laptop.org/about/mission 


\section{Appendix A: Interview Questions}

\section{Context and Beliefs of Work}

1. What is your job title?

a. If you were describing your job to someone who knew nothing about it (like to a kid, or someone from another planet), how would you describe it?

b. Tell me about your daily routine. How does your day begin?

i. If there isn't one, list the different kinds of things you do during the day.

ii. What's typical communication like for you during your work day?

c. What is it like when you are at the station?

i. Describe your relationships with other folks you work with.

ii. Tell me about the community you serve.

d. What is it like when you are at work but outside of the station?

\section{Communication and Technology}

2. List the different kinds of technology (devices, equipment) you use to do your job.

a. How would you describe the technology/equipment you currently use?

b. Are there apps that you use to do your job?

c. Have there been times when technology has gotten in the way?

3. How (if at all) have things changed in terms of communication since you became a first responder?

a. Do these changes make communication better or worse for you?

4. In a typical day on your job, what kinds of information do you need?

a. Are there other kinds of information you need for situations that aren't so typical—and if so, what is it?

5. If you think about the incidents you've responded to over the last few weeks or months, is there information that could have helped you understand the scene before you got there? Tell me about it.

a. What kind of information would be the most helpful, either for typical or for more complicated calls?

b. How would you want to get that information? 
6. What, if anything, do you think causes communication problems in your work?

a. What, if anything, could help with these problems?

7. Let's talk out of the box for a minute, describe your technology wish list: pie in the sky here, if technology could do whatever you wanted it to, what would you want?

a. Are there new or different apps you can think of that could be useful?

8. Is there anything else you'd like to share about your job that you think is important for us to know?

9. Do you have any questions for me/us? 


\title{
Appendix B: Demographic Questionnaire
}

\author{
Your area(s): $\square$ Fire $\quad \square$ EMS $\quad \square$ Law Enforcement $\quad \square$ Dispatch \\ Other Public Safety:
}

Total years of service:
Location:
$\square$ Urban $\square$ Suburban
$\square$ Rural $\quad \square$ Tribal
$\square$ Other:

City, State:

Gender: $\quad \square$ Female $\quad \square$ Male $\quad \square$ Prefer not to answer
Age:
$18-25 \quad \square$ 26-35
36-45
$\square$ 46-55 $\square 56-65$
Over 65

\section{Experience with different kinds of technology:}

(including desktop or laptop computers, tablets, smartphones, and the Internet).

$\square$ I have limited experience using technology and I don't know much about how technology works.

I have some knowledge about how technology works, but often need to ask for help to perform more advanced activities - such as to configure the privacy settings on my cell phone.

$\square$ I can do most things that I want to do with technology and only need help occasionally.

$\square$ I can do all things that I want to do with technology without help from others.

\section{In general, when do you adopt new technologies?}

I try the latest technologies as soon as they come out.

$\square$ I follow technology trends.

$\square$ I let others work out the kinks first.

$\square$ I wait until my old technology dies.

$\square$ I only adopt new technologies when it's required. 
Appendix C: Qualitative Analysis Codes

\section{(a) Initial a priori Code List}

- Frustration - an expression of annoyance, because of inability to change or achieve something

o With dispatch - the person who receives calls from the public and passes them on to the appropriate first responder

o With callers-someone who calls in to 911 or other number to report or ask something

o With technology

o With documentation

o With interoperability

- Technology — devices or equipment utilized by first responders to do their jobs or as part of their daily tasks

o Reliance on-don't know what to do without the technology (either when it breaks or isn't appropriate to use)

o Privacy

o Positives about/with

o Problems With - things that lead to a lack of efficiency and/or effectiveness in the technology

- No Reception/Gaps in reception

- Too big

- Too heavy/bulky

- Too slow

- $\quad$ Limited battery life

- $\quad$ Multiple Devices/Systems

- Why can’t they talk to each other (autofill; too many devices/systems, multiple sign-ons)

o Types of (Just list these)

\section{- Technology-User-related characteristics}

o Wish List (Just list these)

o Risk-when use of technology has the potential to result in something unpleasant or unwelcome

o could happen or harm or damage

o Adoption

- Positive: (Embracing technology)

- $\quad$ Negative: (Resisting technology)

o Skills

- Comfort with/Knowledge about

- $\quad$ Lack of comfort with/Lack of knowledge about

\section{- Technology-Administrative}

o Lack of budget

o Policies and Procedures 
o Rules for behavior

o Risk - when use of technology has the potential to result in something unpleasant or unwelcome

o could happen or harm or damage

- Software/Apps

o Multiple systems

o Information display

- $\quad$ Sign-on issues

- Don't talk to each other

- Information

o Flow of information

o Timing - when do I get information

o Amount of information - too little/too much

o Delivery mechanism

- Physical

- Electronic 


\section{(b) Final Code Book}

\section{Complete Code Book}

Codes and Sub-codes

\section{Communication}

Context of Work

Stress/Overload

Risk/Safety

Relationships

\section{Frustration \\ Information \\ Control \\ Delivery mechanism \\ Operational environment \\ Problems \\ Technology \\ People \\ Information \\ Policies/Procedures}

Rules/Politics

Budget/purchasing

Priority/Influence

Policies/Procedures

Unspoken rules for behavior

Technology

Reliance on technology

Positives about/with technology

Training

User characteristics

Pride

Job commitment/satisfaction

Generation gap

Knowledge/experience/skills

Wish List

\section{Code Operationalization}

This can be about technology, about policy/procedures, rules for behavior, laws, tasks; anything that refers to if/how things have shifted or not over the course of a participant's career

This refers to examples of when information is passed from one entity to another, or when a flow of information is needed but not necessarily there; For example, "I need to talk to my partner"; this is not a specific identification of information or technology

Tasks related to what is done as part of the job

Physical, cognitive, or emotional expressions of anxiety, tension, or feeling overwhelmed

Situation involving exposure to danger; harm or loss

The sense of community developed among individuals or groups of people, a connection, association, or involvement, including relationships present within a discipline, between disciplines, or with the public

An expression of annoyance, because of inability to change or achieve something

Data, evidence, or intelligence related to an incident or to work environment/situation

Entity who has the ability/responsibility to act or pass on information

Physical (paper, evidence, objects, or other artifacts) or Face to Face

This can refer to the station, the department, the leadership, the city/state; anything that's larger than just the user (we)

Identification of issues identified by participants related to doing their jobs

Issues with technology

Issues with people

Issues with information (in getting, receiving, or producing information; situations where there was too little or too much information)

Issues with formal or informal rules and operating processes and procedures for how things should be, have been, or are being done

Formal or informal guidelines that directly or indirectly govern the work, expectations, and/or environments of first responders

Considerations related to funding and/or procurement

Related to priorities of the administration (e.g., station, local government)

Formal rules and operating processes for how things operate

Informal understandings of how things should be done (for example: radio discipline)

Devices utilized by first responders to do their jobs or as part of their daily tasks

Situations when responders don't know what to do without the technology or when it's not available (either when it breaks or is not appropriate to use) Benefits and affirmative views of using technology

Initial and/or ongoing preparation and practice of job-relevant skills

Participant related demographics, or identification of demographic pieces related to other work colleagues

Feelings of dignity about their work, work environment, and/or work organization

Expressions of how participants love what they do or dedication to their work

Real or perceived differences due to age

Discipline relevant understandings and abilities related to their work

Things (funding, information, processes, technology, devices, or equipment) that would facilitate first responders' job. 


\section{Appendix D: User-Identified Technology Opportunities and Needs}

\begin{tabular}{|c|c|}
\hline Technology Opportunities & Participant Quote Exemplars \\
\hline \multirow[t]{7}{*}{ Interoperability } & $\begin{array}{l}\text { We have all this availability of all this technology, but it doesn't communicate with each other, and it transposes information } \\
\text { differently. (FF-R-019) }\end{array}$ \\
\hline & $\begin{array}{l}\text { Currently we have, just on an incident we have three systems that capture data for us. That's our dispatch system, our CAD, } \\
\text { computer-aided dispatch. We have an infer system. Which is just as the in-first reports. And we have a PCR System, a patient } \\
\text { contact report system. In our current system, none of them talk... (FF-S-023) }\end{array}$ \\
\hline & $\begin{array}{l}\text { So, bigger picture now with our incident management team, is one thing we struggle with is when we go to-- I've got my } \\
800 \text { radio, but when we go to [location redacted], we go on wildland fires, we work with different federal agencies, I can't } \\
\text { talk to them. So locally, we do pretty good, but when we get outsiders coming, or we go to the outside, all bets are off. (FF- } \\
\text { S-036) }\end{array}$ \\
\hline & $\begin{array}{l}\text { That's a little bit challenging because they don't have the same radio system we have so the communication-- you would } \\
\text { have to go through-- I would have to call the office for you to find-- or dispatch center, and have them relay the message... } \\
\text { (FF-U-045) }\end{array}$ \\
\hline & $\begin{array}{l}\text { So, interoperability is a big deal. Being able to travel outside the range of your radio system is a big deal. Especially now } \\
\text { digital radio systems. It's not like the old days of, you can go as far as the antennae will reach. Once you're outside of the } \\
\text { foot [inaudible] radio system, you're stuck. We're seeing more and more that, while we have things like P } 25 \text { protocol that's } \\
\text { supposed to keep everything interoperable, it's still not completely interoperable. I think the whole public safety LTE is } \\
\text { huge, but not just for data but also for voice. (EMS-U-001) }\end{array}$ \\
\hline & $\begin{array}{l}\text { [about how forms do not auto-fill] it's frustrating and especially when they're trying to get us to finish our reports and get } \\
\text { back to the service from the hospital as quickly as possible. It's like they want us to get all this done real quick, but they } \\
\text { don't want to provide us the tools or can have them configured so that we can do it quickly. (EMS-U-017) }\end{array}$ \\
\hline & $\begin{array}{l}\text { If there was a way that I could-- some way of kind of-- if it was a big emergency-type situation of-- kind of like an all-call, } \\
\text { all law enforcement in the area. Because even here in Austin, we have constables, marshals, sheriffs, state troopers, police, } \\
\text { and we don't communicate. Rare is it that-- the only time I've ever had communications with a state trooper or a deputy is if } \\
\text { a call that they're working-- if I had to go help them for whatever reason, or if it was a pursuit, if a pursuit came through our } \\
\text { area. But it took a lot of finagling. You have to kind of figure out what channel they're on, and it's just kind of a hassle. (LE- } \\
\text { U-003) }\end{array}$ \\
\hline
\end{tabular}


From a software perspective, I am tired of having a new sandbox for every single thing that I do. Our RMS doesn't really speak very well to our CAD. So again, maybe-- it's easier to explain this way, I think. If I am going to take a call and I need to write a report, I'm going to run the person on the way to the call. But that never makes its way into RMS. So I'm going to type them into my CAD, even though it's on the same computer. I'm going to then-- I'm proficient. So I alt-tab between the screens. But some officers click the bar at the bottom. So they click over, they type the first name. If they can remember the whole thing, then they click back, look at the middle name, click back. And it's a long process. And we duplicate work... So I would like to see an integration between all those separate systems that make it so I'm not repeating the same work over and over and over again, giving me more time to go out and do what I'm supposed to do, which is take calls. (LE-U-006)

So that is a glaring example of why that report writing system, in terms of the technology, we couldn't even search a name. We would have to go to a second or third system before you could search that second or third system. And if it's not something you do on a daily basis-- now we've got five different systems that we've got to use and check and it just gets overwhelming with all the passwords and all the stuff that we've got to utilize. (LE-S-033)

With firefighters and EMS is virtually impossible. And it's vice versa. It's virtually impossible for them to talk to us. It's very, very slow and very, very convoluted, because what we do is we get on the radio and we call our dispatcher. That dispatcher is one dispatcher for each district channel. And then, that dispatcher sends a message from their computer to the fire rescue dispatcher for that geographical area. And then, that person either contacts their-- either answers the question or has to ask their firefighter or EMS person whatever we're asking. (LE-U-037)

I think my biggest gripes are that e-ticketing machine and just the fact that it's not well thought-out for the application. I don't think there's any reason why it couldn't be done on the phone that I already carry or the computer that's already in the car. So integrating technology with stuff that we already have, that we already carry. Because when I'm on patrol, I carry 30 extra pounds of stuff, which doesn't count the two bags which are probably 30-pounds each of stuff that I keep in the car. So adding more stuff to all my stuff is more weight and redundant. So I think finding ways to use what we already carry... (LE$\mathrm{R}-018)$

Reliability and connectivity

So technology with radios, technology with calling on the phone, taking pictures, using thermal imaging cameras. Computers help us in staffing and doing reports and just, the more administrative stuff. Right now I find, kind of, a roadblock on the network part of it. So we're linked into a network, but as soon as I leave my desk, now I've lost my ability to operate administratively as a battalion chief. (FF-U-001)

We have the [name redacted] MDTs, but I think we would call it a failed technology. Because it relies on [company name redacted] to communicate, it just doesn't work. We spend more time wasting time trying to keep that thing working than we do doing our job. (FF-R-019)

I would have to say probably in the last ten to 15 years, the introduction of the mobile data terminal computers became prevalent. Where instead of getting on the radio you'd push a button responding. And when you get on scene, you push a button that you're on scene. But the platform for that delivery failed at the dispatch center. The failure rate of communication and system failures and software crashes was predominant. (FF-S-031) 
Reliability is always an issue. And that can be attributed to-- you might be in an area where you just don't get a good signal. A good mobile signal. So some of our apparatus, they don't always get their calls on the [tablet] but they'll get it on the [cell phone], which is interesting. (FF-S-033)

Absolutely technology has gotten in the way on certain incidents and some of our operations... Obviously, when a lot of these mobile data computers have come about the coverage was not that great. The computers would turn off just going down the road. A lot of the communication from those computers to a cell tower would be horrific...

(EMS-S-014)

I know we have issues with WiFi every once in a while. If I'm on the WiFi of the computer and then I drive to the hospital and now I'm inside the hospital writing my report and I'm on the hospital's WiFi and I go to leave, there is a space in between where I'm on neither network until I get away from the hospital. And I've had reports just get lost. They end up in a cloud, so to speak, somewhere but it's that interface of trying to get stuff to connect. (EMS-S-015)

It's just like, "This shouldn't be this hard! How can it be?" It's like, "Oh, well, the cell is fighting with the network connection." Reports go missing and the staff gets yelled at, and they're like, "Where is this report?" ... I wrote it. It wouldn't download. It was 3:00 in the morning. I got frustrated. I just shut it down. Or they will type all kinds of information in their report and they'll hit download and it'll just, poof... Yeah, not often. But how many times does it take to do that before you park that laptop underneath the rear wheels of an ambulance and say, "I don't know what happened to it." I mean, technology can create terrorists, and by that, I mean internal terrorists. If you frustrate people enough, they'll find a way not to use your system. (EMS-R-008)

The one that really irks people is they made it so that you can't download anything to a local mobile device. So you have to be in continuous contact with the internet in order for it to function. And, of course, when you need stuff like that the most, when you're trying to move maps and stuff around, is the big incident at the football game and the cell sites are hopelessly oversaturated and you lose connectivity, and all of a sudden you can't rely on it anymore because you couldn't preload that information onto your device. That's the really big one that gets us there. (EMS-U-003)

And then the same thing for the cars and internet stuff. You know, it's okay but it's spotty sometimes. Different areas of town you lose reception, so then you lose communication. (LE-R-001)

I think most of the communication, besides reception-wise and just being able to reach, is device issues with the radio malfunctioning, or the officer not plugging it in to charge the battery, or stuff like that. But, as far as radio stuff goes, I think reception is the biggest thing. As far as cell phones go, I can see a problem in bandwidth. As far as, we're working at a [university name redacted] football game, while there's a concert going on right across the street, everyone's texting, and then - I don't know - somebody blows up something. Everyone's texting. Everyone's calling. There's an obvious issue there. (LE-U-004)

Faulty equipment. Coverage issues, even with police radios, even with cell phones. When I say coverage issues, you can walk into a building that's concrete, you're not going to get out. Metal, you're not going to get your signal out there. If you walk into a basement area, your communication's cut off. (LE-U-012) 
But there are certain buildings that are real thick concrete or parking garages that the radios just don't go through. Cell phones just don't go through. So whatever you're doing down there, you wrap it up and then you go upstairs and talk about it... (LER-018)

The only other thing I would say is we use-- the program we use to run license plates through the state of [state name redacted], that seems to go down quite frequently. And so you can't run a tag or you can't run a person because this computer system is down on the state end, not on-- there's nothing our dispatcher can do. That actually seems to have gone down more frequently in the last five years than it used to. (LE-S-037)

Accountability and location

Well, if you're down right here, and I come into this room and let's say you're two stories up, or whatever, we have certain techniques and strategies to try to find you by listening, going in that direction. It was a training issue, we gave them the [product name redacted] to just see how it would work. They went in and tried to find and ran-- because it still points to you even if there's a wall in between us. And they got caught up in, I know the direction, but if they hadn't used it at all, they would've used just basically a rope, done a right-hand search pattern, and they would've kept going. They wouldn't have just been so focused on it. (FF-U-001)

And that information would be transferred onto a device that the incident commander could say, "Oh, there's firefighter Joan. She's on the 10th floor of this building." And we don't have that technology now. And I'm sure there's probably somebody that's working on it, or it's probably military grade. But from an accountability perspective, somebody gets turned around in a building and they're lost, I'd like to be able to say, "They're right there," and we don't have that. (FF-U-014)

Well, the video stuff is always nice to be able to have, just that where-are-they kind of a tracking, keeping accountability. It's like all these things come with just privacy issues too, though. We're trying to figure out how to balance. (FF-R-019)

I'm trying to think if there's any way that they could have a map of where fire fighters are that we could have access to. I don't know. You don't want to have additional equipment to carry, but if they have a-- we have thermal imaging cameras where we can see-- if I show it right at you, I would be able to see your outline because you have different heat than the room. I wonder if they could make a second screen on that, that track people that were working in that incident, so while I'm doing a search, I know that there are three fire fighters in that room and there's a fire fighter above me. But I have no idea how they would actually do that, but that would be pretty cool. (FF-S-039)

There's a lot of rescue stuff for down firefighters. It would be great to have location devices on firefighters' hats so that I can see, "I have two in the basement right now and there's supposed to be only two. Good. I have three on the second floor, and there's supposed to be five. Where are your other two people? Hey, there's a mayday in the basement." And, "Okay. It looks like I have this engine in the basement, and they must be calling the mayday." It'd be great to have a-- and again, that's that screen. It'd be good to have just a regular house layout. (FF-S-041)

Being able to track a patient from the time they call 911 until the time the first responder gets there with their patient tracking, until the time the ambulance gets there, we take them to the ER, they call a helicopter to fly them to another hospital, and to have all of that be one seamless patient record. Right now, there's no way to do that. (EMS-U-001) 
Maybe something along the lines that patient tracking because that's a good tool. Doesn't get used a lot though. I think something that would be an automatic download to the Red Cross. If we had victims, multiple victims from an incident-- on our MRU, once we had their name and information, if we could tap a drop-down menu and say Red Cross or whatever, then that information would go right to their databank. And they would know where that person is. And the reason why we would notify them is if we didn't have-- if it was like a disaster situation, you know? (EMS-U-009)

So I like to-- especially if it's a hot call, I like to kind of get as much as I can, as soon as I can before I get there. I like to know who's responding, how far away they are, their approximate arrival time for when I get there, traffic. (LE-U-003)

We have a guy who died in the woods, and we went to find him in the middle of the night. There are probably 12 to 15 different paths to get to this particular transient camp, and we had cops everywhere. And if one of my cops had fallen, had broken a leg, had set on a booby trap, or had just gotten lost, how am I going to find them? And there are solutions out there. Google's got a great one that allows you to kind of track each other via an app. And that's good if you've got a cell phone tower, but I would definitely want something like that personally, so I can make sure that everybody is okay if things were to happen. (LE-U-005)

And back when I started, I could listen to the radio and on a Friday night, where we have 25 guys working, I could tell you exactly where everybody was in the city. As we've become more and more dependent on computers, I can't do that anymore. Which I'm doubting that anybody here can do that anymore, which kind of makes it hard for me to understand why we don't use more the technology, instead of using the radios. Because the radio, like I said, the bandwidth is such that we can get busy, and I have to make traffic stops where I cannot call out on the radio because I can handle the stop and be done before they're done yammering on about something. (LE-S-016)

[about tracking device and tracking suspect] And then I have to wait to get on the air, and by the time we find out that the tracker has stopped, we now block off the roadway, but by then, the person is already long gone. We don't realize that because we think it's immediate information, which it's not. So speeding up technology. I mean, as fast as we can... (LE-S021)

In a foot chase, when you're chasing somebody. It would be really nice if a dispatcher could just GPS and see where you're going. Instead of you worrying about calling it all out all the time. You've got to run, you've got all this stuff, and you're like, "I'm going left. I'm going right. I'm turning right. Southbound here and northbound here," and sometimes you don't even know what streets you're on. You're running. Could you imagine if you didn't have to do that, and you could have your hands free and just focus on chasing after this guy? And the dispatcher would be like, "All right, northbound, southbound." Because whatever direction the police officer's running, then that's the definite direction that the offender's going. So the police officer's almost like a trail, a marker, a trail marker, a GPS trail marker behind the offender. (LE-U-023)

I mean most of it's just been the difficulty of learning a new system. Like he said with our pre-plans. Everybody got used to one thing and then we switched it. And then that didn't really work, so we switched it again. (FF-S-018) 


\section{Maintenance, technical support and training}

[about radio coverage issues] I guess there are some fixes. You can put a repeater on every chief's buggy that will also take that direct channel and put it into a repeater system that way everybody to hear it that way. That requires infrastructure, investment, and installation, and so forth, and money, so. (FF-U-016)

They set up programming, and then we have to go through and touch every radio with a programming. We have to touch each console with programming. So it's a pretty heady and very time-consuming process. So we don't usually do like, if one person wants to change or if one little thing wants to change we don't do much. We wait, get a big change together, and go out. (FF-S-023)

So there's not much in the way of training on new technology, or certainly no incident for motivation for us to try to reach out to the newest, latest and greatest because of those reasons, that reliability and resistance. (FF-S-032)

Because end up having this tablet, well, someone's got to run it. Before you used to have a wooden board with a piece of paper on it and you could quickly jot down notes. Or you didn't have boxes that had to be populated to lock a record and have a tablet you had to keep track of, and have connectivity to it. (FF-S-035)

We're in the process of upgrading our mobile computers, our patient care computers to newer versions, so they have to relearn it. Even if you've known the system for a while, even though we've kept the same company, it's still a new program. You're going to have to relearn the whole thing. So that may frustrate some people. (EMS-U-010)

But a lot of that, I think, it still seems to be just general configuration issues that could be changed, but just hasn't been done very well. And how much of that configuration can be done by the department themselves and how much requires the software vendor to go and change the programming, I'm not sure either, but. (EMS-U-017)

My experience in most software companies, if it's a big install, they'll come out and they might spend a half a day or a day with you and they're like, "Here you go, good luck, it's all yours." And then as you use it, you go, "Okay, so how does this work, how does that work?” And this is not my full-time job, I've got things to do. (EMS-R-008)

And then we're all issued new helmets and vests for active shooter type situations. Well, soon as you put this additional layer of body armor on, it covers all the stuff up. And everyone's like, "How do I talk? How do I rearrange my stuff now?" And as I'm trying to say, you should always have an earpiece... So then we started looking at the shoulder mics and everything else, and because it's fairly new and we've only had a few trainings wearing all this, people are realizing you're going to have to rearrange stuff to maintain those communications. And then even putting these helmets that are not very comfortable. Just learning to work with all the new equipment that's out. (LE-R-019)

And because of government contracts and because of training and implementation, we constantly stay so far behind the technological curve that I don't know that we'll ever get to that pie in the sky because the T\&E, the safety development, the safety committees, all that sort of stuff that has to take place, puts you two years constantly behind the curve. But the technology is there. The fingerprints are a good example of that, where we have fingerprint readers. Again, but the software is not the swiftest of software and by the time someone who's sitting behind a desk makes the decision, you're years and months ahead. (LE-S-033) 
Video is video. And video takes up space, so it's a huge space hogger. So what it's going to do is that eventually you're going to have places to put that data. And if you maintain your own servers, that's going to be a problem down the road. Probably sooner than later because the cameras are-- all your offices have them now. Plus, you got your cameras coming in from the city, your neighborhood cameras, your Homeland cameras. So all the cameras that you own, that's all coming-- so that video has to be stored. (LE-U-035)

\section{Organizational Policies and administration}

It doesn't restrict the use of cell phones. There's definitely some rules about personal use of cellphones, both personal use of personal phones while at work and then personal use of department cell phones. It is allowed. But there's no expectation of privacy or exemption. And then once again, if you're conducting business with a personal cell phone, it is subject to disclosure as well, so. (FF-S-035)

There's various procedures and things that need to be followed to change anything, and that can be very technical. And there's a whole lot of people who are in charge of this part, and then a whole lot of people that are in this part and getting everyone to meet on the same page. That can take years. And culture is a hard thing to change. Some of it is just a cost. Our [ruggedized laptops - brand redacted] are 6 or 7 thousand dollars new. The new tablets are certainly not cheap. That's an enormous cost when you have 35 ambulances that you need to put at \$50,000 monitor in. And so some of its budgetary constraints. (EMS-U-004)

If it's a personal device, I can see issues in basically just what the officer's outlook on it is. "This is my device. I don't want to take a picture of a crime scene with my cell phone. I don't want that saved on my phone. If I'm now taking pictures of a crime scene, can my whole phone be subpoenaed? Are they going to see all of my text messages? This is none of their business. This is my personal cell phone." So I can see-- now none of that can actually happen if they know the law, they can only subpoena the actual business content on your phone. But not a lot of people know that. (LE-U-004)

I had my department email routed to my phone, and there was some kind of a disclaimer. And it said basically, "We're going to be able to access your phone." They figure, "If we're going to use the Internet, we're going to be able to access your entire contacts of your phone if we want." Which it was like, "Oh, man, that kind of sucks." My partner went off of it after that. He was like, "Man, I'm going to have to not get my email on my phone anymore." So now, he took, literally, 10 steps back because of that. (LE-U-023)

\section{Current Technology Needs}

Better solutions for microphones and cords e.g., microphones: clarity, feedback, noise reduction;

\section{Participant Quote Exemplars}

The only way it's a hindrance is if the person you're next to, usually it's your officer that's going to be talking on the radio, if they talk on the radio and you're right next to them, you're going to get feedback. So, some officers will address that in the morning by saying either, "Keep your volume down or keep your radio off until you need it." They'll say, "Set your channel that we're going to and just leave your radio off. Unless you're in trouble or something, you can just turn the volume on and you'll already be on the right channel.” (FF-U-010) 
cords: melting in high heat, need cordless solution
I think that the development of Bluetooth wireless technology for clear, better communication built into your air pack would be fabulous. And it needs to be bombproof, bulletproof, and so there can't be any loss of communication in smoke, heat, and all the other things that go along with it... If you listen to any of my tapes from my fires that I get, I would bet-- I ask 30 to 40 percent of the transmissions to repeat. Repeat what you just said. Yeah. Some of it is because radios are turned up and you get feedback when they go to transmit, and I get that feedback sound. But a lot of it is people that just are not comfortable speaking on the radio. And that's all fine until you get that one call that you missed where somebody's calling for help. (FFU-014)

And it's got to be functional. I mean, it's great that we have mics, but mics don't work. It's got to integrate better with our masks. It's got to be clearer. There's nothing worse than talking through a mic when you're wearing an air mask. (FF-R-019)

The mic in the fire service has become kind of a big issue. We're pretty early adapters at Arvada. We tried a Bluetooth system. And the problem with a Bluetooth system is it has to pair every time you turn it on. And it doesn't always pair. And then you're trying to smash the button to make it pair. And so we got rid of it...that's why the big push was for the in-mask communication. But then it had the Bluetooth pairing problem, and we abandoned it. And then we went to this radio, which has a microphone on the back that's supposed to do noise canceling, but it works 50/50. (FF-S-022)

[about earpiece] The problem that we found is, as far as just one, there isn't one solution that fits all. So we're walking around like this, with just nothing else. I may be able to use my earpiece in here and it may stay in fine. But if I go into the firefighting mode where I have to put in a hood over myself and I have to put on the SCBA mask with straps, that same mechanism may just not be able to stay in the ear or something like that... I may go onto a hazardous materials response, where we get into the big moon suits, the self-encapsulated whatnot. They've got a helmet and whatnot and your arms are in gloves, you can't really reach so you're kind of doing this kind of stuff... We'll keep the radio in a holster on the inside, but as far as the audio stuff, we've tried conductive mics, either on the throat or on the head. We've tried hands-free stuff, but we just have not found any one solution that meets all of those needs. (FF-U-030)

So there is some limit with the radio, as far as the communication aspect of-- especially when you're in a fire, when somebody's running a chainsaw and different things, that makes it very difficult to hear out of a mic that's not in your kind of your locale, so to speak. So that has its limitations, as well as the cord can sometimes get grabbed or caught. But they seem to kind of be getting, to some degree, smaller than what I first started with. We call them bricks because they were probably about that big. About that tall. (FF-S-034)

So when you have a mask on and you're inside your building, we recently got the wire earpiece, kind of like a Secret Service agent, if you want to call that. But you've got to remember to put that on before you put a mask and helmet on, because once all that stuff's on, you can't get it back in without taking it off. So now you're not just listening to a lapel mic - which you can miss a lot of things in the heat of battle, if you want to call it that - that thing's squawking away. You don't realize that you're being called. (FF-S-035) 
Wires are bad because when I got out on a building fire, I've got a lot of stuff to be doing: getting my gear on, figuring out where we're going, figuring out what we're going to do when we get there. If I've got to be plugging in a whole bunch of wires, it's probably not going to happen.... And even if it doesn't entangle me, for me just to damage it inadvertently because I get it snagged and then I pull away and I cut the wire or pull it out of the port it's plugged into to or pull the whatever it's connected to off of wherever it's supposed to be. Just all sorts of things. (FF-S-040)

Where one of them's[sic] cord burnt through and he had priority on the channel and nobody could talk, nobody could talk over him until the key out time timed out. (FF-U-042)

So we were having an issue with our microphones. They weren't as clear, so he actually got us better mics for our radios, and they were way clearer. And we also, for a while, we actually went to this Scott mask that had that clip-in mic that you could-- hands-free. We didn't like them because the Bluetooth was messed up, so we went away from them. (EMS-R-002)

Because the back of the ambulance is loud, so the driver up front will just hear all the static and background noise from the road, driving down the road. But I mean, you can manually turn it on and use it, but it's easier to just yell back there. And if you need to talk to your partner, it's effective communication front to back. (EMS-S-006)

The only thing I can think of is the radio-- the wire that comes from the microphone to your radio. I mean, we had a guy almost get choked out by that. I never wore one. I had a earpiece that went under my shirt, and then into my [inaudible] for that, basically for that exact reason, and so I could hear it better. I could hear better with it right here, as opposed to right here. And so that if I'm talking to someone, and they say, "Hey, he's wanted for such-and-such,” he doesn't hear that. Only I hear that. (LE-U-004)

Currently, we have a single one that just stuffs in your ear, and everybody is deaf in the ear they use it in now because they have to turn it up so dang loud. People that work downtown, they all wear earpieces and they can still never hear anything. So there's no way of something working for both. (LE-U-005)

It would be awesome to have that cordless opposed to a long cord that tends to either get caught in something or it can theoretically be used as a weapon against you, strangled with.... but quite frequently, we run into it getting pulled off your uniform shirt, or stretched, or gets caught on something where a Bluetooth-affixed microphone would be really nice or even a better headset system. (LE-S-037)

Critical communication devices should be the most affordable - e.g., radios, cell phones can be less expensive and more ubiquitous
A lot of technological solutions exist in the current fire service if you can pay for them. And I say this as you don't have to pay for them. So a lot of times, a lot of the technology needs - before I get to the pie in the sky - of most American fire service members is just the state-of-the-art stuff that whatever company is already making. Just it costs 10 grand a member, and they're not going to buy it, right? They have things like thermal imaging cameras that can check heat. Well, they make them now where it can be embedded within your SCBA mask, so you don't have to carry a camera. It's like Terminator vision, right? So those kinds of things actually do exist. They're just incredibly cost prohibitive. (FF-U-012)

Buying a radio is cheap, but changing the repeater and all of the other stuff that goes along with it is very expensive. (FF-U014) 
It has to be affordable, and that's the challenge. Of course, they're loosely related. I mean, there are companies out there that sell all this stuff, but it's never achievable for us. We'll never be able to spend $\$ 10,000$ on a radio.... right now, I mean, our radios are costing almost 4 grand for radio. And that's why we have older radios because we can't afford the new stuff. (FFR-019)

Because you got districts in this county, like us, who are pretty well funded. You get districts in this county, like [name redacted], they are completely volunteer. Their budget is, I mean-- we give them our used equipment because they need it. They have no money to spend on anything, so how are you going to apply technology evenly across even as small an area as our county and make sure that it benefits everybody? (EMS-R-008)

There's not a budget for it in our department. If you're, I believe, a second lieutenant and above, they get cell phones. Everyone else just has to use their personal cell phone.... it's really kind of hard to do the job now without your cell phone. (LE-U-003)

[about their radios stay on one channel] The cop is in the middle of a pursuit, and he's chasing somebody on foot. He's not going to take two seconds, because now he has to try to find that switch to go over. It would be a lot easier if the dispatcher just hits the button and it patches it through to the [transportation agency name redacted] dispatcher, but that takes money, the technology is there, it just costs so much. (LE-U-010)

Well, in technology-based is nothing talks to each other. And if you want it to talk to it-- if you want program A to talk to program B, A and B is going to have their hand out for a monetary supplement to give you the patch that they've already created or to create a patch. So that's frustrating. (LE-R-017)

We have one of those. One of those vehicles assigned to each precinct and it's called automated license plate reader... Not every vehicle. Some of the parking enforcement officers have those as well, but I have one in each precinct. I would love to get more. They're fantastic. That's just a cost. I mean, they're very expensive... Everybody has a portable radio. At this point, I would love to buy officers smart phones, but I don't have the funding for it. So right now the only communication device that the department supplies is the radio... And then for me, it's just going to be finding the money to get the technology to the officers - of tablets, of cell phones, things like that. Our department's trying to get larger. We've actually gotten the authorization to hire up to 200 more officers. (LE-U-029)

Longer Battery life And I'll say this, the more integrated it is into our protective equipment that it's not so ancillary or exterior that it bogs us down, the more-- because I really am asking somebody to be a triathlete. And all these extra clothes and anything that's cumbersome, wires or anything, is going to be a hazard. And so the more streamlined we can make it, lighter, faster, longer battery life, all those things, protection. (FF-U-001)

Battery technology is always a limitation for any rescue service because-- how great is that radio? It's terrific. How long's that battery last? 45 minutes. Okay, so it's not that terrific, right? I could get you from Mars once, and then the battery dies, right? And that's with our thermal imagers, with our radios, with our rescue tools. You name it. We are limited by the distance of a power cord or the distance of battery... So I think battery life is the new future towards, how do we fix some of those problems you're-- if the batteries lasted longer on anything you have, everything would be better. (FF-U-012) 
Some of the downsides is obviously it's got a battery. So the battery's got a certain amount of life to it. So there'll be times, if you're using it multiple times during the day, if you haven't had the opportunity to maybe swap out a fresh battery, you can get to points where it starts balking on you, indicating that it's getting low. So that's a negative because there's a set level of power. And obviously as that battery works down, the less power you've got, the less actual transmission power you're getting to send your signal out. That's all based upon battery too. So that's a downside, as far as signal strength. (FF-U-034)

But you're talking about a battery that you just added potentially another two inches to the bottom of it. So I'm already carrying this radio that's like this. Now do I want to add it-- we're going back in technology where we're carrying around bricks because we're adding... I mean, we haven't even gotten to, I think, well, I know, our full potential on our portable radios. [Company name redacted] is pushing out different things now where the radios can receive picture messages and things like that, and we're not using any of that technology yet. We're not there in a firmware aspect or any of that. So when you start pushing data like that, what's that going to do to the life of the batteries? (FF-U-043)

It's an enormous computer on wheels... The electric load in these ambulances is just nuts. I mean, they are just maxed out right now on power capability... We have this, that, and the other thing that's all battery operated. It's all plugged in. When an ambulance is not running, it's on a shoreline plug. And if you forget to plug your ambulance in for an hour, it's dead. (EMS-R-008)

Even telling some of the guys, going, "You really should have an earpiece in. I know you don't want to, and you never had before, and it hasn't been an issue, but it's going to be at some point.” As they talk about, well, Bluetooth, and I think, "That's just more batteries to charge." And batteries are always an issue now. Making sure the batteries, after so long getting rotated out, so they can go a full shift. Everyone knows the dead or low battery chirp and what that means. So I do have some concern as all these new technologies come out and everything's taking more juice. (LE-R-019)

\section{GPS Location tracking -} e.g., provide exact locations (including z-axis) of responders, units, callers, and building occupants.
So I think that my number one thing would be that, either through the use of our radios or some device, that we can get accurate physical accountability on the fire ground. So it's not just the X, Y coordinate. I want the X, Y, Z coordinate. (FFU-014)

I can tell you that for large-scale events, from the command side of things, I would like to see or have some type of a [inaudible] saying, "Okay, you know what? These ambulances are coming from this direction and these ambulances are coming from this direction. Where can I place them so that they don't running into each other or direct them?”... Some kind of GPS locator. I know it exists, it's just that we don't have it. (EMS-U-010)

In a foot chase, when you're chasing somebody. It would be really nice if a dispatcher could just GPS and see where you're going. Instead of you worrying about calling it all out all the time.... Could you imagine if you didn't have to do that, and you could have your hands free and just focus on chasing after this guy? ... So the police officer's almost like a trail, a marker, a trail marker, a GPS trail marker behind the offender.... I would like to be able to see where the rest of your guys are at too. It would be nice to see that. If I'm here, where are my other guys at? And maybe we could kind of position them better and coordinate better. (LE-U-023) 
Real-time information for situational awareness - e.g., provide visual information to augment audio communication from radios and cell phones
I would just love to see a manageable picture from RP [reporting person] to end user, a way to-- a picture's worth a thousand words. Let's get those pictures out there. And I know dispatchers might not want to see that or whatever. We spent 62 minutes yesterday chasing drywall dust from our [location redacted] line, but we have to take it seriously... And it's not just as easy as looking across the mountain or going to the same vantage point. In fact, we have to verify and double-verify that that isn't going to go big bad. So a picture's worth a thousand words, and I think that's the other thing. Get it out there. (FF-R-019)

It would be great to know what the building looks like, or what the streets look like, at the time of the incident. If we had access to cameras on the apparatus, or even our dispatch center, they could say, "What I'm seeing from this location is no smoke or I see a fully-involved structure.” (FF-S-023)

So there's tons of information out there that we just aren't capturing, or that's already captured and is just not accessible. So on the medical side of the calls, so we don't really have any access to any of the patients' history, or any medical information that is maybe there, but not readily accessible... A better access to those records would help us make better decisions in the field. And some of that's already captured, it's just not--available to us in a way...So the ability to have access to the information about where I'm responding and who I'm responding to. So access to that patient information, the access to the information about the building that I'm going to be into and how that could affect our safety or our tactics, or how that information could be utilized to help us predictively plan where our calls may be to help us. I think we would actually end up-- our job to try to help people and save people, really ultimately is most effective probably done in the preventative means... But we can do more of it with data, so I think ultimately, for me, it's that access to better data and utilizing that to make better decisions and keep everybody safer and all that kind of stuff. How to collect it, how to store it, how to utilize it, disseminate it in a way that is standardized and useful. (FF-S-032)

We've got a better system now that would manage that information. But still, there's never going to be a perfect thing. Never a perfect system in terms of always having good, real-time intel. (FF-S-035)

So some type of a drone with a camera. And before we go into this area, what do we have there? Is there something that can be relayed back to us and say, "Okay, you have three cars in this type of an accident. Here's a picture of where you can come in, it's easier for you to come in." (EMS-U-010)

So we have in-car cameras. Right? And the technology is there for us to be able to stream what is going on in our car to our supervisors or anyone else, but we-- I think, mainly due to bandwidth, we do not have that feature turned on. But that would be something that would be kind of nice. If you were going to a call, to be able to look to see what your partner is currently seeing would be very helpful. So you can have an idea of maybe where I should come in from or if he's in trouble, what's going on or I look at the suspect before you even get there in case he bolts and just starts to run. (LE-U-003) 
[about potential uses of drones] You're not going somewhere blind. You're not going into an alley blind. You're not going into-- we have a lot of areas that are-- I grew up in a very bad neighborhood by the [location redacted]. A lot of that area is just grass and dirt, no street signs, trees. The criminals know the area better than we do. I grew up in that neighborhood, so I know it. But you're going to go into alleys. You're going to go into areas that are-- it's almost like a lot of the projects in [city name redacted], they're built on hills, which is a sniper's advantage. So we have to trek up these hills, when the suspect already has an advantage over us just from the hike. There's areas that are dark. We don't know... Yes, information. Yes, recon. I would love to get drones, but that's not-- I'll be retired before that ever happens... Even ground drones. I was thinking about the BB-8 character from Star Wars. So there's a guy with a gun in the building, and I get that little ball with the camera and just send him in there. (LE-U-013)

I would like that GPS. I would like the situational awareness type of thing. I would like to have some type of dynamic information dissemination technology if it exists. (LE-U-023)

[about potential uses of drones] Well, searching that for a lost person is pretty difficult, but you can put a drone up. Especially with a forward-looking infrared, you might be able to find them. I wouldn't be a big fan of them for routine patrolling and that kind of stuff. It is a little too big brotherish[sic] for me. But for a barricade, being able to put a drone up to get a view of the house to purchase barricade in, or looking for lost people in like [location redacted] or something, I think they'd be phenomenal... But for specific reasons, for specific incidents or reasons I think they'd be great. But again, very sensitive over here. Any kind of surveillance technology is something that gets people's attention right away. (LE-U029)

More details. But I don't get that on a bike. So police work's kind of changed. A lot of times, bike officers will see things that don't fit and we will get on radio and we'll ask, "Hey, can you run that license plate for me?” And then when they run the license plate, we ask them, "Is there any RMS on it?" which is Report Management System. So is there any prior thing associated with that plate? But our 911 center won't give us that information over the air anymore... I can't look at anything historical, and radio won't give me that information. So in a car, you have all that. And a lot of times, you-- well, not a lot of times-- I think now almost every time, officers are-- before they're heading to the call, unless it's a priority one call, which is a really-- what I'd call hot call, they're going to stop and they're going to look. They're going to look to see what's happened, whether there's a name associated. They're going to see if we've handled that person before. And that's actually really good information. It's officer safety information. (LE-U-031)

\section{Futuristic Technology Needs}

\section{Participant Quote Exemplars}

I can get some kind of heads up information that the IC could send from something inside. If we can't communicate well that way, can I get stuff that would come up on a small heads-up display? (FF-S-017) 
Heads Up Display (HUD) e.g., provide environment and operational information

So I've got the thermal imager attached to my face piece, so where I look, I've got a little heads-up display right in front of me. So I can either look out through my face piece and just see what's in the environment or I can glance down at that HUD and look through the thermal imager if the smoke is too thick for me to be able to see through otherwise. A HUD for the radio would not be a bad thing either. To put a display that mirrors the display on my radio so I can see what my coverage is, I can see what talk group I'm on. I can see all the stuff. (FF-S-40)

If you can have your information put into-- like vehicles now, they have their odometers, pedometers on the glass on the dashboard. That would be something nice for the officers, because now your eyesight is not looking down towards the computer. Everything is visual on the screen, transparent to you, in front of you while you're driving. (LE-U-012)

\section{Advanced medical}

equipment - e.g., facilitate faster diagnosis and to support patient care on the spot
So if you could find a way to confirm in a more rapid and more efficient way without having to wait until they get to the emergency room to have a CT, but something like that could be done in a field setting and not waiting.... If you could definitively identify those things in the field and then begin that treatment right there. And so you start that treatment at the patient's side.... There's all kinds of stuff. Even something as simple as a wireless EKG. But detection stuff-- I mean, we've seen it through the years. I mean we moved to the cardiac monitors that we have now.... the end title, the pulse ox, the EKG, the defibrillation, the cardioversion, the pacing. I mean it's all in one, so who knows where it's going to end up. But anything that would make the medics' lives and the patients' outcomes become more effective, where we can do stuff in the field, obviously. I mean, even shooting an x-ray or something like that. And then having the training and ability to even set and cast or something right there, so you're avoiding having to take people into the ER... (EMS-U-001)

Also, those rural agencies, as is the case with the CPR machine, the less people you have available, the more equipment you need to take up the slack. Denver, we have so many ambulances, so many fire stations, so many cops. There's generally all these extra bodies to help you lift this, pull that, push on that. So for better or for worse, it works for our system to not have some of that equipment. (EMS-U-004)

It would be great to transmit our patient data to the hospitals so that when we get there they're already registered and have an armband, and they were in the system. It would also be nice for us to see some of the data points from the hospitals. (EMS-S-016)

Self-driving cars - e.g., allow first responders to attend to more important information rather than focusing on driving
Self-driving ambulance is an interesting concept. And the reason why is because right now you rely on one individual in the back. And if you're treating, even if you're just treating one patient, not multiple patients, but a single patient, but a multisystem injured or ill patient that requires more than maybe one brain and more than one set of hands in order to better manage the treatment side of that patient's modalities, then you're doing it by yourself... But if you have the ability for-- take me to this medical facility and both of those skilled medical professionals can be in the back managing that patient. (EMS-U-001)

I'd like to be able to fly my car into work to be honest with you. It seems that should've happened a long time ago because you've got your limitations to, obviously, how much space you have for highway. I always felt maybe it would be nice if there was something I can come up with that was somewhere in between a regular automobile and a helicopter or a plane that was safe and kind of lift, take yourself to work and not have to follow behind every other person in congestion. (EMSU-011) 
A Google car driving us somewhere 80, 90 miles an hour. Yeah, that'd be great. I think that's fantastic. With the ability to take over when we need to because sometimes we need to violate traffic laws or drive over a median or a curb. That would be great. (LE-U-005)

Smart Buildings - e.g., provide smarter intelligence (e.g., occupant number and locations) or to put its own fire out
Building telematics thing where we're talking about pushing out the building information to the user in the firetruck so I can see what zone and stuff it is, where the smoke detector is activated, on what zone are the sprinkler systems activated.... I'm actually getting a heads-up display with that data as I'm walking through the building and maybe even providing context in terms of location within the building. So the building is smart enough to know, hey, I'm walking down this hallway and the zone that you're going to is up here around the corner to the left. And that heads-up display is telling me, hey, I'll go down the hallway, took a left here, you're in the zone. That's the sprinkler valve that's activated or the zone that's activated. There's the smoke detector that's activated.... Now, the challenge with that stuff is providing it in a way that is useful but it doesn't saturate the user. Because if you provide too much stuff, the user gets too distracted and they forget what they're supposed to doing and it actually becomes detrimental instead of helpful. (FF-S-040)

But having access or having the victim having access to some sort of security system, this is kind of big world stuff maybe doesn't-- but having access, to be able to hit a button that gives a layout of the house or provides that to-- I mean, that's just kind of cool. That's on the TV step. But I mean, hey, it probably exists somewhere. But having a layout, knowing where they are, giving us an idea when we go there, we have a better view. But somehow maybe they can give us access with the push of a button to their security cameras.... Yeah. I mean, having us be able to gain access to their surveillance when we get there or if we're sent. Because what if it's a hostage situation where-- or a barricaded subject. We're not going in right away. We're going to stage out front and come up with a plan. What if we have access to that? Can they give us-- it's some sort of emergency button on their remote or on their phone that says, "Okay. Access can be granted to-" and then I don't know. Probably, it's feasible. So it might already exist. I don't know, so. (LE-S-027) 